\title{
Personalized energy systems based on nanostructured materials
}

\author{
A. N. Kovalenko ${ }^{1}$, E. A. Tugova ${ }^{1}$, V. I. Popkov ${ }^{1}$, O. N. Karpov ${ }^{1}$, A. I. Klyndyuk ${ }^{2}$ \\ ${ }^{1}$ Ioffe Institute, 26 Politekhnicheskaya, St. Petersburg 194021, Russia \\ ${ }^{2}$ Belarusian State Technological University, 13a Sverdlova, Minsk, 220006, Belarus \\ ras-kan@mail.ru,katugova@inbox.ru, vadim.i.popkov@gmail.com, o_karpov@list.ru,kai_17@ rambler.ru
}

PACS 05.70.-a, 05.70.Ln, 05.70.Np, 05.45.Df, 81.20.Ka, 61.82.Fk, 72.15.Jf, 89.30.Cc

DOI 10.17586/2220-8054-2021-12-3-368-403

\begin{abstract}
In this paper, the achievements, problems and prospects of creating personalized energy systems based on nanostructured materials are analysed. Various concepts of developing methods and ways of personalized energy provision for autonomous human survival in remote natural habitat, emergency situations of natural disasters and technogenic catastrophes when centralized power supply is unavailable or in an effort to reduce the economic and environmental costs of remote energy production and transportation are also considered. The possibilities and limitations of using traditional and renewable alternative energy sources, processes and devices for extracting, storing and converting their energy into the necessary consumer forms due to fundamental physical laws are discussed as well. The article covers the new nanostructured materials with special functional properties for personalized energy systems development. The mechanisms for formation of the required nanostructures in synthesized materials, especially those with a high content of fractal interfacial formations, are considered as well as methods for studying their structural and phase characteristics that determine the achievability of the specified parameters of model converters and energy storage devices.
\end{abstract}

Keywords: autonomous energy provision, energy sources, optimization of energy conversion and storage modes, functional materials, nanostructures, fractals, non-autonomous phases .

Received: 2 December 2020

Revised: 31 March 2021

\section{Contents}

1 Introduction

2 Individual energy needs of the human body and the possibility of sources of additional energy supply in personalized energy industry

3 Regulation of processes and optimization of energy transformation modes in personalized energy systems

3.1 Problems of model description of energy conversion processes in nanostructured media

3.2 Principles of thermodynamic extremes in the generalized analysis of energy transformation processes

3.3 Modes of energy transformation in non-equilibrium systems

3.4 Regulation of operating modes of non-equilibrium systems

3.5 Stability of processes in non-equilibrium systems

3.6 Influence of nonlinearities in the structure and properties of the material on the processes of energy transfer and transformation

4 Features of energy conversion processes using renewable sources of the environment and the body's own capabilities

4.1 Solar power systems

4.2 Thermoelectric converters

4.3 Background electromagnetic radiation and optical nanoantennas

4.4 Optical communication systems in the ultraviolet range

4.5 Human muscle power, mini wind- and hydro-electric generators

5 Development of new functional materials for personalized energy based on nanotechnology approach

5.1 General methods of the nanotechnological approach to the development and synthesis of functional materials

5.2 Characterization of properties and features of synthesis of new nanostructured thermoelectric materials by "wet chemistry" methods

5.3 Features of the implementation of the combustion method of gel-like media in high-speed kinetic mode

5.4 Characteristics and features of methods for the synthesis of new nanostructured catalysts

5.5 Features of implementation of high-energy methods for synthesis of nanostructured materials for personalized energy systems 
6 Conclusion

7 List of references

\section{Introduction}

Currrently, two complementary approaches to the development of energy supply systems have been formed: there is a centralized "external" energy industry of large capacity and autonomous distributed, or local "internal" energy industry [1-4]. They differ in various interests of energy producers and consumers, different indicators of energy productivity and energy efficiency, different costs for creation, and operation, energy sources used, technological schemes for converting primary fuel and distributing converted energy flows, and different levels of losses for generating and transporting consumed types of energy. However, this division is rather conditional. As in any complex system, in natural and technical complexes of centralized and autonomous power supply, there are numerous direct and inverse relationships between the selected hierarchical levels, which are based on fundamental and applied scientific achievements of the nineteenth to twenty-first centuries, primarily in the field of thermo- and electrodynamics, hydroaerodynamics, mechanics, heat transfer, atomic physics, chemistry, and materials science.

Centralized energy industry of large capacity (up to $1200 \mathrm{MW}$ in a single at a time when the total installed capacity of all power plants of the Unified Energy System of Russia is over 246 GW as of January 1, 2020) is intended for remote electricity and heat supply through the electric and heat networks of industrial enterprises, public social services and household needs of the population from large generating units of thermal (TPP), nuclear (NPP) and hydro- (HPP) power plants which, respectively, use fossil energy resources of chemical (organic) and nuclear fuel, as well as the energy of nature-renewable movement of large masses of river water. In terms of the unavailability of centralized power supply or in case of attempts to reduce economic and ecological costs of remote production and transport of energy; in order to provide power supply for small industrial and community facilities of different local groups, the autonomous energy industry is used in forms of distributed power installations of low and medium power ( 5 to $50 \mathrm{MW}$ in a single unit). Along with traditional generation plants, alternative solar, wind, tidal, geothermal, biofuel, thermoelectric and other power units are also used here as well [5-10].

A special area of autonomous energy industry is a personalized energy industry, the power of which is comparable to the power of the human body in the range of its normal and peak loads (about $100-1200 \mathrm{~W}$ ). It is designed in order to maintain the efficiency of individual life support equipment and human survival in remote natural habitat, as well as in terms of emergency situations such as technological catastrophes and natural disasters. This includes provision of food preparation and water supply, housing maintenance, use of tools and devices for personal labor, transport, electronic communication and navigation, medical devices, sports and tourist equipment, personal protective equipment and equipment for rescuers, firefighters, security personnel, emergency medical services and other emergency services. Along with traditional and alternative sources for personalized energy supply, such as, mechanical movement and heat of the human body and environmental objects, as well as the electrical processes occurring in them and accompanying magnetic phenomena, background electromagnetic radiation in the radio and television broadcasting bands, human muscle strength and the strength of domestic animals, secondary energy sources, in the form of agricultural and local industry waste, etc., can be also used [11-13].

Although the development of the scientific and technological base of energy industry in the current understanding dates back about 200 years, the recent problems of depletion of intensively used fossil energy resources, concomitant environmental pollution and attraction of renewable alternative sources stimulate the search for new approaches and solutions in all the energy areas mentioned above. Fundamental and applied physical and chemical problems, as well as the results of such searches, are reflected in numerous original articles published and in a large number of generalizing reviews and monographs [14-20], in which you can find interesting details and additional links. This review is devoted to the consideration of a still poorly presented, but promising and rather intensively developing area of modern research in the field of autonomous personalized energy industry using nanostructured converters. The use of functional materials of such a structure, especially those with a high content of interphase formations of fractal geometry (non-autonomous phases [21-23]), which differ significantly in their properties, structure and composition from the corresponding characteristics of bulk phases, allows us to purposefully influence the processes of energy transformation. In particular, it is possible to develop nonlinear regimes with the so-called exacerbation [24, 25], when the effects of local energy concentration appear with their retention for a finite time practically without spreading to other zones. In this case, the change in the space-time structure is not accompanied by a general destruction of the material, in contrast to known examples of thermal explosion, shock wave accumulation, self-focusing of light beams, plasma instability, and other variants of such effects in continuous nonlinear media [26]. Other unusual structural and functional properties of processes in such media (changes in the melting temperature, transport coefficients, etc.) are also found, which are studied in the framework of the theory of dissipative structures and synergetics [27]. They can be used in many applications of physics, biophysics, chemistry, and biology, but they are especially important for solving 
problems of personalized energy industry due to the specific requirements for the power of the sources used and their availability, low weight and size characteristics, as well as the unstable operating modes. This review also addresses, as necessary, the main points of research in related areas of energy that are important for the analysis of the topic under consideration. In particular, physical constraints limit the possibilities of converting various forms of energy, the conditions and mechanisms for modes of increasing maximum power and efficiency of these transformations, their thermodynamic stability and regulation of controllability, influence the functional properties of the underlying environments and structures of materials, the development of methods for their synthesis, determining the attainability of the desired properties and the desired intensification of the transformation modes. In this review, these issues are analyzed based on the available literature data, as well as original author's developments.

\section{Individual energy needs of the human body and the possibility of sources of additional energy supply in personalized energy industry}

Individual energy needs of the body are determined, first of all, by the energy costs of ensuring human's vital activity. This is the maintenance of a constant body temperature, heart and respiratory muscles, the nervous system, physical activity in the processes of work, changes in the structure and physiology of organs in certain age periods. This also includes carrying out functional responses to stressful situations, including the mobilization of all energy and regulatory resources of the body for its survival in the event of sudden changes in the external and internal environment. The physiological source of body energy supply is a combination of metabolic processes as a set of multi-stage biochemical reactions of the exchange of incoming food substances at the tissue and cellular level. Enzymatic selfregulation of the kinetics of these reactions is carried out by the nervous and endocrine systems of the body with the maintenance of hemodynamic balance, indicators of water exchange of biological fluids and gas balance, depending on environmental conditions and internal factors.

According to medical and biological data [26,28], the individual energy expenditure of an adult of medium build in a temperate climate is $2800-3200 \mathrm{kcal} / \mathrm{day}(11.7-13.4 \mathrm{MJ})$ for men, $2100-2300 \mathrm{kcal} /$ day $(8.8-9.6 \mathrm{MJ})$ for women, and about $2000 \mathrm{kcal} / \mathrm{day}(8.4 \mathrm{MJ})$ for a 10 -year-old child. In adults, from 10 to $25 \%$ of energy is spent on the brain, while the brain of a 5-6-year-old child can consume up to $60 \%$ of the body's energy [29]. As the body grows from the age of 20 , the energy consumption begins to decrease with a gradual decrease first by 3 , then by 7.5 , and then by $10 \%$ approximately every 20 years. The intensity of energy consumption depends on the physical activity of the body, slightly different in women and men. Thus, the intensity of energy consumption in light work is 3.5 and $5.3 \mathrm{kcal} / \mathrm{min}$, respectively (which is equivalent to the energy transformation power of $250-370 \mathrm{~W}$ ), in moderate work 5.7 and $8.0 \mathrm{kcal} / \mathrm{min}(400-560 \mathrm{~W})$, in heavy work 7.8 and $11 \mathrm{kcal} / \mathrm{min}(550-770 \mathrm{~W})$. During short-term peak physical activity, energy consumption increases to $14-16 \mathrm{kcal} / \mathrm{min}(980-1120 \mathrm{~W})$ or more, while at rest during sleep, energy consumption is only $1-1.5 \mathrm{kcal} / \mathrm{min}(70-100 \mathrm{~W})$. These data taken at rest are calculated from the rate of basal exchange, i.e., the formation of heat in the human body. As for various physical activities, these data take into account the additional exchange associated with the intensity of muscle load, when mechanical work is added to the formation of heat and the total energy expenditure increases by $15-20 \%$. The latter means that only about $1 / 5$ of the body's own energy can be spent on transforming the environment in order to improve living conditions. And it may happen only in a time-limited working period within the range of developed power at normal and peak loads (from 100 to $1200 \mathrm{~W}$ ) in accordance with the physiological capabilities of the body and the rhythms of human life. Approximately the same level of capacity, determined by the density of energy flows in the biochemical reactions of metabolic processes in the human body, is typical for renewable environmental sources as derivatives of solar radiation, which is the main source of renewable energy on the planet's surface. A comparative assessment of the energy capabilities of these sources for additional energy supply in personalized energy systems is given in Table 1 according to the data [6,30-35]. This includes solar and wind energy, energy of natural magnetic and background electromagnetic fields of anthropogenic nature, thermoelectric materials, including those that convert the heat of the human body, piezoelectric materials that convert the energy of mechanical vibrations, motion or acoustic noise, pyro- and ferroelectric materials that convert radiant energy into high electrical voltage, etc. These sources complement the energy capabilities of the human body discussed above, among which the greatest power density is represented by the thermal energy of the human body $\left(135 \mathrm{~mW} / \mathrm{cm}^{3}\right)$ and the energy of its mechanical movement $\left(800 \mathrm{~mW} / \mathrm{cm}^{3}\right)$.

These indicators are at least one hundred times less than the corresponding indicators of continuous power supply in centralized systems used for covering of general household and industrial needs that are used currently in developed countries (up to 10 or more $\mathrm{kW}$ of installed capacity per each resident). According to the materials provided by the academician P. L. Kapitsa in the report "Energy and Physics" at the scientific session in honor of the $250^{\text {th }}$ anniversary of the Academy of Sciences of the USSR [36] and in his Nobel acceptance lecture [37], based on data from the UNO and the International Bank for Reconstruction and Development in the 70s of the last century, which have kept the general trends to the present day, there is a direct proportionality between the cost of gross national (domestic) product 
TABLE 1. Comparison of capacities of possible sources and technologies of energy collection in personalized energy systems $[6,30-35]$

\begin{tabular}{|c|c|}
\hline Harvesting Method & Power density \\
\hline SOLAR & \\
\hline Solar energy - outdoors & $\begin{array}{c}15 \mathrm{~mW} / \mathrm{cm}^{3} \text { - bright sunny day } \\
0.15 \mathrm{~mW} / \mathrm{cm}^{3} \text { - cloudy day }\end{array}$ \\
\hline Solar energy - indoors & $10-100 \mu \mathrm{W} / \mathrm{cm}^{2}$ \\
\hline MECHANIC (Vibrations) & \\
\hline Piezoelectric - shoe inserts & $330 \mu \mathrm{W}$ \\
\hline Electrostatic conversion & $0.021 \mu \mathrm{W} / \mathrm{mm}^{3}-105 \mathrm{~Hz}$ \\
\hline Electromagnetic conversion & $154 \mu \mathrm{W} / \mathrm{cm}^{3}$ \\
\hline THERMIC & \\
\hline Thermoelectric $-5^{\circ} \mathrm{C}$ gradient & $40 \mu \mathrm{W} / \mathrm{cm}^{3}$ \\
\hline PYROELECTRIC & \\
\hline Temperature rate of $8.5^{\circ} / \mathrm{s}$ & $8.64 \mu \mathrm{W} / \mathrm{cm}^{3}$ \\
\hline MAGNETIC & \\
\hline Magnetic field energy & $130 \mu \mathrm{W} / \mathrm{cm}^{3}-200 \mu \mathrm{T}, 60 \mathrm{~Hz}$ \\
\hline RADIO FREQUENCY & \\
\hline GSM 900/1800 MHz & $0.1 \mu \mathrm{W} / \mathrm{cm}^{2}$ \\
\hline WiFi $2.4 \mathrm{GHz}$ & $0.01 \mu \mathrm{W} / \mathrm{cm}^{2}$ \\
\hline WIND & $\begin{array}{c}380 \mu \mathrm{W} / \mathrm{cm}^{3} \\
\text { (at the speed of } 5 \mathrm{~m} / \mathrm{s} \text { ) }\end{array}$ \\
\hline ACOUSTIC NOISE & $\begin{array}{l}0.96 \mu \mathrm{W} / \mathrm{cm}^{3} \text { at } 100 \mathrm{~dB} \\
0.003 \mu \mathrm{W} / \mathrm{cm}^{3} \text { at } 75 \mathrm{~dB}\end{array}$ \\
\hline
\end{tabular}

produced and energy consumption (Fig. 1). When they decrease, not only the level of well-being falls, but the resulting life expectancy of people in these countries also suffers (Fig. 2).

The report presented by P. L. Kapitsa emphasized not only the fundamentally different level of energy flow density (about $10 \mathrm{MW} / \mathrm{m}^{2}$ ) for large-capacity centralized power generation using concentrated fossil energy resources, from the above-mentioned energy flow density for alternative renewable environmental sources (about $100 \mathrm{~W} / \mathrm{m}^{2}$ at the surface to $1.35 \mathrm{~kW}$ at the boundary of the Earth's atmosphere), but also noted their relationship with the efficiency (efficiency) of energy transformation processes. These indicators are determined by the fundamental laws of conservation of energy and increasing entropy in transformation processes, which do not allow the creation of "perpetual motion machines" of the $1^{\text {st }}$ and the $2^{\text {nd }}$ kind, as well as by the restrictions on the maximum power of its transmission through the material medium by the value of the Umov-Poynting vector $U<\nu F$. Here, $\nu$ is the distribution velocity of the medium-deformation, which is usually equal to the speed of sound in gaseous medium, and $F$ is the volume power density of the medium during the transfer of any type of energy (elastic, thermal, electrical, etc.) in it. In stationary processes, the value of $\operatorname{div} U$ determines the amount of energy conversion to another type. The example given by P. L. Kapitsa of the effect of this restriction on the parameters of various converters shows that in order to generate $100 \mathrm{MW}$ of power while using the direct conversion of solar energy into electrical energy from a sunlit surface at the usual energy flux density of $100 \mathrm{~W}$ per square meter, a working area of $1 \mathrm{~km}^{2}$ is required. The same working areas of almost impossible dimensions will be needed for the wheel of a wind power plant, for the installation of direct conversion of the chemical energy of hydrogen oxidation into electricity, for an electrostatic generator (Van de Graaff type), thermoelectric generators and similar converters on energy sources with energy flows of similar density. 


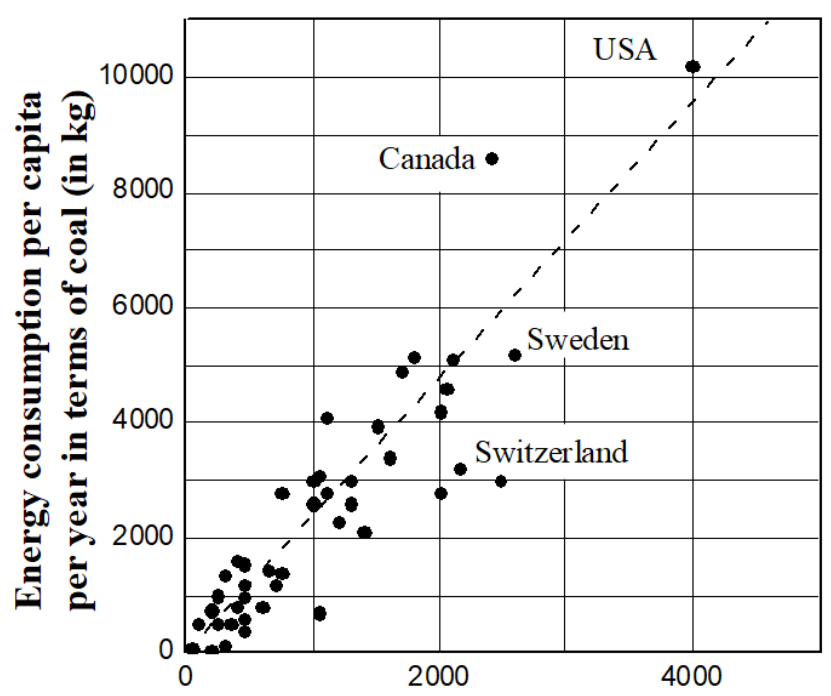

GNP in dollars per person per year

FIG. 1. Dependence of gross national (domestic) product on energy consumption per person per year for different countries of the world $[36,37]$

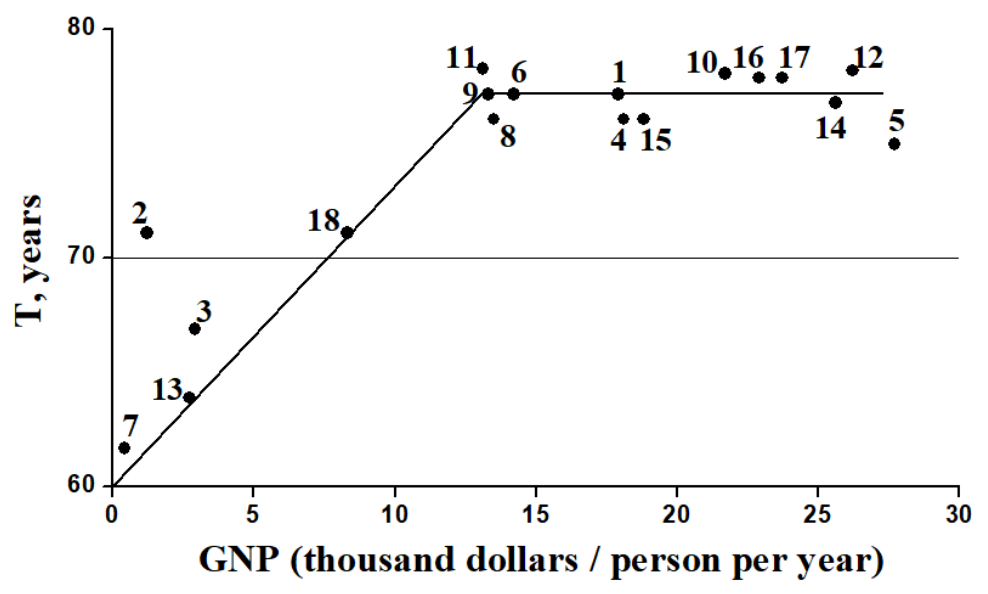

FIG. 2. The dependence of life expectancy in countries of the world on GDP according to the United Nations and the International Bank for Reconstruction and Development (year 2000): 1 - Australia; 2 - Bulgaria; 3 - Brazil; 4 - Great Britain; 5 - Denmark; 6 - Israel; 7 - India; 8 - Ireland; 9 - Spain; 10 - Netherlands; 11 - New Zealand: 12 - Norway; 13 - Russia; 14 - USA; 15 - Finland; 16 France; 17 - Sweden; 18 - South Korea

Similarly simple estimates show that generating even much smaller capacity by using renewable environmental sources in personalized energy systems will also require quite large converter workspaces. In particular, for an additional external energy supply of a person at the level of capacity at least its peak capacity (about $1 \mathrm{~kW}$ ) by using solar photovoltaic cells, wind power plants, thermoelectric generators, small water flow energy, etc. if the flow density of the actual power removed in them is about $100 \mathrm{~W} / \mathrm{m}^{2}$, the working area of each of these installations will be required at least $30-40 \mathrm{~m}^{2}$, taking into account the relatively low values of their efficiency of about $25-30 \%$. The increasing of their energy efficiency through the use of new materials, as well as using possible processes of direct (non-thermal) conversion of source energy into electrical energy by the type of fuel cells with an efficiency of $60-$ $80 \%$, allows reducing the weight and size characteristics of such installations. The possibilities of implementing such one-stage transformations are shown in Table 2, presented as a matrix of mutual transformation of various types of energy [38,39]. As it follows from the the matrix of energy transformations that have practical significance, the possibilities of direct one-stage processes are very limited. A wider choice is provided by the multi-stage organization of sequential transformation of various types of energy with the use of intermediate working bodies. In all cases, it 
TABLE 2. Matrix of possible transformations of various types of energy

\begin{tabular}{|c|c|c|c|c|c|c|c|c|c|c|}
\hline Type of energy & 1 & 2 & 3 & 4 & 5 & 6 & 7 & 8 & 9 & 10 \\
\hline \hline 1. Nuclear PSE, SSE & $(+)$ & {$[+]$} & $++\mid$ & + & {$[+]$} & {$[+]$} & + & {$[+]$} & $<+>$ & {$[+]$} \\
\hline 2. Chemical PSE, SSE, ES & - & {$[+]$} & + & + & + & + & - & $(+)$ & $<+>$ & {$[+]$} \\
\hline 3. Electromagnetic EC & - & $(+)$ & + & + & + & - & - & $(+)$ & $(+)$ & + \\
\hline 4. Gravistatic SSE, ES & - & - & - & {$[+]$} & {$[+]$} & - & - & + & + & + \\
\hline 5. Elastic SSE, ES & - & - & - & {$[+]$} & + & {$[+]$} & + & {$[+]$} & + & $(+)$ \\
\hline 6. Electrostatic SSE, ES & - & - & - & + & + & + & + & {$[+]$} & + & + \\
\hline 7. Magnetostatic SSE, ES & - & - & - & + & + & + & + & + & + & {$[+]$} \\
\hline 8. Electric EC & - & {$[+]$} & + & + & + & + & + & $<+>$ & $<+>$ & $<+>$ \\
\hline 9. Thermal PSE, SSE, ES & - & + & + & - & + & - & - & $(+)$ & $<+>$ & $<+>$ \\
\hline 10. Mechanical PSE, SSE, ES & - & - & - & + & + & + & + & $(+)$ & $(+)$ & $<+>$ \\
\hline
\end{tabular}

Designation: “ - " - transformation impossible; “+”- transformation is possible, but of no practical interest; $|+|-$ transformation is possible and of practical interest, but not for energy purposes; $[+]-$ the transformation is possible and of practical interest for energy purposes, but so far almost never used; $(+)$ - same as previous but partially already in use; $\langle+\rangle-$ same as previous but widely used; PSE primary source of energy; SSE - secondary source of energy; ES - energy storage; energy carrier.

is necessary to ensure the proper level of energy concentration and select working bodies of certain properties for conversion. The simplest, most reliable and promising ways have already been used and can only be improved in the direction of increasing the efficiency of transformations and the specific power of the converter.

Along with the need to increase efficiency, another problem in the development of personalized energy devices is the coordination of energy generation and consumption modes, taking into account the instability of renewable environmental sources and the physiological rhythms of human life. In order to ensure their coordination, wellknown electro-galvanic accumulators are used, as well as new types of super-accumulators and double-layer electric accumulators [40-46] with special schemes for their buffer connection (Fig. 3 and Fig. 4), which control the automatic charging of these devices during periods when the amount of incoming energy exceeds the amount of consumed one. Otherwise, accumulated energy is returned to the consumer [9].

A separate extremely important task of personalized energy systems is to ensure a person's potable water requirements in extreme and emergency conditions in the absence of sufficient sources of clean fresh water. The physiological norm of its daily consumption for an adult is considered to be $30-40 \mathrm{~g}$ per $\mathrm{kg}$ of body weight, which on average is about 2.5 liters of water per day, and the same amount is excreted from the body. Under survival conditions, water consumption can be reduced to one quarter of the norm, but its complete absence or replacement with salty seawater leads to rapid dehydration with a fatal outcome in 3 to 5 days $[11,12,47]$. Possible solutions of this problem include distillation methods for cleaning and desalination of existing salty sea and ground waters using energy sources of the environment, primarily solar radiation.

In all these cases, the main criteria for the practical selection of energy sources in personalized energy systems are not only their availability and capacity indicators presented in Table 2 above, but also the possibility of implementing heat and power supply devices based on them as the most used types of energy, taking into account the specific conditions of their operation. In this regard, the mainly solid-state photo- and thermoelectric converters enumerated below, without mechanically moving elements, are considered as very attractive and preferable ones. A special role in solving the problems of their further improvement is assigned to the development of new functional materials for such devices and the identification of optimal modes for regulating the processes of energy conversion in them in terms of specific output power, efficiency and stability of energy transformation. 


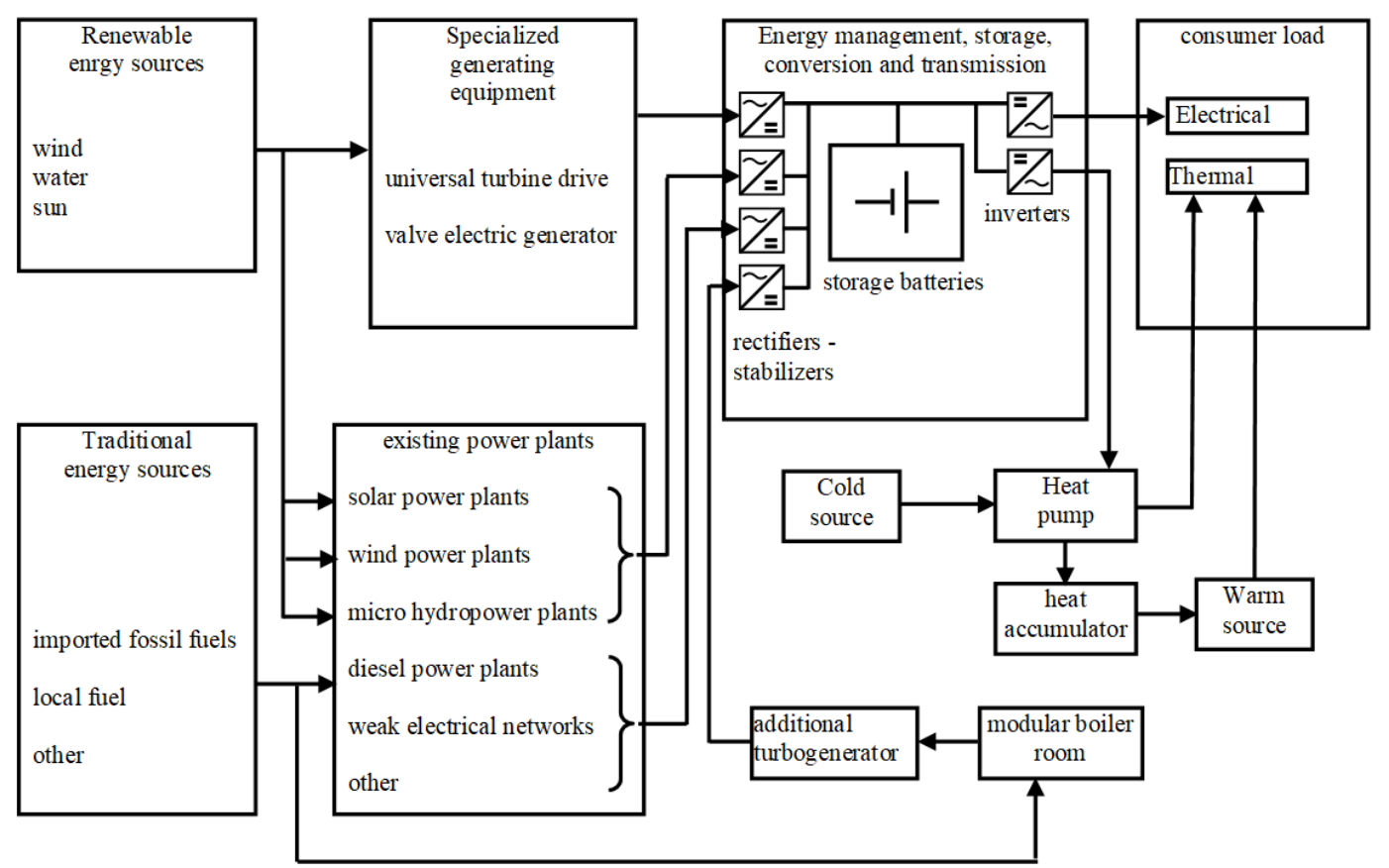

FIG. 3. Autonomous energy system with energy storage buffer

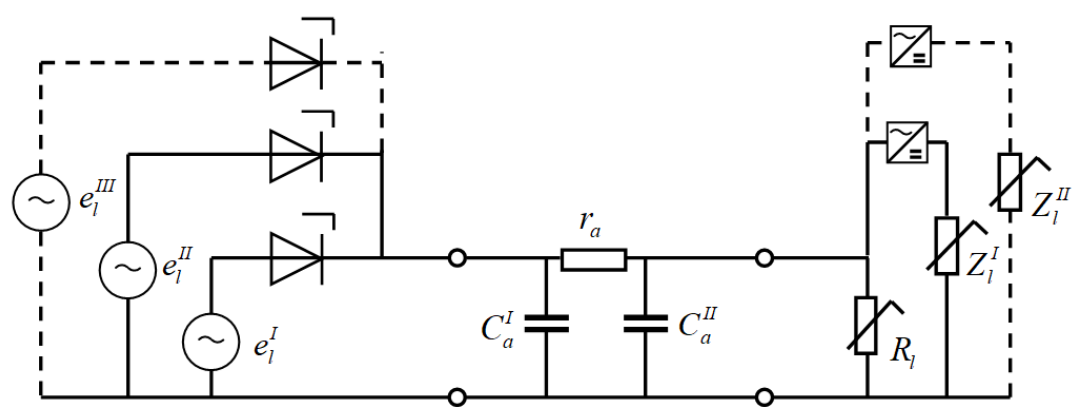

FIG. 4. An equivalent circuit for the calculated replacement of the buffer mode for turning on the drive as part of an autonomous energy system with several energy sources and consumers

\section{Regulation of processes and optimization of energy transformation modes in personalized energy systems}

\subsection{Problems of model description of energy conversion processes in nanostructured media}

The problems of optimal regulation of energy conversion processes in terms of specific output power, efficiency and stability in personalized energy systems remain very relevant not only in connection with the above-mentioned instability of its receipt from renewable environmental sources and uneven consumption in the physiological rhythms of human life. It is equally important to set requirements for the development of new materials for such converters, taking into account their operation in variable modes.

In the available works, energy conversion processes are usually considered either in the thermodynamicallyequilibrium approximation $[48,49]$ or on models of transport phenomena in non-equilibrium thermodynamic systems, usually applied to problems of continuous media, including not only natural [50-53], but also biological objects [5456] and even social systems [57]. However, the application of the classical thermodynamic approach to small nanoscale objects requires a certain adjustment of the models used.

The proposed variants of "nanothermodynamics" which are based on the development of classical equilibrium thermodynamics take into account the contribution of surface energy [58], the extension of classical thermodynamics considering "separation energy" - the so-called nanothermodynamics of Hill $[59,60]$, methods of molecular dynamics and Monte Carlo [61], lattice models [62], the van der Waals theory of inhomogeneous media [63], chemical approach 
to the description of the nanoparticles as chemical education is a complex of supramolecule [64-66], statistical thermodynamics of small systems [67], nonextensive statistical thermodynamics, including the use of Tsalis entropy [68,69], "non-equilibrium" equilibrium thermodynamics with allowance for fluctuation theorems [70-72]. When the material contains a large number of non-autonomous interfacial formations of a fractal nature (non-autonomous phases), which are formed in a limited space between bulk macroscopic phases in the form of intermediate (transient surface or internal) structures, the classical method of J. V. Gibbs is used for thermodynamic description of the system. It reduces the differences in the properties of these structures from the properties of bulk phases to a dedicated conditional tension surface located in the region of the interface [73].

\subsection{Principles of thermodynamic extremes in the generalized analysis of energy transformation processes}

In non-equilibrium processes, the thermodynamic behavior of non-autonomous phases, as well as the behavior of macroscopic bulk phases, can be conveniently considered based on the analysis of changes in the entropy of the system by using the principles of the extremum of thermodynamic potentials [74]. This approach, as more general in comparison with the Gibbs-Duhem equilibrium relation, is associated with the condition of positivity of internal entropy production due to the irreversibility of the processes [75]. Since the density of flows of various forms of energy increases with increasing nonequilibrium of the system, and the efficiency of their redirected transformation decreases due to the concomitant increase in irreversibility losses, the condition for obtaining the maximum power of energy transformation must correspond to the optimal level of thermodynamic nonequilibrium. Its estimation can be made on the basis of considering the processes of transfer and transformation of one type of energy into another as occurring in a certain volume (Fig. 5). Here, the initial energy type corresponds to the input thermodynamic flow $J_{1}$, which, under the action of the conjugate thermodynamic force $X_{1}$, is the driving force for the output flow of the converted energy type $J_{2}$, induced against the non-conjugate thermodynamic force $X_{2}$ [49].

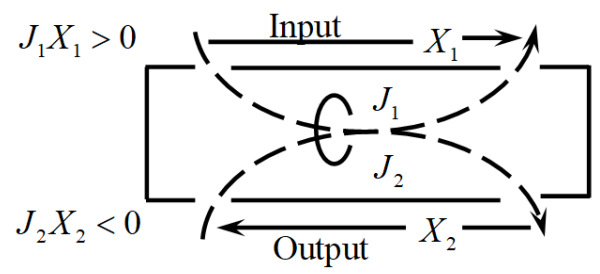

FIG. 5. Generalized energy conversion scheme

The phenomenological connection between thermodynamic flows $J_{i}$ and the thermodynamic forces $X_{i}$ in case of deviations from the equilibrium state, in close proximity to it and in stationary processes is described by a linear Onsager relations: $J_{i}=\sum_{k=1}^{m} L_{i k} X_{i k}$ [76]. Here, $L_{i k}$ means the kinetic coefficients of direct and cross-effects of the transport of converted types of energy, which reveal reciprocity relations $L_{12}=L_{21}$, which are considered a theoretical consequence of the principle of microscopic reversibility of time [75,77], and a consequence of the relationship of convective components of heterogeneous flows at the macro level [78].

Using the Prigogine theorem on the representability of the power source of entropy in the form of a bilinear form of the generalized fluxes and forces,

$$
I_{S}=\sum_{i} J_{i} X_{i}=\sum_{i} \sum_{k} L_{i k} X_{i} X_{k}=\sum_{i} \sum_{k} R_{i k} J_{i} J_{k}=\min \geq 0,
$$

the number of components, which is equal to the number of degrees of freedom of the system, and stationary stable states correspond to minimum entropy production, and entropy moving from performance to energy, for the value of efficiency as the relationship of output and input power, $\eta=E_{2} / E_{1}=T^{\prime \prime} J_{2} X_{2} / T^{\prime \prime} J_{1} X_{1}$ in dimensionless form, we can obtain [49]:

$$
\begin{gathered}
W=-T^{\prime \prime} J_{M} X_{M}=G\left(\Delta H-T^{\prime \prime} \Delta S\right)=\frac{r(1-r) z}{z+1} L_{11} X_{Q}^{2}=\frac{r(1-r) z}{[1+(1-r) z]^{2}} R_{11} J_{Q}^{2}, \\
\eta=\frac{-T^{\prime \prime} J_{M} X_{M}}{T^{\prime \prime} J_{Q} X_{Q}}=\frac{G\left(\Delta H-T^{\prime \prime} \Delta S\right)}{\left(J_{Q}-H^{\odot} G\right) \Delta T / T^{\odot}}=\frac{r(1-r) z}{1+(1-r) z} .
\end{gathered}
$$


Here, the parameter $r=-\left(L_{22} / L_{21}\right)\left(X_{2} / X_{1}\right)$ corresponds to the dimensionless ratio of components in the output energy flow, and the parameter $z=L_{21}^{2} /\left(L_{22} L_{11}-L_{21}^{2}\right)=R_{21}^{2} /\left(R_{22} R_{11}-R_{21}^{2}\right)$ corresponds to the dimensionless q-factor of the converter. The inverse values of the conductivity coefficients $L_{i k}$ characterize the transfer resistances of the corresponding energy flows in the system $\Omega_{1}=X_{1} / J_{1}$ and $\Omega_{2}=-X_{2} / J_{2}$.

\subsection{Modes of energy transformation in non-equilibrium systems}

By means of using the standard apparatus of maxima and minima depending on the ratio $r$ and $z$ the main modes of energy transformation are revealed:

- idle mode and short-circuit mode with zero output power of the converter; $W_{2}=0$ at $r=0$ and at $r=1$;

- maximum output power mode $W_{X Q}^{\max }=[(1 / 4) z /(1+z)] L_{11} X_{Q}^{2}$ at $r=1 / 2$ for a fixed power source (DC voltage $X_{i}=$ const) and $W_{J Q}^{\max }=\left[(1 / 4) z /(1+z) R_{11} J_{Q}^{2}\right]$ for a fixed flow source (DC $J_{i}=$ const) at $r=(1+z)(2+z)$;

- maximum efficiency mode with the maximum value of the efficiency of the converter

$$
\eta^{\max }=(\sqrt{1+z}-1) /(\sqrt{1+z}+1)
$$

at $r=1-(\sqrt{1+z}-1) / z$.

As you can see, the maximum power mode is close to the maximum efficiency mode only for low-efficiency installations, with low q-factor at $z \ll 1$ with its increase, all other things being equal, the efficiency and output power increases. However, even for installations with infinitely high q-factor in the maximum output power mode, the efficiency cannot exceed $50 \%$ of its maximum possible value for this type of converter, for example, the Carnot efficiency for heat engines, the Beitz-Zhukovsky coefficient for wind wheels, the Ioffe efficiency index for thermoelectric generators, etc. [79-81]. In the maximum efficiency mode, with an increase in the q-factor of the system, the efficiency value can approach $100 \%$ of the possible efficiency as the limit for reversible equilibrium of the system, however, the output power tends to zero. In order to obtain high output power, high-quality installations with a constant-force power source must have low internal resistance and are poorly adapted to work with high load resistances, and systems with a constant-flow power source must have low internal conductivity and do not work well with high-conductivity loads. At the same time, in modes with zero output power and zero efficiency, energy costs $E_{Q}=T^{\prime \prime} R_{11} J_{Q}^{2}$ for maintaining the output power at idle are required, at a time when energy costs $E=T^{\prime \prime} L_{11} X_{Q}^{2}$ are required for maintaining the flow of matter at short-circuit mode. The graphical interpretation of the above energy conversion dependences, according to the generalized thermodynamic scheme, is shown in Fig. 6.

The analysis of the given energy characteristics makes it possible to identify the shaded area in Fig. 6 as the most appropriate for creating energy conversion devices, since there is a simultaneous loss in both output power and efficiency beyond its borders. The characteristics of real large-scale power plants presented here show that they are primarily focused on achieving maximum efficiency.

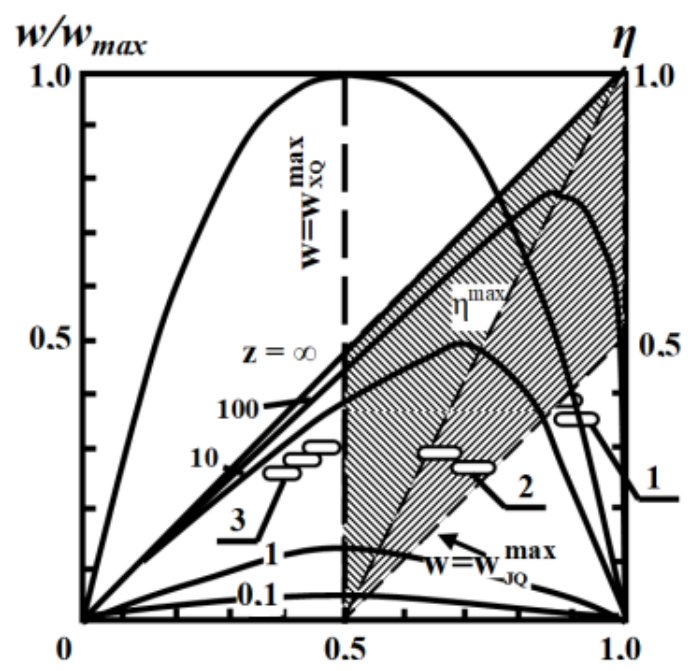

FIG. 6. Generalized characteristics of energy conversion in nonequilibrium thermodynamic systems with conjugate energy flows: 1,2,3-observable data on large-capacity power turbines of thermal power plants, nuclear power plants and gas turbines according to $[80,81]$ 


\subsection{Regulation of operating modes of non-equilibrium systems}

The possibilities of the considered thermodynamic systems to adapt to work in a wide range of loads are illustrated by the diagram in Fig. 7 [54-56]. It is based on the fact that the linear Onsager equations formally describe the operation of affine transformation of the space of input variables $J_{i} X_{i}$ into the space of output variables $J_{i} X_{i}$, translating a rectangular coordinate grid into a skew-angular grid with the image of constant load lines in the form of rays coming out of the coordinate center. The examples of transition path from one state (mode) to another shown in the diagram correspond to various output power control programs used in power plants. Thermodynamic expressions for various paths are obtained from ratios that describe the change in output power and efficiency of the converter for the selected method of regulating the power of energy source or load taking into account the boundary flow values, $\left[J_{1}\right],\left[J_{2}\right]$ and forces $\left[X_{1}\right],\left[X_{2}\right]$ that are maximum allowable under the terms of the destruction of the system.

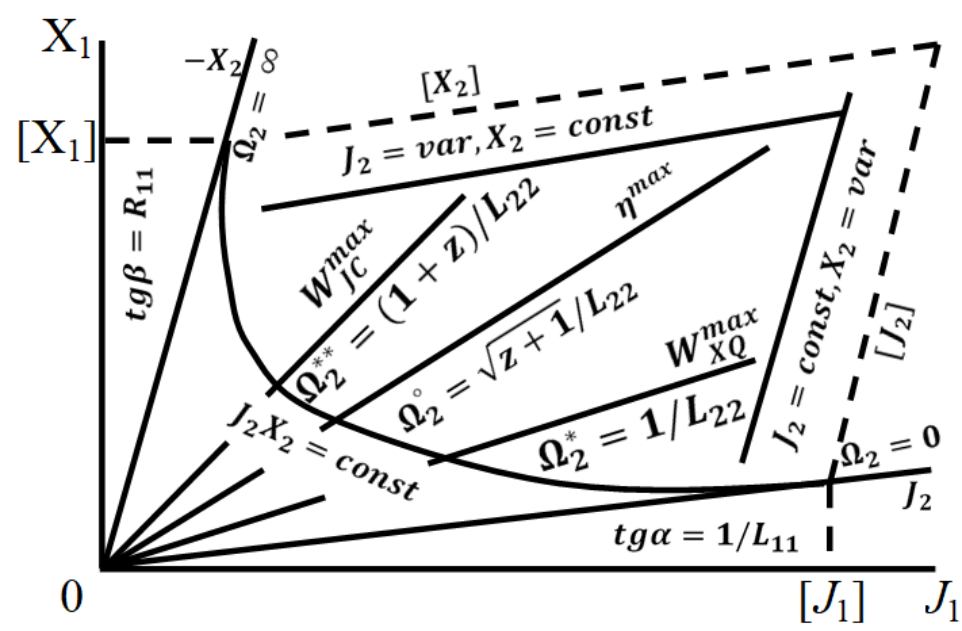

FIG. 7. Load path of energy converters in the input-output space for various control programs

These programs can be implemented by either adjusting the power used by the power source with the converter and load parameters unchanged, or by changing the parameters of the converter and load itself with the input source power unchanged. As can be seen, the greatest thermodynamic gain in efficiency is provided when regulating along the path $\Omega_{2}^{0}$, and in terms of output power - along the paths $\Omega_{2}^{*}$ or $\Omega_{2}^{* *}$ depending on the types of energy source discussed above. The control along the path $J_{2} X_{2}=$ const ensures constant output power of the converter. The corresponding schemes of serial and parallel regulation are shown in Fig. 8.

\subsection{Stability of processes in non-equilibrium systems}

The described energy-entropy approach is used in our work in order to analyze the stability of non-equilibrium systems under deterministic and spontaneous fluctuations of thermodynamic quantities with the formation of selforganizing dissipative regimes and structures $[80,81]$. The variational synergetic principle of least energy scattering (dissipation) was used as a thermodynamic stability condition, which is equivalent to the theorem of Prigogine on the minimum entropy production in stationary linear systems of the Onsager type, but also allows for the contribution of nonlinear effects. At the same time, a relative non-stationary coefficient of the form $\varepsilon=\left\langle\dot{E}\left(J_{i} X_{i}\right)\right\rangle / \dot{E}\left(J_{0 i} X_{0 i}\right)$ is introduced for a general assessment of the influence of dynamic perturbations of flows and forces on changes in entropy production in comparison with their stationary values and determination of self-organization parameters on this basis.

Here, $E\left(J_{0 i} X_{0 i}\right)=T^{\prime \prime} S$ is the variable energy dissipation (entropy production). In a system with stationary values of flows and forces, $\left\langle E\left(J_{i} X_{i}\right)\right\rangle$ is the average value of this variable in a system with perturbed flows and forces, determined by the usual averaging rules for both deterministic, for example, harmonic $X_{i}(\tau)=X_{0 i}\left[1+n_{i} \cdot \sin \left(\omega_{i} \tau+\nu_{i}\right)\right]$ and random $\bar{E}=\int_{-\infty}^{+\infty} E \cdot \psi(E) \cdot d E$ processes. The value $\varepsilon=1$ corresponds to a stationary undisturbed state (mode) of a non-equilibrium system; the values $0.5 \leq \varepsilon \leq 1$ correspond increased or decreased dissipative energy losses at various deviations from this mode. The mathematical formulation of the problem of regime stability and energy-entropy self-organization in such a system is reduced to finding the lowest value of entropy generation $\varepsilon=\varepsilon_{\min }$ depending on the perturbation parameters. This is quite valid even 

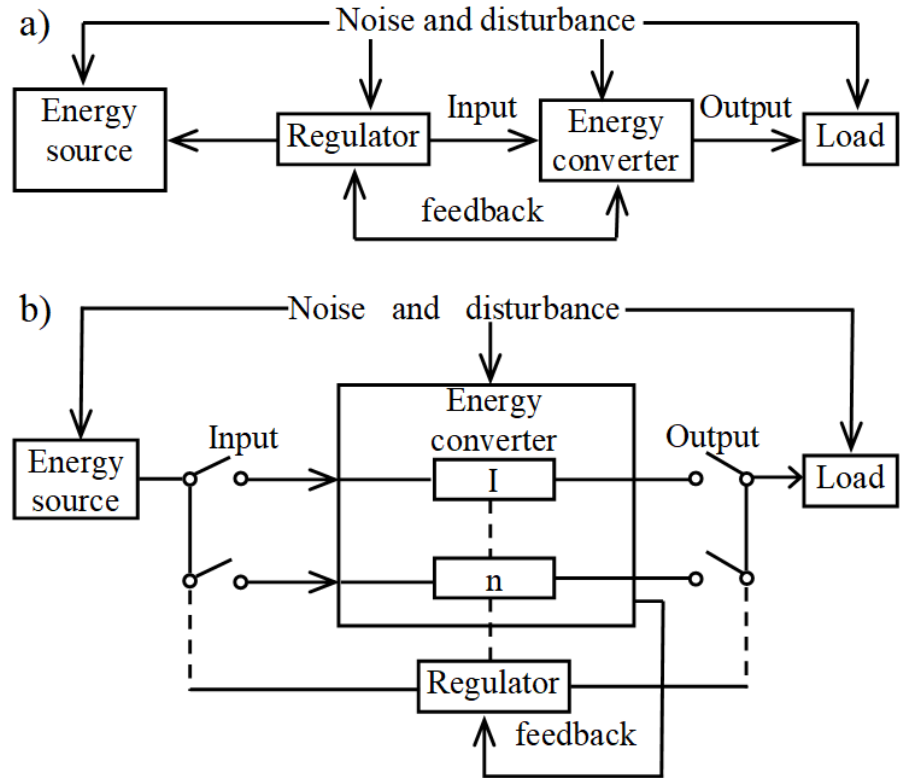

FIG. 8. Schemes of sequential (a) and parallel (b) regulation of input and output power

for systems that allow a linear relationship between thermodynamic flows and forces, $J_{K}=\sum L_{k i} X_{i}$, due to the general quadratic (bilinear) function of entropy production from the acting flows and forces. The minimization of the expression in this case

$$
\varepsilon=\frac{\left[L_{11}\left\langle X_{1}^{2}\right\rangle+2 L_{12}\left\langle X_{1} X_{2}\right\rangle+\left\langle X_{1}^{2}\right\rangle\right]}{\left[L_{11} X_{01}^{2}+2 L_{12} X_{01} X_{02}+L_{22} X_{02}^{2}\right]}
$$

leads to the identification of three successive modes of self-organization system, delimited by the roots of the characteristic equation $\frac{\partial \varepsilon}{\partial\left(n_{1} / n_{2}\right)}=0$ (Fig. 9). As follows from this analysis, a necessary condition for energy-efficient selforganization of the considered thermodynamic systems with the achievement of minimal entropy production $\varepsilon=\varepsilon_{\text {min }}$ in the range $\varepsilon_{\min } \leq 1$ is an antiphase $\left(\nu_{1}-\nu_{2}\right)=\pi$ feedback between the input and output flows (forces) carried out through direct and cross-coefficients of conductivity $L_{k i}$.

The explicit form of expressions for flows and forces, as well as for the source of entropy production in the dependencies of the generalized thermodynamic model is determined by comparing the records of the Onsager and Prigogine relations with the results that follow from the generalized Umov-Poynting balance equations

$$
\rho \frac{d C}{d \tau}+\operatorname{div} J_{c}=I_{c}
$$

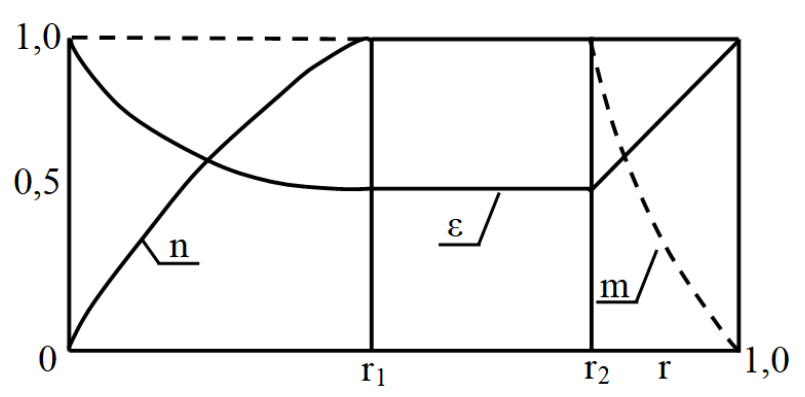

FIG. 9. Change in the relative non-stationarity coefficient $\varepsilon$ during self-organization of energy conversion processes for nonequilibrium thermodynamic systems depending on the relative perturbation amplitudes $n$ and $m$ of the acting thermodynamic forces and the ratio of the components of the energy flows $r$ [53] 
describing the transfer of an arbitrary substance $C$ (mass, momentum, energy, entropy, etc. in a moving medium), together with the Gibbs relation

$$
T d S=d U+p d V+\sum \mu_{j} d M_{j}+\sum a_{\nu} d A_{\nu}
$$

considered for non-equilibrium conditions based on the local equilibrium principle. Here: $\rho$ - medium density, $I_{C}-$ sources of the target substance, $T$ - temperature, $S$ - entropy, $U$ - internal energy, $p$ - pressure, $V$ - volume, $\mu_{j}-$ chemical potential, $M_{j}$ - molar mass of substance $j$ in the system.

The central place among these relations belongs to the entropy balance equation, which separates the total change in entropy $d S=d_{e} S+d_{i} S$ due to the interaction of the system with the environment $\left(d_{e} S\right)$ and due to the action of an internal source of entropy due to irreversible processes $\left(d_{i} S \geq 0\right)$.

It should be noted that for the first time many historically significant estimates of the specific power and efficiency of energy transformation processes were obtained when solving specific scientific and technical problems of their time, which later determined the directions of modern development of personalized energy considered below. We also note that the use of new nanostructured materials with nonlinear energy transfer effects of various levels expands the nature and areas of manifestation of stability and instability of processes, the possibilities of their regulation and selforganization conditions in thermodynamic systems, where the determining role is played not by entropy production as in linear systems, but by the rate of its change [75].

\subsection{Influence of nonlinearities in the structure and properties of the material on the processes of energy transfer and transformation}

Non-linearities in the structure and properties of the material are reflected in the processes of energy transfer and transformation in nanostructured converters and storage devices up to the development of modes with aggravation, which express the inertia of transfer processes in a limited part of the medium and local energy concentration with their retention for a finite time practically without spreading to other zones. Such regimes were studied by A. A. Samarsky and other scientists in problems for quasi-linear parabolic equations in continuous media [24,25]. The analysis of the influence of structural inhomogeneities and functional properties of nanodisperse materials on the nature of the development of such regimes can be carried out on the basis of the modified Fourier-Fick law and the nonlocal transport equation in fractional derivatives with respect to coordinate and time [82-86].

For a general assessment of the influence of metrico-statistical characteristics of the structure of nanodisperse and composite materials on such effects, in particular, manifested in the non-smoothness of the phase paths of solutions of these equations and the stochasticity of their phase attractor up to violations of the ergodicity of the system, fractal analysis methods are used $[87,88]$. They consider the self-similarity of different-scale phase formations with a fractional non-Euclidean dependence $M \sim \varepsilon^{D}$ between the rate of increase in the number of elements considered $\mathrm{M}$ and the increase in the scale of their consideration $\varepsilon$ based on the generalized Renyi relation

$$
D_{R q}=\lim _{\varepsilon \rightarrow 0} \lim _{r \rightarrow 0} \lim _{m \rightarrow \infty}\left[\frac{1}{1-q} \cdot \frac{\ln I_{R q}(q, \varepsilon)}{\ln (1 / \varepsilon)}\right] .
$$

Here, $I_{R q}(q, \varepsilon)=\left[\sum_{i=1}^{M(\varepsilon)} p_{i}^{q}(\varepsilon)\right]-$ is the generalized Renyi entropy of order $q ; M(\varepsilon)$ - is the minimum number of "measuring" elements with $\operatorname{size} \varepsilon$, required for covering of the fractal in the $n$-dimensional phase coordinate space of the embeddings; $p_{i}$ - is the probability of visiting the $i$-th cube by the phase path; $m$ is the number of points used to estimate the dimension [89]. This relation is followed by well-known expressions for the Kolmogorov-Sinai entropy and the Kolmogorov-Hausdorff fractal dimension $(q=0)$, Shannon entropy and the corresponding information dimension $(q=1)$, correlation entropy and correlation dimension $(q=2)$ as special cases for different $q$ [90]. The establishment of these characteristics allows us to link the indicators of structural and phase heterogeneity and their self-organization in the development of new materials with changes in their physical and chemical properties.

The establishment of these characteristics allows us to link the indicators of structural and phase heterogeneity and their self-organization in the development of new materials with changes in their physical and chemical properties.

The characterization of the fractal dimension of nanostructured materials, including micrographs of their chips according to the method discussed in detail in [91], indicates the multifractal nature of their structural-phase inhomogeneity with a whole spectrum of fractal dimensions according to the generalized Renyi ratio, in contrast to the classical regular monofractals of the Sierpinsky structure type [88]. The essential role of fractal structures in regulating the functional properties of such materials is shown for almost all technologies and methods of nanomaterial synthesis [22]. This is determined by the special role of energy and entropy characteristics of non-autonomous phases (interphase layers), the correlation scale of the phenomena of matter and energy transfer in different-sized macro-, 
micro- and nano-structural blocks of the material, as well as the tolerance factor of their interface. At the same time, the kinetic and dynamic characteristics of energy-mass transfer and chemical kinetics processes that occur under the conditions of spatial and mass restrictions of non-autonomous interphase formations, where the energy dissipation rate is significantly higher than in macro-volume blocks of matter, change. In particular, the result of changes in the fractal dimension over a layer of strongly micro-homogeneous material may be an unevenness of its thermophysical characteristics, which was experimentally recorded in [92] with the wave-like nature of the temperature distribution characteristic of the acute regime (Fig. 10).

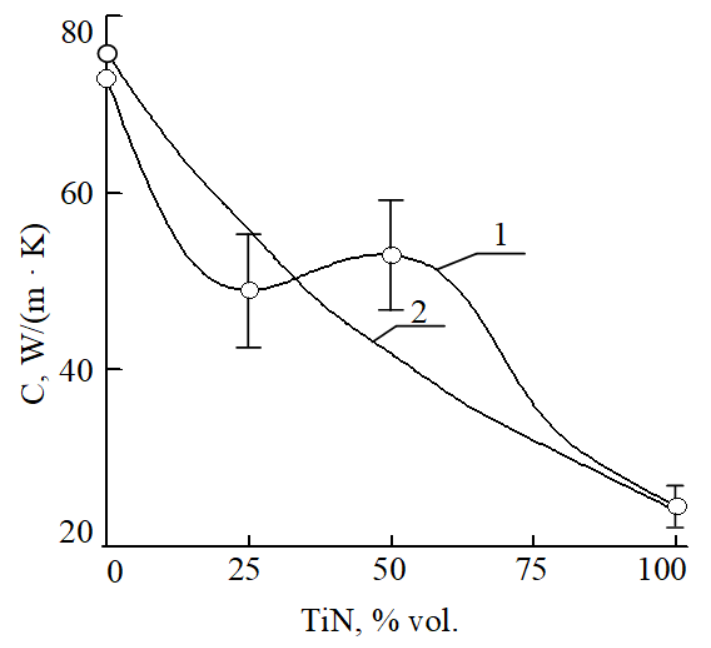

FIG. 10. Comparison of theoretical and measured values of thermal conductivity of the sintered TiN-AlN composite: 1 - thermal conductivity, determined on the basis of the measurement results at $T=30{ }^{\circ} \mathrm{C} ; 2$ - theoretical dependence for the "ideal" mixture of non-interacting components [92]

\section{Features of energy conversion processes using renewable sources of the environment and the body's own capabilities}

\subsection{Solar power systems}

Solar radiation is the common basis of all the Earth's renewable energy, with an available power of about $100 \mathrm{~W} / \mathrm{m}^{2}$ on a surface illuminated by the Sun. The use of this energy in personalized energy systems can now be carried out by transforming it into the most commonly used electrical and thermal forms using photovoltaic and photochemical generators, as well as heating elements. The first type of generator is based on three types of photoelectric effect (external, internal, and lockable layer), the second - on the photovoltaic effect and solar regenerative fuel cells, and the third - on the effect of thermal accumulation by materials with a high specific heat capacity [93,94].

In the above-mentioned three types of effects, the liberation of electrons out of a substance by incident light, a significant energy result is only achieved while using semiconductor elements with a locking layers of p-n junctions. The volt-ampere characteristic, or the relationship between the thermodynamic force and the thermodynamic flux in terms of the general energy transformation model, for such a solar cell is the superposition of the Shockley voltampere characteristic of an unlit diode $J=J_{S}[\exp (q V / A k T)-1]$ and its light current $J_{L}$ when the p-n junction is illuminated, as shown in Fig. 11. The latter is characterized by the appearance of a parallel photo-emf on the internal resistance $V_{R S}=(A k T / q) \ln \left[\left(J-J_{L}\right) / J_{S}+1\right]$ due to the excitation of light-generated charge carriers of the hole-type in the $n$-region and the electron type in the $p$-region [95].

The maximum output power of the photovoltaic transformation of solar radiation energy is determined from the condition $\left[d\left(V_{R} \cdot J_{L}\right) / d V_{R}\right]=0$ and is achieved when the internal resistance of the element is optimally matched with the shunt p-n junction external load, amounting to $W_{\max }=J_{L}^{2} R_{L} F=J_{L}^{2} R_{S} F M_{\text {opt }}$. Here $J_{S}=A k T / q R$ is the diode saturation current due to the thermal generation of hole and electronic carriers of elementary charge $q ; A$ is a dimensionless coefficient depending on the type of semiconductor; $k$ is the Boltzmann constant; $T$ is the temperature; $R$ is the load resistance; $F$ is the illuminated area; $M=R_{L} / R_{S}$. This indirectly takes into account the energy contribution of the spectral composition of solar radiation photons, both in the generation of useful power and in the 


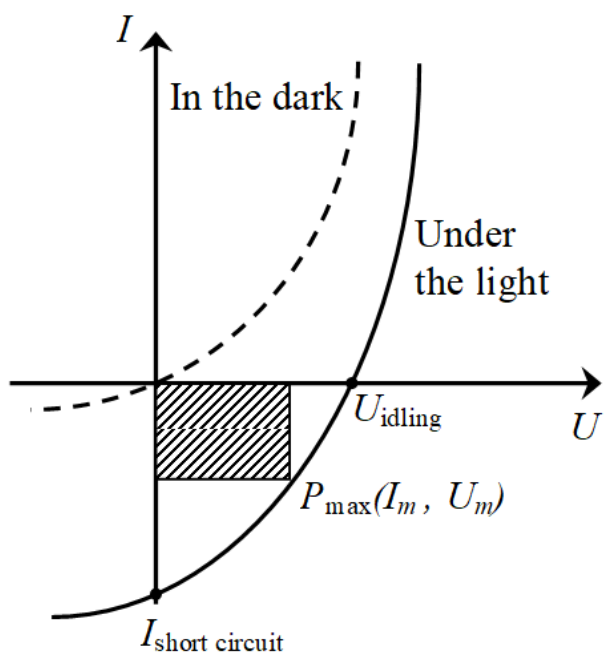

FIG. 11. Current-voltage characteristic of a solar cell based on p-n junction [96]

thermal vibrations of the semiconductor lattice in the form of

$$
J_{L}\left(E_{g}\right)=q \int_{h \nu=E_{g}}^{\infty} \frac{d n_{p h}}{d(h \nu)} d(h \nu),
$$

where $E_{g}$ is the band gap. The spectral response of the used types of semiconductors is also indirectly taken into account through the dimensionless coefficient $A$. The optimal load ratio $M_{o p t}=R_{L} / R_{S}$ can be found graphically from Fig. 11 from the aspect ratio of the shaded rectangle of the maximum area.

The effective efficiency of a solar power generator is determined by the formula

$$
\eta_{q}=\frac{q V}{\left[(h \nu)\left(J / J_{D}\right)\right]},
$$

where $h \nu$ is the photon energy spent on the formation of a pair of carriers; $V$ is the potential difference, and $J / J_{D}$ is the ratio of the useful load and diffusion current through the locking layer of the p-n junction due to the uneven distribution of charge carriers over the volume of contacting semiconductors. Although the maximum thermodynamic efficiency of a solar cell in accordance with the Carnot formula $\eta_{\lim }=\frac{\left(T_{1}-T_{2}\right)}{T_{1}}$ is estimated at about $95 \%$ when the solar radiation spectrum is approximated by the blackbody radiation spectrum with the emitter temperature $T_{1}=5800 \mathrm{~K}$ and the receiver temperature $T_{2}=300 \mathrm{~K}$ [97], this estimate for the maximum power mode decreases by at least half according to the consequences of the generalized energy transformation model, remaining, however, at a fairly high level of $45-48 \%$.

At the same time, the actual achieved efficiency of solar cells, which has significantly increased from 11 to $15 \%$ for those previously created on the basis of silicon and germanium, currently does not exceed $39-41 \%$, even for a new generation of photovoltaic semiconductor converters. They are developed on the basis of multilayer, for example, AlInGaPAs/GaAs/Si, InGaP, InGaAs and Ge nanoheterostructures of cascade type grown by gas-phase epitaxy from organometallic compounds on silicon and germanium substrates [98-106]. At the same time, an increase in the maximum power of the solar cells is achieved not only by improving the structure of p-n junctions, but also by focusing the sun's rays using mirrors and Fresnel mini-lenses. Experiments show that with increasing intensity (countrywoman) incident flux in 100 - 150 times output power grows 20 - 30-fold, as many times is reduced occupied by the phototransducer working area, however, when increasing concentrations above $4-5 \mathrm{~W} / \mathrm{cm}^{2}$, a significant increase in power occurs.

It should be noted that the highest efficiency values of solar photovoltaic cells have been achieved for systems based on $\mathrm{A}^{\mathrm{III}} \mathrm{B}^{\mathrm{V}}$ compounds belonging to straight-band semiconductors, in which direct optical zone-to-zone transitions are allowed, while for other semiconductors the efficiency currently does not exceed $20-25 \%$ [107, 108]. In addition, the widespread use of solar cells on inorganic materials is constrained by relatively expensive technology for the production and processing of inorganic semiconductors, which requires high temperatures and high vacuum.

In this regard, to create new types of cheap solar cells, technologies of thin-film $(0.5-1.0$ microns $)$ solar cells based on amorphous hydrogenated silicon (a-Si:H) with a $p-i-n$ structure have been developed since the 1970's. They 
are obtained by a relatively cheap method of decomposition of $\mathrm{SiH}_{4}$ monosilane in a glow discharge plasma without the use of expensive silicon substrates or harmful and toxic substances, with a thickness of 300 microns, and they have higher electronic properties and 20 times greater optical absorption compared to single-crystal silicon [109-115]. The proposed $p-i-n$ structure makes it possible to create a uniform internal electric field in the entire region of optical light absorption (i-region), which is necessary to provide the film with (a-Si:H) the drift of hole charge carriers with a very small diffusion length $(\sim 100 \mathrm{~nm})$, in contrast to crystalline solar cells based on $p-n$ junctions, where charge carriers with a larger diffusion length (100 - 200 microns) reach the electrodes in the absence of an electric field. Such ultra-thin photosensitive semiconductor films on organic and/or polymer substrates of millimeter thickness can be made using roll technology, and they are already competitive in the market of mass power production.

Along with this, there is an increasing interest in organic and hybrid materials, in particular, with the implementation of a bulk heterojunction based on a donor-acceptor composite polymer (donor) with an acceptor material based on fullerene derivatives, polymer and low-molecular acceptors, discussed in detail in the review paper [116-118]. In order to expand the spectral sensitivity of polymer solar cells, it is possible to use narrow-band acceptor components with strong absorption in the region of the optical gap of the conjugated polymer. Such components can be inorganic nanoparticles, for example, quantum dots based on metal chalcogenides stabilized by suitable ligands, as well as coreshell quantum dot structures [119]. The resulting problem of extracting charge carriers from nanoparticles when they are stabilized by organic ligands is solved quite effectively in an electrochemical Gretzel's solar cell [120-123], created on the basis of nanocrystalline titania $\mathrm{TiO}_{2}$, a metal-complex ruthenium dye and an iodine electrolyte and having an efficiency of up to $11 \%$ (Fig. 12).

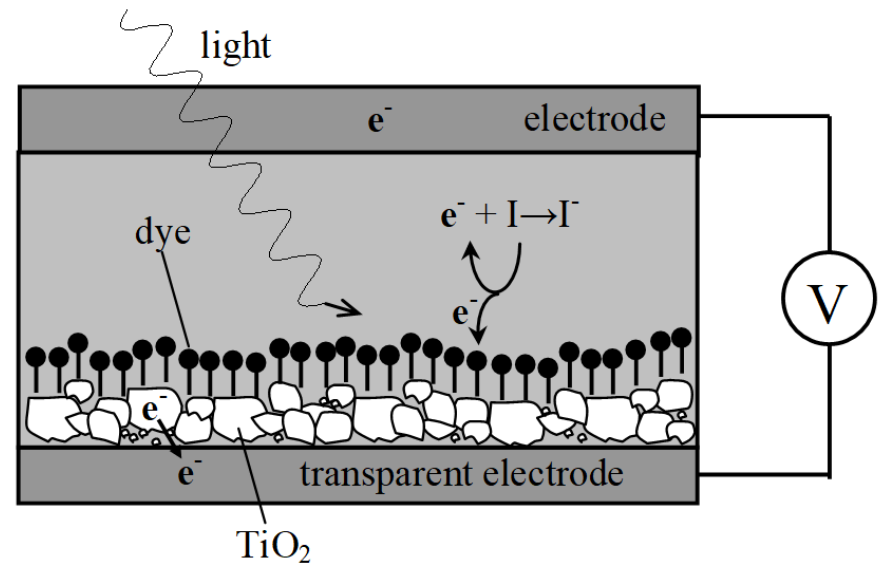

FIG. 12. Gretzel's electrochemical cell [120]

In order to overcome one of the main disadvantages of Gretzel's electrochemical cells associated with the use of a liquid electrolyte that evaporates during long-term operation, the problems of replacing it with a solid electrolyte or eutectic melt are considered [124-134].

Among the chemical methods of solar energy conversion, photochemical, photoelectrochemical (including photoelectrolysis of water into hydrogen and oxygen) and photocatalytic methods are traditionally considered [135, 136], the analysis of which is not included in the tasks of this work. We note only the prospects for using the photocatalytic properties of titania $\mathrm{TiO}_{2}$, which is widely distributed in nature, not so much for photoenergetic purposes, but for use in water and air purification systems from toxic chemical compounds and disinfection of various types of microorganisms [120-122,137-139].

Solar radiation, along with the possibility of transformation into an electric current source, can also be easily converted into a heat source $[93,94]$. The simplest devices of this type for personalized energy systems are lowtemperature heaters in the form of a "hot box". They allow one to obtain the temperature of the intermediate heat carrier circulating inside its pipe system in the range from $55-85^{\circ}$ with an efficiency of $20-40 \%$ to $200{ }^{\circ} \mathrm{C}$ at an outdoor temperature of $15-20{ }^{\circ} \mathrm{C}$. The physical basis of heating is a local greenhouse or greenhouse effect, which is manifested by the re-emission of heat from the heat-insulated internal volume of the "box" heated by the sun with different transparency of its cover glass (or polyethylene film) in the visible and far infrared ranges. The removed heat can be used not only for heating and cooling of premises, water lifting and drying installations, for cooking, but also for other needs, including desalination of salt sea water. Various designs for the implementation of a solar desalination plant with a specific capacity of $3-5 \mathrm{l} / \mathrm{m}^{2}$ per day have been developed for a long time, including for the crews of aircraft and ships in distress on the high seas $[140,141]$. One of the modern versions of such a desalination plant 
produced by a German company "Augustin Produktentwicklung" is an inflatable floating shell made of transparent plastic with an inner rim and a blackened bottom strip made of a sponge soaked in sea water (Fig. 13). The water evaporated by the sun's heat condenses when it comes in contact with the cooler sealed sub-cone shell, and the distillate flows down to the lower part of the desalinator. The cone can also be installed on wet ground soaked in salt water. The desalination plant also works at night due to the temperature difference inside and outside the cone.

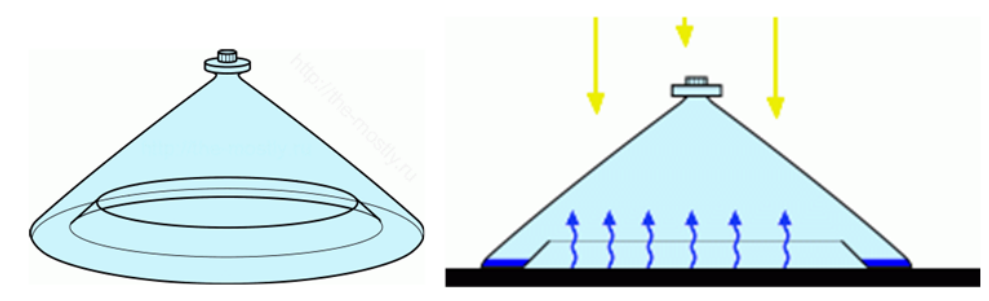

FIG. 13. A desalination solar cone with a base diameter of about $0.8 \mathrm{~m}$ and with an optimum 78 degree angle for draining condensed moisture at the apex, providing $40 \%$ efficiency for 1 1.15 liters of fresh water per day (URL: http://www.augustin.net/, http://www.watercone.com/)

In principle, it is also possible to recover from the air the moisture always contained in it, for example, by condensing it under strong cooling, which, however, requires excessive energy consumption for each liter of moisture. The proposed cheaper options are based on the phenomenon of intensive absorption of atmospheric moisture by various substances. For example, we can use liquid lithium chloride, followed by the separation of water from the lithium salt by semipermeable membranes due to reverse osmosis. Special nanofabrica "for fog-catching" with alternating nanoporous capillaries and a water-repellent network for collecting absorbed moisture are also proposed.

\subsection{Thermoelectric converters}

With regard to the problems of heat and power supply as the most used types of energy, this type of solidstate devices without mechanically moving elements can be attributed to the historically first developments in this field, taking into account the specific operating conditions of personalized energy systems. Their characteristics for specific conditions of direct conversion of heat to electricity were first analytically obtained by A. F. Ioffe [142]. This contributed to the widespread use of such devices in the 1940's and 1950's to power battery-operated lamp radio stations and radio receivers up to $10 \mathrm{~W}$ of power by heating with a kerosene lamp or a fire pot (Fig. 14).

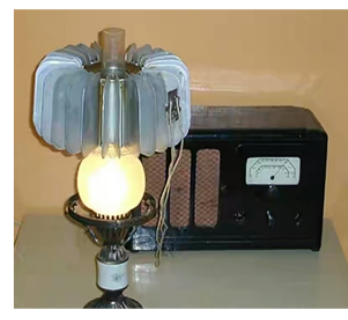

a)

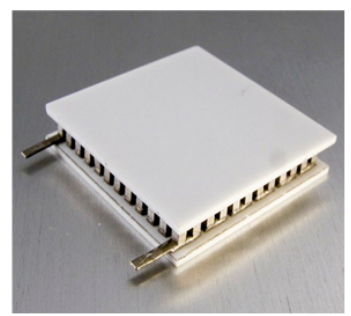

b)

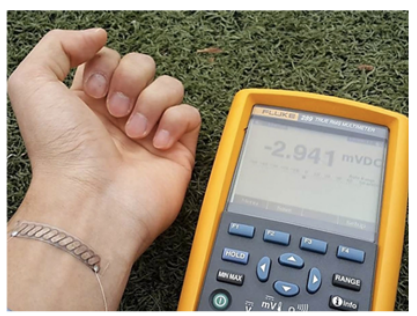

c)

FIG. 14. Museum copy of the thermoelectric generator with a power of $10 \mathrm{~W}$ at $\Delta T=$ $300{ }^{\circ} \mathrm{C}$ (a) [146] and modern thermoelectric modules of the same power with a size of $40 \times 40 \times 3 \mathrm{~mm}$ at $\Delta T=170{ }^{\circ} \mathrm{C}$ (b) [147]; as well as glass fabric (c)

Currently, thermoelectric converters are being improved based on the development of new nanostructured materials, available heat sources and technologies $[143,144]$, and work is underway to use the existing background electromagnetic radiation in the radio frequency and light range, and even the heat of the human body for similar purposes [145].

The results obtained by A. F. Ioffe [142] and based on the consideration of the Seebeck effect underlying thermoelectric converters for the appearance of a potential difference $\Delta V$ at the ends of series-connected dissimilar conductors at different temperatures $\Delta T=T_{1}-T_{2}$ (Fig. 15) specify the above relations of the generalized model in the form of the following dependencies for efficiency and output power. 


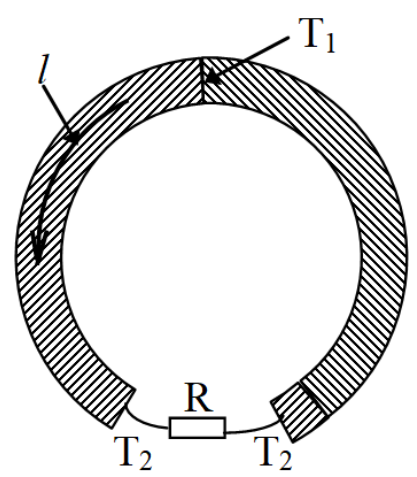

FIG. 15. Scheme of thermoelectric thermogenerator, $T_{1}, T_{2}$ - temperature $\left(T_{1}>T_{2}\right)$; $R$-electric load; $l$-current direction $[93,142]$

All in all, the expression for the efficiency of converting thermal energy into electrical energy is given by the formula:

$$
\eta=\frac{T_{1}-T_{2}}{T_{1}} \frac{m /(m+1)}{1+\left(k r / \varepsilon^{2}\right)(m+1) / T_{1}-0.5 \Delta T / T_{1}(m+1)}=\frac{m /(m+1)}{1+(m+1) / Z T_{1}-0.5 \Delta T /(m+1)} .
$$

Here $T_{1}$ and $T_{2}$ are the temperatures of the hot and cold sides of the thermoelectric converter; $m=R /\left(r_{1}+r_{2}\right)$ is the ratio of the resistances of external and internal loads in the circuit of connected conductors;

$$
Z=\left[\left(\varepsilon_{1}+\varepsilon_{2}\right)^{2}\right] /\left[\left(\sqrt{\lambda_{1} r_{1}}+\sqrt{\lambda_{2} r_{2}}\right)^{2}\right]
$$

is the total thermoelectric $q$-factor of the converter, depending on the values of the Seebeck thermoelectric coefficients $\varepsilon=\Delta V / \Delta T$ for the selected $\mathrm{p}$ and n-type materials, their thermal conductivity $\lambda_{p}\left(\lambda_{n}\right)$ and resistivity $r_{p}\left(r_{n}\right)$. We should note that in solids, the thermal conductivity $\lambda=\lambda_{l}+\lambda_{e}$ includes the lattice (phonon) $\left(\lambda_{l}\right)$ and the electronic $\left(\lambda_{e}\right)$ components, the latter being related to the specific electrical conductivity of the material by the WiedemannFranz law $\lambda / \sigma=L T$, with their ratio practically unchanged for different metals at the same temperature $\lambda_{e}=L \sigma T$, where $L$ is the Lorentz number [148].

Taking into account the value of the current in the circuit $i=\varepsilon \Delta T /(r+R)=\varepsilon \Delta T[R(m+1)]$ and the magnitude of the generated voltage to an external load equal to the thermo-emf, minus the voltage drop on the internal resistance $U=E-U_{r}=\varepsilon \Delta T-i r$ the following modes of thermoelectric conversion are determined.

For the mode of maximum electric power $W^{\max }=I U$ at $m=R / t=1$, the expression efficiency takes the form

$$
\eta_{t, N}=\frac{\Delta T}{2\left(T_{1}+2 / z\right)-(\Delta T / 2)}
$$

for the mode of maximum efficiency - the form

$$
\eta_{t}^{\max }=\frac{T_{1}-T_{2}}{T_{1}} \cdot \frac{(M-1)}{M+\left(T_{2} / T_{1}\right)}
$$

at $m_{\text {opt }}=(R / r)_{o p t}=M \sqrt{1+0.5 z\left(T_{1}+T_{2}\right)}$. As can be seen in mode $\eta_{T}^{\max }$ the power drops compared to the maximum $w_{\max }$, however, largely reduced the total heat flow through the thermoelectric power source by reducing the Peltier heat taken from the hot junction due to the fall of $i$ in the chain while $m$-increasing. In this way, an optimal energy balance is achieved.

Ignoring the accounting Joule heat $i^{2} r$, we can simplify the expression of the optimal ratio of resistance $M^{\prime}=\sqrt{1+z T_{1}}$ and corresponding optimum efficiency:

$$
\eta_{t}^{\max }=\frac{T_{1}-T_{2}}{T_{1}} \cdot \frac{\sqrt{1+z T_{1}}-1}{\sqrt{1+z T_{1}}+1} .
$$

A graphic illustration of the dependences obtained by A. F. Ioffe with the graphs of the above dependences of energy conversion according to the generalized thermodynamic scheme is shown in Fig. 16.

As it can be seen, the full electromotive difference of potential of the thermoelectric power source $E=\varepsilon \Delta T$ provides the current strength in the electric circuit $i_{\text {sh.c. }}=E / r$ when the junctions are short-circuited at $R=0$ to $i=0$ when the load resistance is open $R \rightarrow \infty$, and in the maximum power mode $i \cong 0.5 i_{\text {sh.c. }}$. Therefore, one 


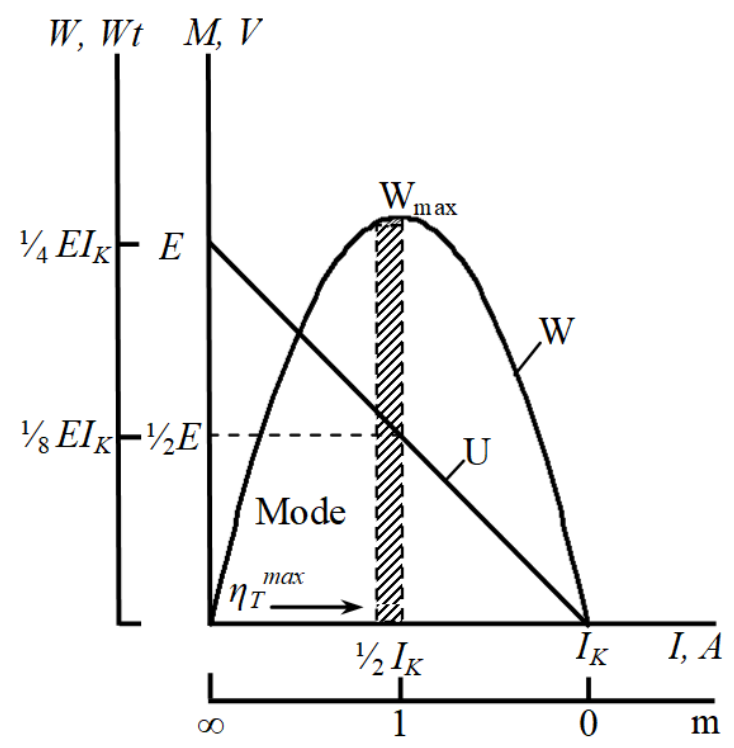

FIG. 16. Characteristics A. F. Ioffe Energy Efficiency Thermoelectric Power Generators [93, 142]

element can only be used with low ohmic loads, but to ensure high-resistance loads, it is necessary to use a system of series-connected elements in a thermal battery with a sufficiently high internal resistance and total efficiency [93]:

$$
\eta_{\Sigma}=\eta_{1}+\eta_{2}\left(1-\eta_{1}\right)+\eta\left(1-\eta_{1}\right)\left(1-\eta_{2}\right)+\ldots+\eta_{n}\left(1-\eta_{1}\right)\left(1-\eta_{2}\right) \ldots\left(1-\eta_{n-1}\right)
$$

The reverse of the Seebeck effect, the Peltier thermoelectric cooling effect is used in solid-state thermoelectric refrigerators that do not have mechanically moving elements, as well as thermal generators. The main energy characteristic of such devices is the cooling coefficient $\eta_{c}=Q_{c} / A=Q_{c} / I \Delta V=Q_{c} / \varepsilon I \Delta T$, where $\Delta T=\left(T_{1}-T_{2}\right)$ is the temperature difference between the hot and cold junctions of dissimilar conductors, and $Q_{c}$ is the absorbed heat at the cold junction at temperature $T_{2}$.

Taking into account the Joule heat release on the internal resistance of the branches of the thermoelement when transferring heat from a cold to a hot junction at a temperature $T_{1}$, it is possible to express the efficiency

$$
\eta_{c}=\left(\varepsilon I T_{2}-0.5 I^{2} R-\lambda \Delta T\right) /\left(I^{2} R+\varepsilon I \Delta T\right)
$$

and determine its maximum value for the current value $[149,150]$ :

$$
I=(\varepsilon \Delta T) /\left[R\left(1+0.5 Z\left(T_{1}+T_{2}\right)-1\right]^{1 / 2} .\right.
$$

As you can see, the cooling coefficient tends to its maximum value $\eta_{c}^{\max }$ at $Z \rightarrow \infty$, and the maximum cooling capacity $Q_{c}^{\max }$ is achieved at the maximum operating current $I_{\max }$ with $\eta_{c}=\left[T_{2}-2 \Delta T / Z T_{2}\right] / 2 T_{1}$. In this case, the total heat output of the device in this mode will exceed the Joule heating of $0.5 I^{2} R$ by the variable $Q_{h}^{\max }=Q_{c}^{\max }+0.5 I^{2} R$, where $Q_{X}=\eta_{X} \varepsilon I \Delta T$. This allows it to be used as a heat pump with an efficiency coefficient of $\left.\eta_{h}=Q_{h} / I \Delta V=Q_{c}^{\max }+0.5 I^{2} R\right) / I \Delta V$ [151]. The high functional flexibility of thermoelectric coolers and heat pumps allows somebody easily change their operating mode from the maximum efficiency $\eta_{X}^{\max }$ up to the maximum thermal power $Q_{X}^{\max }$ regimes by changing the applied voltage and the q-factor $Z$ of the thermoelectric materials used.

According to A. F. Ioffe [142], the main criteria that must be met by effective thermoelectric materials with high qfactor are: a) the presence of heavy atoms in the material that reduce the lattice thermal conductivity; b) the possibility of deep doping of the matrix to achieve a concentration of charge carriers of the $10^{19}-10^{20} \mathrm{~cm}^{-3} ; \mathrm{c}$ ) high values of the Seebeck coefficient ( $\varepsilon>200 \mathrm{mV} / \mathrm{K})$; d) not too small band gap; e) high effective mass of charge carriers. In this case, solid solutions should have a higher thermoelectric q-factor compared to individual compounds due to lower values of their lattice thermal conductivity due to the disordered nature of one or more sublattices. To a large extent, the functional characteristics of thermoelectrics are determined by the concentration of charge carriers. The electrical conductivity and the electronic component of the thermal conductivity increase with increasing concentration of charge carriers, and the thermo-emf, on the contrary, decreases; the power factor of a thermoelectric material and its thermoelectric q-factor pass through the maximum corresponding to the transition zone between semiconductors and metals, and the thermoelectric converter itself consists of two p- and n-type semiconductor columns (Fig. 17). 


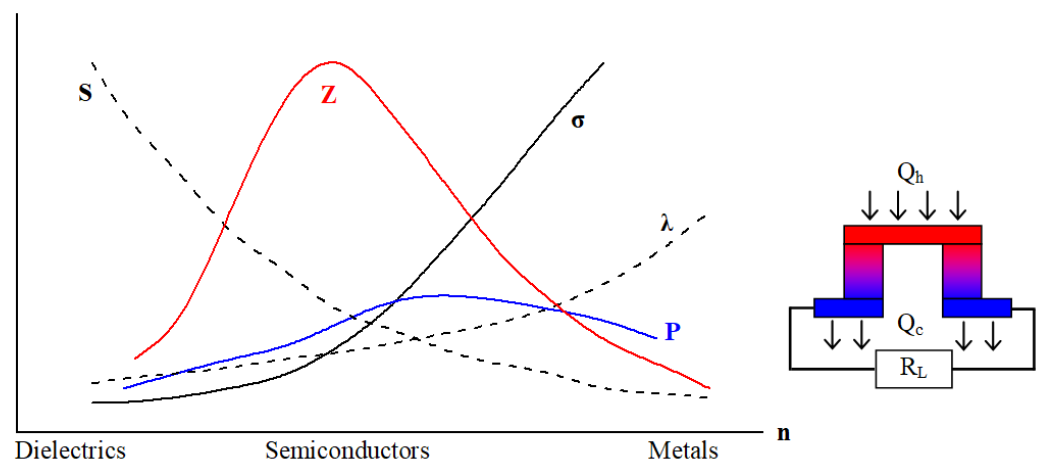

FIG. 17. Concentration dependences of the main characteristics of thermoelectrics. The maximum value of the thermoelectric figure of merit corresponds to a concentration of charge carriers of the order of $10^{19} \mathrm{~cm}^{-3}$

\subsection{Background electromagnetic radiation and optical nanoantennas}

The targeted application of the fractal organization of nanostructured objects described above creates a possibility for using background electromagnetic radiation, in particular, radio radiation, to power wearable low-power electronic devices in personalized energy systems. Although in the environment, background radio frequency energy has the lowest specific power compared to other alternative sources, such as solar and wind energy, magnetic field energy, thermoelectric materials, including those that convert human body heat, piezoelectric materials that convert the energy of mechanical vibrations, motion or acoustic noise, etc., compared in Table 2 according to [30] and detailed in [32-35], it radiates in a very wide frequency range, independent of the time of day, temperature fluctuations, the presence of noise and vibrations. The beginning of the development of this topic can be considered the simplest detector receivers, which were widely used in the first decades of radio broadcasting, did not need a power source and used exclusively the energy of the received radio signal of the DV and SD bands according to the principle proposed by Nikola Tesla in 1890 .

Currently, the power of background radio emission has increased many times (up to $1 \mathrm{~mW} / \mathrm{cm}^{3}$ in total) due to the development of HF and VHF radio broadcasting, analog, digital and satellite television, cellular communications, etc. The energy transmitted by them can be converted into a constant voltage and stored for subsequent power supply of low-power electronic devices by special receivers-microchipsets (energy harvesters with dimensions of about $5 \times 5 \mathrm{~mm}$ ), developed by various companies [152]. In order to collect this energy, additive antenna technologies with a fractal or fractal-like topology are being developed [153]. Thus, the Institute of Radio engineering and Electronics (IRE named after V. A. Kotelnikov) of the Russian Academy of Sciences proposed broadband fractal antennas (Fig. 18) with a wide absorption band of electromagnetic energy and a wide directional pattern and programmable frequency-selective properties with a transition from 2D to 3D electrodynamic media [154]. They use direct current magnetron sputtering technology and $3 \mathrm{~d}$ inkjet printing technology with the use of nanoparticles based on metal nanoparticles.

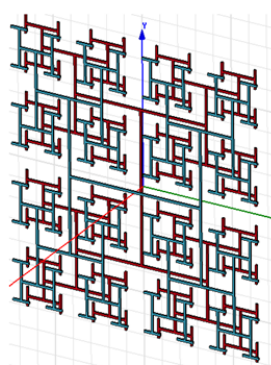

a)

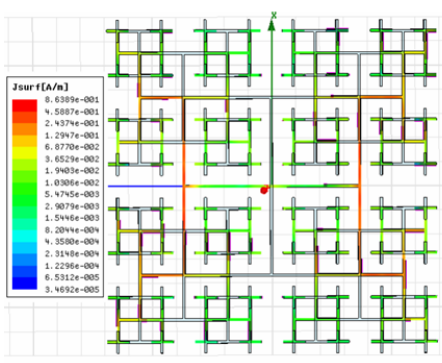

b)

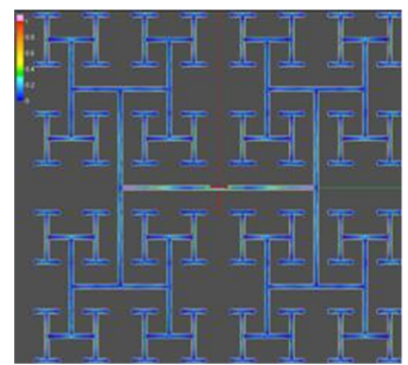

c)

FIG. 18. Antenna plates of fractal frequency-selective surfaces based on the 'Keighley Tree' (a) and current distribution over the surface of fractal structures in normal (b) and inversion (c) color images [154] 
Optical nanoantennas are being developed to solve a similar problem of direct collection of the energy of natural electromagnetic radiation from the Sun in the optical range [155].

As in conventional radio antennas, they use the effect of inducing currents by an incident electromagnetic wave with optimization of their spatial distribution. In this case, it is achieved by converting optical frequency radiation from submicron and even nanometer-sized objects into a highly localized electromagnetic field concentrated in a region of small size compared to the wavelength. Nanoparticles, small groups of them, and even individual molecules, atoms, ions, or clusters of them are used as such objects. The spatial spectrum of a concentrated field does not contain uniformly flat transverse waves, but is a superposition of longitudinal evanescent waves whose polarization is directed along their propagation, and the intensity when working with nanometer objects can significantly exceed the intensity of ordinary (transverse) electromagnetic waves. Special cases of nanoantennas are devices that convert light radiation into wave modes of so-called plasmon non-waveguides with sizes much smaller than the optical wavelength based on various spherical, pin-shaped, rhombic, "bow tie" and fractal configurations of metal, semiconductor and dielectric nanoparticles, as well as their hybrid combinations (Fig. 19).

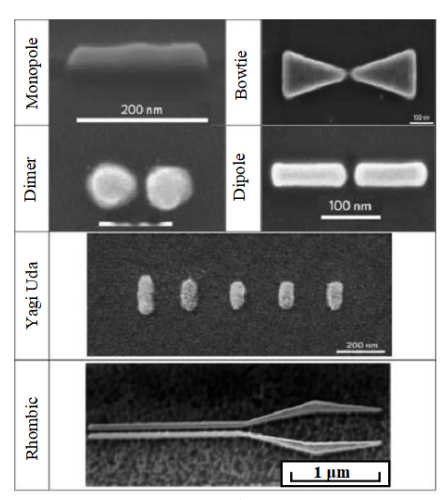

a)

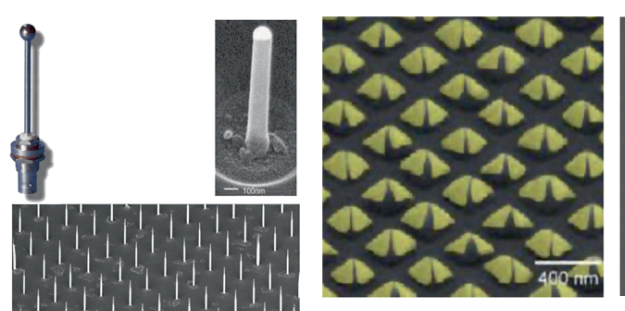

c)

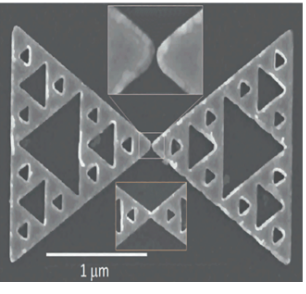

d)

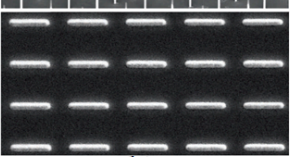

b)

FIG. 19. Main types of optical plasmon nanoantennas (a) [155], their monopole (b) [156-160] and dipole 'bow tie' (c) [161] arrays, including those using Sierpinski fractal structures (d) [162]

Such a wide variety is determined by the various advantages and disadvantages of the presented types of nanoantennas in terms of their broadband, dissipative losses, effective gain, and other parameters, a detailed analysis of which is presented in a large specialized review taking into account various applications [155]. The use of nanoantenn arrays as light-trapping nanostructures for thin-film batteries in photovoltaics promises to realize the mode of localization of incident light inside the sub-wavelength region of an optically thin photosensitive layer. This will allow us to solve the issues of compensation of light reflection and prevent its loss when passing through such a thin film [163, 164].

\subsection{Optical communication systems in the ultraviolet range}

Among the specific tasks listed in the introduction in personalized energy systems, there is one which corresponds to the increasing of the reliability of wireless mobile communications through a self-organizing information transmission network that is protected from deliberate suppression and interception under the influence of destructive factors of natural and man-made natures. One of the promising directions for solving this problem with the possibility of significantly increasing the bandwidth compared to radio frequency communication systems is the development of optical communication systems based on the use of an ultraviolet channel in the sun-blind range of wavelengths. This range makes it possible to use a huge unlicensed communication spectrum and has good electromagnetic compatibility with various electronic devices. A significant number of scientific articles, in particular, [165-170], as well as numerous patents, for example, [171-176], are devoted to the problems of modeling and experimental research of such communication systems. An important advantage of this channel in comparison with other optical bands is also the ability to provide reliable communication in the absence of line-of-sight (NLOS) in the presence of obstacles between the transmitter (led or laser) and the receiver (photodiode or photoelectric multiplier). The feasibility of communication lines in the ultraviolet range without direct visibility is based on the reception of molecular and aerosol scattering of optical radiation in the atmosphere [177-182].

The calculated and experimental evaluation [183-185] of the pulse characteristics of an optical atmospheric ultraviolet channel with scattering according to a model geometric scheme (Fig. 20) generally indicates the applicability of small-sized semiconductor emitting LEDs based on multilayer semiconductor heterostructures and receiving photodiodes created so far for the UV range as an element base for transmitters and receivers of communication systems. This 
is also shown by the results of the first field tests performed at the Institute on Laser physics of the Siberian Branch of the Russian Academy of Sciences in the field of non-line-of-sight ultraviolet communication links, multicast network communications by using a pulsed copper bromine laser as the emitter at the converted wavelength $\lambda=281.1 \mathrm{~nm}$ and a photoelectronic multiplier FEU-142 as the receiver [186].

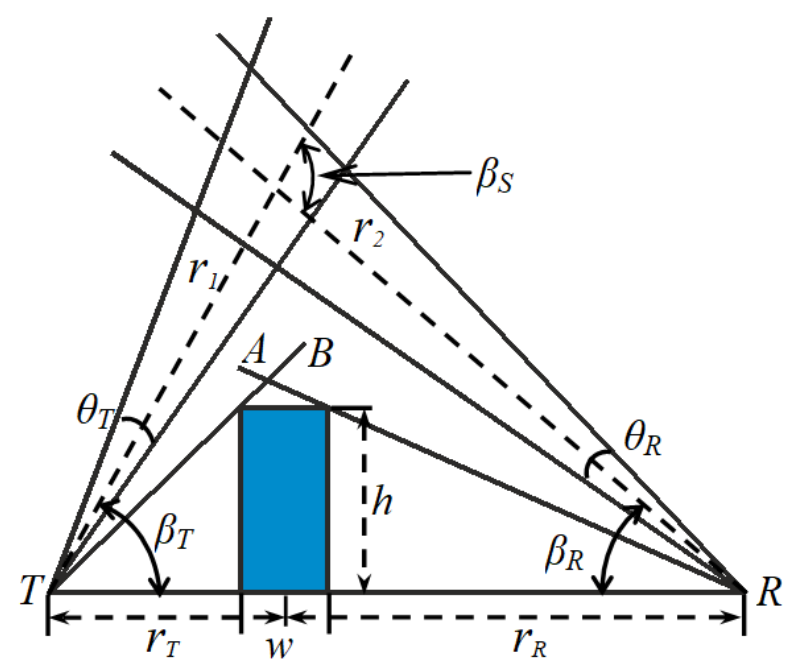

FIG. 20. Model of a UV channel with a line of sight. UV channel model with an obstacle of width [183-185]

\subsection{Human muscle power, mini wind- and hydro-electric generators}

The above-mentioned energy capabilities of the human body, among which the greatest power density is represented by the thermal energy of the human body $\left(135 \mathrm{~mW} / \mathrm{cm}^{3}\right)$ and the energy of its mechanical movement $\left(800 \mathrm{~mW} / \mathrm{cm}^{3}\right)$, are used in a number of proposed "hiking" tourist solutions for generating electricity through muscle power. The technical basis of these solutions are manual electrodynamic flashlights - "bugs", known since the 1980s with the modern replacement of incandescent lamps with emitting LEDs, bicycle high-speed dynamo-machines that rotate from the side wall of the tire of a moving wheel, and modern bicycle bushing multi-pole generators installed as the wheel axis. The latter provide an electric power output of $3 \mathrm{~W}$ at a current of $500 \mathrm{~mA}$ and a voltage of $6 \mathrm{~V}$, sufficient for the operation of powerful led lighting and for charging portable electronics at relatively low wheel speeds (160 $200 \mathrm{rpm}$ ). On their basis, compact low-speed wind and hydro-wheel generators are also designed, equipped with blades located directly on the Bicycle spokes, in contrast to the development of bulky wind wheels with a high-speed dynamo-machines. The latter work well at $1500-3000 \mathrm{rpm}$ and require a gearbox when using wind or water flow as the driving force. Recently, bladeless non-rotating wind generators have also been proposed [187], based on the effect of frontal wind pressure on a round "sail" that oscillates due to built-in air valves, with further transformation of this movement by hydraulic drive or piezoelectric elements similar to acoustic and thermoauxtic electric generators [188].

In all cases, in order to increase the power and efficiency used in such devices generators with permanent magnets, further development coercivity materials with powerful magnetic induction type known neodymium magnet, consisting of an alloy of rare earth element neodymium, boron and iron with the tetragonal crystal structure of $\mathrm{Nd}_{2} \mathrm{Fe}_{14} \mathrm{~B}$ are required [148].

A historical prototype of power engineering devices using renewable environmental energy without electricity generation can be considered made of wood as a natural nanocomposite wind- and water mills that reached the height of perfection in the $17^{\text {th }}$ century.

\section{Development of new functional materials for personalized energy based on nanotechnology approach}

\subsection{General methods of the nanotechnological approach to the development and synthesis of functional materials}

The development of nanostructured materials for working bodies and media of energy converters and storage devices is a developing and very promising area of modern research in the field of autonomous personalized energy industry. The nanotechnology approach involves the creation and use of materials, devices, and technical systems whose 
functioning is determined by a nanostructure with ordered structural fragments ranging in size from 1 to 100 nanometers. Features of nanodisperse systems are associated with the manifestation of quantum-dimensional effects, changes in the atomic-crystal structure, and an increase in the proportion of "surface" atoms that are under different conditions compared to the bulk phase atoms. The nonequilibrium state of nanoparticles, which is formed as a result of extreme production conditions, is reflected in the properties of nanomaterials in comparison with massive samples. The use of such materials, whose structure and properties significantly differ from those of a continuous medium, allows us to purposefully influence the energy transformation processes to reduce dissipative losses in various types of generators and converters: thermoelectric, solar and wind generators, fuel cells, batteries and galvanic batteries, supercapacitors and other devices, up to high-temperature superconductivity systems [189-211].

A special influence on the change in the functional properties of a nanostructured material is exerted by the presence of a large number of interphase formations of a fractal nature (so-called non-autonomous phases), which in their properties, structure and composition differ significantly from the corresponding characteristics of bulk phases. These studies were initiated by the works of T. Jung (1805-1807), D. W. Gibbs (1878), and J. D. van der Waals (1908-1912), who considered the properties of surface layers (phases) of finite thickness, as well as the works of R. Defey (1934) and I. R. Prigogine (1947), who defined such formations as "non-autonomous phases" and "non-autonomous state of matter" due to the impossibility of their independent (isolated from bulk phases) existence [21, 50, 51, 75, 212, 213]. New developments in this direction have been made in research on the physicochemistry of surface phenomena and microheterogenic systems [214,215], as well as intergranular and surface layers at the contact boundaries of solid regions of bulk phases in polycrystalline [216-221].

Current works in the field of development of nanostructured converters and storage devices are mainly focused on the problems of physical and chemical formation of structural and functional characteristics and the development of methods for technological support of the synthesis of nanodisperse and nanoporous materials [222-234]. Also their technological applications in different types of converters, in particular, thermoelectric, solar and wind generators, fuel cells, batteries and galvanic batteries, supercapacitors and other devices, up to systems of high-temperature superconductivity are being discussed [235-248].

To date, plenty of different methods for creating nanostructured materials are known, which can be divided into two large groups according to the type of nanostructure formation.

The "top-down" nanotechnology approach is based on reducing the size of physical bodies up to obtaining objects with nanoscale parameters. When large particles are dispersed to nanoscale sizes, a significant amount of energy must be expended from the outside to dramatically increase the solid-liquid (or gas) interface. In order to do this, we have methods that are conventionally called physical methods which use use low-temperature plasma, cathode sputtering, molecular beams formed by various heating sources, electric explosion, mechanical grinding in its various variants etc. [249]. The extremely fast (extremely non-equilibrium) thermodynamic processes of high-speed phase transitions of the aggregate state of matter through the "solid-liquid-gas", including transitions through the critical point are of particular interest for dispersion [250]. It is the only extremum on the equilibrium curves of the phase diagram that belongs to both a liquid and a vapor, and the approach to it is accompanied by a significant increase in density fluctuations in the micro volumes of matter compared to the regions of existence of metastable states adjacent to the equilibrium curves of the two phases. In case of a sufficiently intensive input of energy, density fluctuations can selforganize, leading to a loss of thermodynamic stability of the substance and the formation of dissipative microstructures. They can serve as "pre-germs" for the subsequent formation of dispersed particles during the destruction of the initial consolidated material and the transfer of part of the energy to the environmental substance. This makes it possible in principle to obtain very small sizes of such particles, up to units of nanometers, in contrast to the observed results of other well-known dispersion mechanisms under mechanical or thermal action, for example, impact grinding of a solid, its melting and crushing of a liquid into droplets, evaporation and subsequent vapor deposition. This significantly increases the energy saturation of nanoparticles, which can cause their unique catalytic, sorbent and other properties, as well as the observed threshold phenomena. For example, the total surface of all particles contained in a metal $\mathrm{Ni}$ powder with an average size of $0.1 \mathrm{~mm}$ increases by a factor of 1000 when they are dispersed to a size of $100 \mathrm{~nm}$ from a consolidated substance in non-equilibrium thermodynamic processes.

In case of the opposite "bottom-up" technology, a nanoobject is "assembled" from individual atoms, molecules, biological cells, etc. The possibility and prospects of this approach were first pointed out by Richard Feynman [251] in a speech at the annual meeting of the American Physical Society in 1959. This process mainly occurs by selfassembly or chemical reactions resulting from the transformation of a precursor compound and subsequent aggregation of molecules or atoms of the reaction product, and therefore these methods are often referred to as chemical [252]. Most technologies for assembling nanomaterials from individual atoms are based on the phenomenon of condensation or chemical deposition from a matrix medium under conditions close to thermodynamic equilibrium. The formation of nanostructures is significantly influenced by clusters of pre-germ micro-formations, as well as spatial restrictions 
in the evolution of matter from the formation of pre-germ clusters to the aggregation of nanocrystals in the material of both individual compounds and solid solutions based on them. However, even in this case, a large excess of surface free energy, which is the driving force of spontaneous enlargement of nanoparticles, can also cause their instability and loss of unique properties. To prevent undesirable aggregation and stabilization of nanoparticles, dispersants are used, which are introduced into the medium containing nanoparticles, or the method of so-called matrix isolation of nanoparticles in porous bodies is used, etc.

It should be noted that in the practical implementation of both approaches, both physical and chemical methods can be used, as well as their various combinations. It is fundamentally important that the structure of nanoparticles of the same size obtained by dispersion and construction from atoms may differ. When compact materials are dispersed to nanoscale sizes, the resulting particles usually retain the structure of the original sample. Particles formed by aggregation of atoms may have a different spatial arrangement of the atoms, which affects their electronic structure and the lattice constant.

The choice of specific methods and conditions for the synthesis of nanocomposite materials aimed at use in personalized energy systems is determined by specific requirements for their functional properties noted above, first of all, the efficiency of regulating energy conversion processes in terms of specific output power, efficiency and stability. In particular, according to the results of joint research of the Ioffe Institute and the Belarusian State Technological University have identified advanced technological methods for obtaining basic model compounds with a high content of non-autonomous phases. They are designed to create a new generation of functional nanostructured materials for chemical-catalytic and thermoelectric purposes due to the obvious disadvantages of materials traditionally used for these purposes with a high content of toxic and expensive components.

\subsection{Characterization of properties and features of synthesis of new nanostructured thermoelectric materials by "wet chemistry" methods}

The development of new classes of thermoelectric materials is based on a number of concepts, one of which is the idea put forward by Slack that a good thermoelectric should be a substance that conducts electric current well ("electron crystal") and poorly conducts heat ("phonon glass"), the so-called PGEC [253]. On the basis of this idea, such classes of thermoelectric materials as filled scutterudites (for example, $\mathrm{Yb}_{x} \mathrm{Co}_{4} \mathrm{Sb}_{12}$ ) [254-257], semiconductor clathrates $\left(\mathrm{Eu}_{8} \mathrm{Ga}_{16} \mathrm{Ge}_{30+x}\right.$, etc.) [258, 259], as well as Goisler half-alloys (in particular, $\left(\mathrm{Zr}_{0.7} \mathrm{Hf}_{0.3}\right)_{0.7} \mathrm{Ti}_{0.3} \mathrm{NiSn}$ ) [260]. The another concept is the idea put forward by Dresselhaus that nanostructuring of thermoelectrics is an effective way to increase their thermoelectric q-factor, due to a sharp decrease in the lattice component of thermal conductivity arising from a decrease in the average free path of phonons [261].

In this regard, the synthesis of nanoceramic materials based on metal oxides such as cobalt and zirconium, in particular, the system of layered calcium cobaltites of the $\mathrm{CaO}-\mathrm{CoO}_{x}$ type, is of great interest due to their low cost and high stability at elevated temperatures. At the same time, partial substitution of cobalt with transition or heavy metals, and calcium with rare-earth elements or bismuth can be used to improve their thermoelectric characteristics. The essence of the applied synthesis method consists in the chemical deposition of the hydroxide components of the solution on the solid phase suspended in this solution. $\mathrm{CaCO}_{3}$ suspension in $\mathrm{Co}\left(\mathrm{NO}_{3}\right)_{2}$ solution was used as the initial components, and $\mathrm{NaOH}$ solution was used as the precipitator. Initial nanopowders in the form of solid solutions of the composition $\mathrm{Ca}_{3-x} \mathrm{Bi}_{x} \mathrm{Co}_{4} \mathrm{O}_{9+\delta}(0.0 \leq x \leq 1.5)$ were obtained by solid-phase reactions from $\mathrm{Co}_{3} \mathrm{O}_{4}, \mathrm{Bi}_{2} \mathrm{O}_{3}$ and $\mathrm{CaCO}_{3}$. Further high-temperature treatment of the resulting initial mixture was carried out in a muffle furnace aerobically in the temperature range of $400-900{ }^{\circ} \mathrm{C}$ with an isothermal exposure time of 3 hours.

This method was also used for synthesizing the samples of new materials based on perovskite-like layered compounds in the $\mathrm{Ln}_{2} \mathrm{O}_{3}-\mathrm{MO}-\mathrm{Al}_{2} \mathrm{O}_{3}$ system (where $\mathrm{Ln}=$ rare earth elements: lanthanum, scandium, yttrium, and lanthanides; $\mathrm{M}=\mathrm{Mg}, \mathrm{Ca}, \mathrm{Sr}$, and $\mathrm{Ba}$ ) with the structure of the Ruddlesden-Popper phases [262-264]. Using a wide range of physical and chemical analysis methods, the main of which are X-ray fluorescence and X-ray spectral microanalysis, X-ray diffractometry, scanning electron microscopy, synchronous thermal analysis, pycnometry, etc., their physicochemical and functional properties were studied, and their structural features were determined (Fig. 21).

Based on the results of these studies, it was found that the power factor and the thermoelectric q-factor in bismuthcontaining ceramics based on layered calcium cobaltite, as well as in polycrystalline substances based on lanthanumstrontium-aluminum oxide, can be significantly improved by creating a chemical [265] or phase inhomogeneity in it [266-269].

The revealed characteristics of these compounds indicate the prospects of their use as p-branches of hightemperature thermoelectric generators of a new generation. Promising materials for the $\mathrm{n}$-branches of thermoelectric generators are perovskite calcium manganites $\mathrm{CaMnO}_{3}$ doped with rare-earth materials [270-276], perovskite plumes of alkaline-earth materials [277-280], and materials based on titanium dioxide and strontium titanate [281-288]. High-density n-type thermoelectric ceramics are produced by the same methods as p-type ceramics, additionally using 


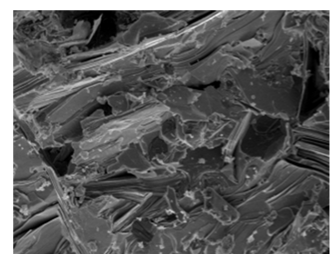

a)

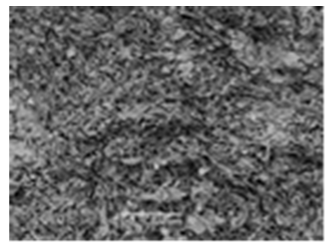

b)

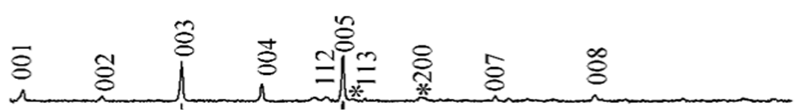

c)

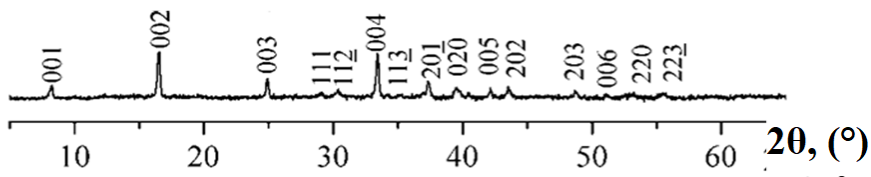

d)

FIG. 21. $50 \mu \mathrm{m}$ electron micrographs of nanostructured $\mathrm{Ca}_{3-x} \mathrm{Co}_{4} \mathrm{O}_{9+\delta}$ ceramics at: $x=0$ (a), $x=1.5$ (b) and $\mathrm{X}$-ray diffraction patterns of appropriate compositions ceramics (c, $\mathrm{d}$ ). * marks $\mathrm{Co}_{3} \mathrm{O}_{4}$ reflections.

annealing in a reducing atmosphere to create the desired level of oxygen sublattice defects that provides the required electrophysical properties [289].

Such complex oxide thermoelectrics can also be used for direct conversion of solar energy into electrical energy [290-292], with higher efficiency than in photovoltaic devices, since the latter allow only UV and part of the visible region to be converted to electricity, while in thermoelectric generators, the entire spectrum of solar radiation is converted.

In order to determine the stability boundaries of complex oxides with the structure of one-layered RuddlesdenPopper phases, based on the structural-energy approach and taking into account the comparison of geometric tolerance conditions of the perovskite block size parameter with the parameter showing the number (fraction) of compounds from the set of potentially possible [293], the formation of a new $\mathrm{DySrAlO}_{4}$ thermoelectric compound is predicted and synthesized by solid-phase reactions in the temperature range $1300-1500{ }^{\circ} \mathrm{C}$. A simplified diagram of the layer coupling mechanism is shown in Fig. 22.

\subsection{Features of the implementation of the combustion method of gel-like media in high-speed kinetic mode}

The combustion method of gel-like media in high-speed kinetic mode [201, 208, 224, 225, 232, 248, 294] is an alternative to the described synthesis method, which proceeds in a relatively slow diffusion mode [216-221,262,293,

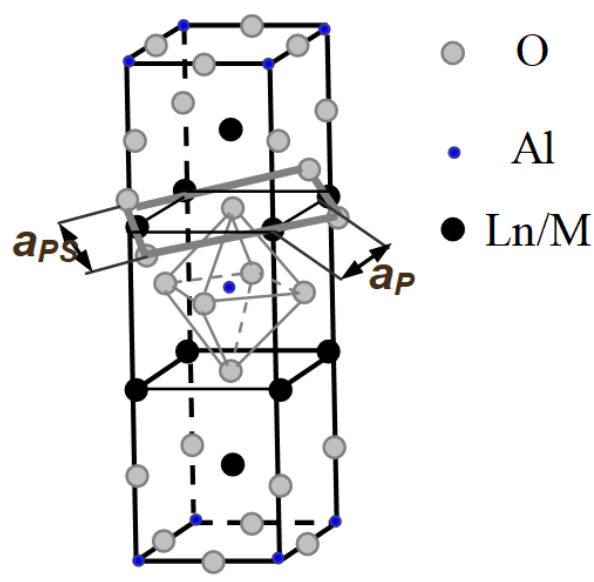

FIG. 22. Scheme of conjugation mechanism of $\mathrm{LnAlO}_{3}(\mathrm{P})$ and rock salt MO (RS) blocks, which form the one-layered Ruddlesden-Popper phases structure. The geometric associativity of $\mathrm{P}$ and RS blocks fragments can be estimated by the comparing of these blocks areas sizes or unit cell parameters, in particular, by the size ap, as shown in the scheme. 
295], as well as to the sol-gel and hydrothermal technology with nanopowder deposition from the initial mixture and subsequent dehydration during heat treatment [195, 196, 198, 200, 229, 231, 296-298]. It is used to produce layered calcium cobaltite $\mathrm{Ca}_{3} \mathrm{Co}_{4} \mathrm{O}_{9}$ during the combustion of a glycine-nitrate gel precursor [299-302]. This method provides a higher dispersion and uniformity for the synthesized powders, including stoichiometric composition, which helps to solve the problem of their sinterability, and brings the properties of materials based on them closer to the properties of single-crystal samples. Examples of the structures of highly dispersed $\mathrm{Ca}_{3} \mathrm{Co}_{4} \mathrm{O}_{9}$ samples obtained by this method are shown in Fig. 23.
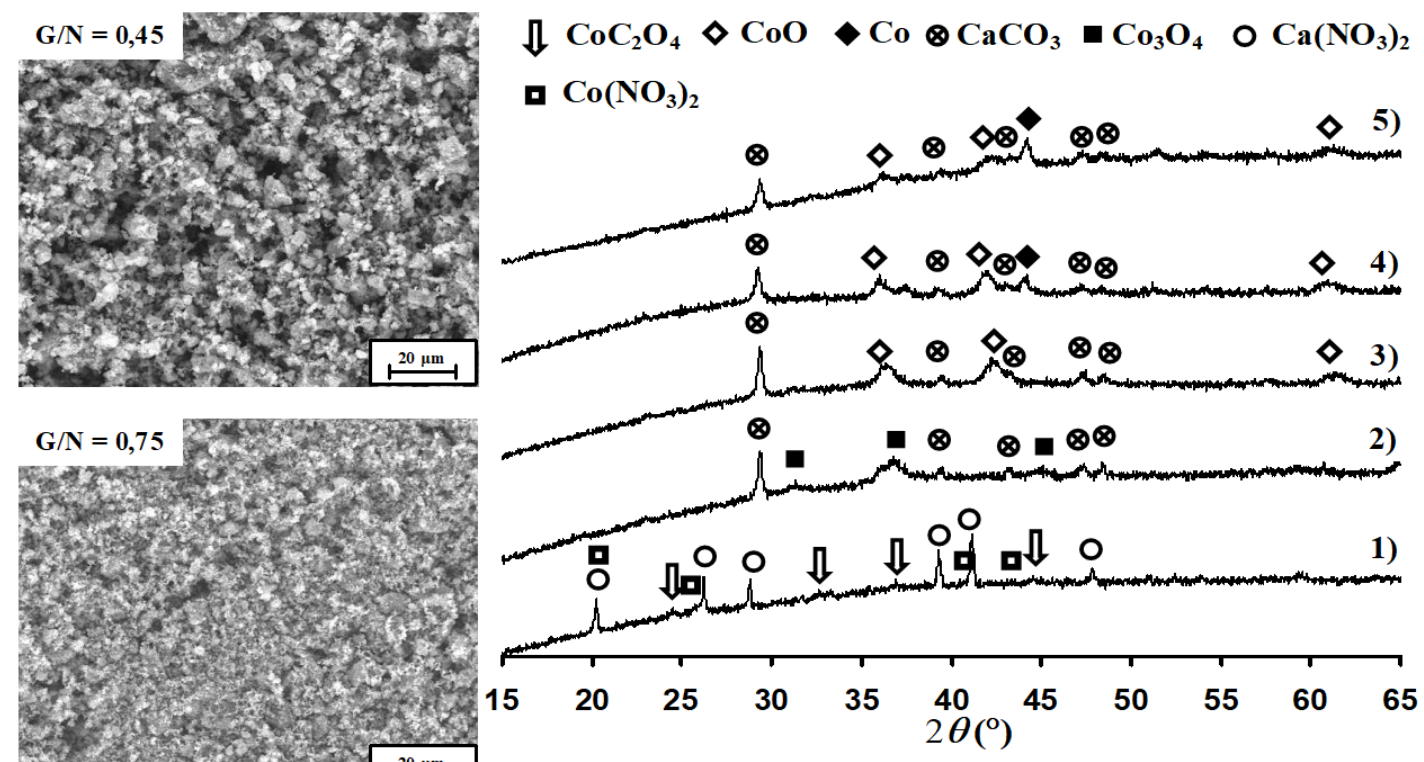

FIG. 23. Electron micrographs of dispersed $\mathrm{Ca}_{3} \mathrm{Co}_{4} \mathrm{O}_{9}$ samples obtained by heat treatment of precursors got at $G / N=0.45,0.75$ ratio under $T=700{ }^{\circ} \mathrm{C}$ and $\mathrm{X}$-ray phase analysis data of the initial $\mathrm{Ca}_{3} \mathrm{Co}_{4} \mathrm{O}_{9}$ samples after combustion with different $G / N:$ 1) $\left.\left.\left.\left.0.15,2\right) 0.30,3\right) 0.45,4\right) 0.6,5\right) 0.75$

Recently, the solution combustion (SCS) method has been used to obtain new nanostructured multiferroic materials with unique magnetic, electrical, and catalytic properties based on rare-earth element (REE) orthoferrites $\mathrm{RFeO}_{3}$ ( $\mathrm{R}=\mathrm{Y}, \mathrm{Ln})[194,207,231,297,303-310]$ with a perovskite-like structure, combining ferromagnetic and ferroelectric ordering. In some cases, it has been shown that the use of additional heat treatment of solution combustion products and other chemical precursors leads to the formation of metastable forms of REE orthoferrites and a significant change in the functional characteristics of materials based on them [231,311,312]. It has been shown that in this case, the chemical and structural background of the precursor exposed to thermal action plays an important role [313-316], while for other systems, for example, $\mathrm{KNO}_{3}-\mathrm{BaTiO}_{3}$-based ferroelectrics, the necessary properties can be achieved by simple mechanical mixing of the components and the background does not play a significant role [317]. Among the oxide magnetic materials that are promising for use in personalized energy devices, it is also worth noting substances with a spinel structure $-\mathrm{Li}_{0.5} \mathrm{Fe}_{2.5} \mathrm{O}_{4}, \mathrm{NiFe}_{2} \mathrm{O}_{4}, \mathrm{ZnFe}_{2} \mathrm{O}_{4}$ and others synthesized by solution combustion, successive ionic layer deposition (SILD) (Fig. 24) and plasma-chemical synthesis [318-321]. Their use as the basis for low-coercivity microwave ceramics and corresponding functional devices is also of particular interest [322, 323].

The use of other methods of "wet chemistry", such as hydrothermal synthesis, coprecipitation with subsequent annealing-quenching in a neutral, oxidative or reducing atmosphere, can significantly expand the structural, morphological and disperse characteristics of the resulting nanostructured functional substances and materials [195, 196, 198, $200,207,228,229,231,235,236]$. Thus, new oxide materials with high acid-base properties that are of interest in the field of heterogeneous catalysis and new methods of material functionalization have been developed using "wet chemistry" approaches [121-123,138,139,207,223,231,297]. It was shown that, just as in the case of materials for supercapacitors $[41,45,46,204,211]$, the type and concentration of functional groups on the surface of the substance play a decisive role here. On the other hand, these synthesis methods make it possible to obtain substances in the form of nanocrystals of uniform size and morphology, which can be used as the basis for MRI contrast agents [202,324-326], catalyst carriers $[22,198,207,228,231]$, sorbents $[45,115,116]$, and other useful materials. 


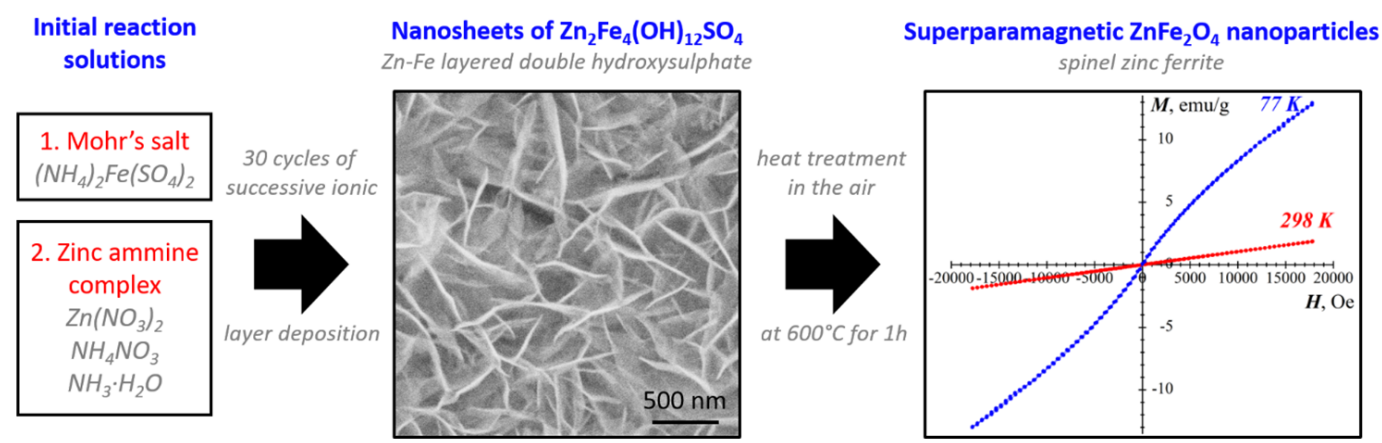

FIG. 24. Synthesis of superparamagnetic $\mathrm{ZnFe}_{2} \mathrm{O}_{4}$ via SILD technique by results of the work [318]

\subsection{Characteristics and features of methods for the synthesis of new nanostructured catalysts}

Nanostructured catalysts represent a separate area of materials for personalized energy. In this area, effective catalysts based on nanoparticles of $\mathrm{d}$ - and f-element oxides and hydroxides have been developed for the electrocatalytic production of hydrogen from water-alcohol solutions [327-331], photocatalysts based on simple and complex oxides [123, 135-139, 233,332], carbon monoxide oxidation catalysts [333-336], and acid-base $n$-hexane conversion catalysts [337-339]. Obtained in the form of isometric nanoparticles, nanorods, nanoplates, and porous compositions (Fig. 25), these nanostructured catalysts exhibit high catalytic activity and stability compared to materials obtained by using traditional catalytic techniques. Besides, catalytic materials that do not contain expensive metal elements, such as graphite-like carbon nitride or $\mathrm{g}-\mathrm{C}_{3} \mathrm{~N}_{4}$, have a great potential for development [328]. This catalytic material can be obtained by simple thermolysis of urea, melamine, and other organic precursors in air and exhibits high, stable catalytic characteristics both in the processes of photocatalytic oxidation of organic substances [340,341] and in the electrocatalytic release of hydrogen [342].
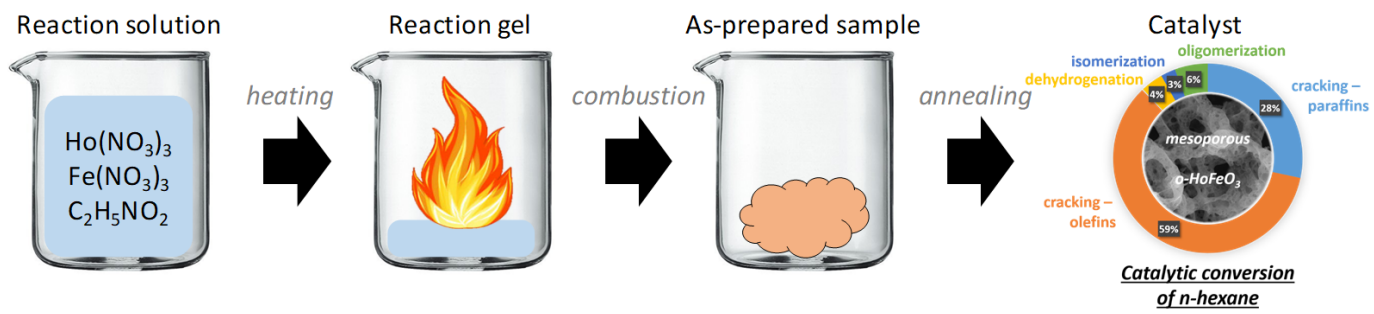

FIG. 25. Synthesis of porous $\mathrm{HoFeO}_{3}$ catalyst via SCS technique (by results of the work [339]

\subsection{Features of implementation of high-energy methods for synthesis of nanostructured materials for personalized energy systems}

In a number of cases, additional energy effects are used in the synthesis, including sonochemical and microwave synthesis in addition to those mentioned above [343-347]. It is revealed that the size and degree of disorientation of their constituent crystallites have a great influence on the structure and contribution of non-autonomous phases and properties of polycrystalline materials. Depending on the degree of disorientation of the crystallites, the thickness, composition, and structure of the intercrystalline layer change. The ratio of the size of crystallites and the thickness of the intercrystalline layer (non-autonomous surface phase), in turn, determines the volume fractions of crystallites and intercrystalline formations in a polycrystalline material [22, 23, 216-221,315, 348-351].

As follows from the results of a number of studies on the formation of nanomaterials, in many cases their functional properties are determined by the chemical and thermal prehistory of the initial compositions and the mechanism of their formation $[176,177,182,186,189,190,194,198,199,228,352,353]$. It is also shown that solid-phase reactions are, in a certain sense, liquid-phase, since reactions in a solid system are activated with the transition of two-dimensional non-atomic phases (intergrain formations) to a liquid-like state, when the reaction rate increases sharply [216-221].

Electroexplosive technologies are also being developed for dispersing the initial conducting materials that experience the transition of the aggregate state through the "solid-liquid-gas-plasma" [354-358]. Great prospects for the 
development of this direction for obtaining nanoscale metal oxides containing non-autonomous phases are opened when performing an electric explosion of conductors in various chemically active media. In particular, an installation was developed for an electric explosion in a supercritical water fluid with dispersion of the conductor due to the development of thermodynamic instabilities of its physical state in the vicinity of the critical point [250].

The ML-ALD chemical layer deposition method can be used in order to form a molecular or atomic monolayer on complex-shaped substrates without forming three-dimensional "germs" [359]. It is carried out by cyclic alternate supply of gaseous (MOCVD - Metal Organic Chemical Vapor deposition) or liquid (followed by pyrolysis - MOD Metal Organic deposition) reagents - precursors of the buffer layer and the source material to the substrate. In this case, chemical reactions that lead to the growth of films occur only in chemisorbed layers, that is, with the exception of reactions in the gas phase. The specified increase in the thickness of the formed film is easily and very accurately controlled by the number of deposition cycles using the property of self-organization (self-limitation) of surface reactions, which are completed automatically when all reactive areas on the surface are exhausted. In principle, this technology can be implemented by applying atomic layers, for example, by the method of atomic layer deposition (ALD), that was initially proposed by V. B. Aleskovsky in the middle of the twentieth century [360-364].

\section{Conclusion}

The analysis of the problems of personalized energy supply for autonomous human survival in remote natural habitat, emergency situations of natural disasters and technical catastrophes with the unavailability of centralized power supply indicates a major role in its solution of developments in the field of nanostructured materials with special functional properties. Their application is designed to provide the possibility of preferential use of available renewable energy sources of the environment, processes and devices for extracting, storing and converting their energy into the necessary consumer forms, taking into account specific operating conditions and requirements for power, efficiency, operating modes, and weight and size characteristics. Fundamental restrictions on these indicators are imposed by the characteristics of physical effects associated with these processes and interactions.

The study of these features for various types of such devices by methods of non-equilibrium thermodynamics, chemical kinetics, nonlinear dynamics, fractal analysis, and quantum physics demonstrates the great attractiveness in this regard, primarily for solid-state photo-and thermoelectric semiconductor converters based on a new generation of inorganic compounds that do not have mechanically moving elements. The results of the nanotechnological approach to their development using various technologies and synthesis methods, including "wet chemistry" and solid-phase reactions in diffusion modes, combustion of gel-like media in high-speed kinetic modes, chemical layer deposition and other types of epitaxy, as well as high-energy effects of various types, show the special role of non-autonomous interfacial formations and processes of fractal self-organization in the formation of functional properties of the synthesized materials.

The development of this concept makes it possible to carry out a directed physical and chemical design of new nanostructured materials with an unusual composition, structure, and unique functional behavior as a base for personalized energy systems.

\section{Acknowledgements}

The authors would like to thank Prof. V. V. Gusarov for useful discussions.

\section{References}

[1] Fortov V.E., Popel O.S. Energy in the modern world. Intellect, Dolgoprudnyy, 2011, 168 p. (In Russian).

[2] Bansal R.C. Dr. Optimization methods for electric power systems: An overview. International Journal of Emerging Electric Power Systems, 2005, 2 (1), 1021.

[3] Trukhny A.D., Makarov A.A., Klimenko V.V. Fundamentals of Modern Energy (in two parts). MPEI Publishing House, Moscow, 2002, 368 p. (In Russian).

[4] Danilevich Ya.B., Kovalenko A.N. Energy and its place in the modern world. Bulletin of the Russian Academy of Sciences, Energetika, 2004, 6, P. 20-28 (In Russian).

[5] Alkhasov A.B. Renewable energy. Fizmatlit, Moscow, 2010, 255 p. (In Russian).

[6] Twidell J., Weir T. Renewable energy resources. Taylor \& Francis, London and New-York, 2006, 602 p.

[7] Popel' O.S., Frid S.E., et al. Independent hydrogen power installations with renewable sources of energy. Thermal Engineering, 2006, 53, P. 208-216.

[8] Pozdnyakov B.S., Koptelov E.A. Thermoelectric power engineering. Atomizdat, Moscow, 1974, 264 p. (In Russian).

[9] Danilevich Ya.B., Kovalenko A.N., Shilin V.L. Autonomous systems of electric and heat supply with buffer energy storage. Proceedings of the RAS. Energetika, 2002, 1, P. 69-78 (in Russian).

[10] Danilevich Ya.B., Kovalenko A.N. Heat pumps in small energy systems. Proceedings of the RAS. Energetika, 2005, 1, P. 63-69 (in Russian).

[11] Dobarina I.A., Zhigarev O.L. Fundamentals of life safety and first aid. In: Survival in an autonomous existence. Ed. R.I. Aizman, S.G. Krivoshchekova, I.V. Omelchenko. Siberian University Press, 2004 (in Russian). 
[12] Volovich V.G. Man in extreme environmental conditions. Mysl', Moscow, 1983, 197 p. (in Russian).

[13] Davy N., Sezen-Edmonds M., et al. Pairing of near-ultraviolet solar cells with electrochromic windows for smart management of the solar spectrum. Nat Energy, 2017, 2, 17104.

[14] Makarov A.A., Fortov V.E. World energy development trends and energy strategy of Russia. Herald of the RAS, 2004,74 (3), P. 195-208 (in Russian).

[15] Belyaev L. S., Lagerev A. V., Posekalin V. V. Power Engineering in the 21st Century: Conditions of Evolution, Technologies, Prospects. Ed. Voropai N.I., Novosibirsk, Nauka, 2004, 386 p. (in Russian).

[16] Bushuev V.V. Prospects for global energy development until 2050. 2010, URL: http://portal-energo.ru/articles/details/id/292.

[17] Olkhovsky G.G. Global Energy Issues. Global energy problems. Power Technology and Engineering, 2005, 1, P. 4-10 (in Russian).

[18] Stennikov V., Voropai N., Barakhtenko E., Sokolov D. Digitalization of integrated energy systems. Energy Safety and Energy Economy, 2020, 4 (94), P. 5-10.

[19] Ushakov V.Ya. The main problems of energy and possible solutions. Bulletin of the Tomsk Polytechnic University, 2011,319 (4), P. 5-13 (in Russain).

[20] IEA. Energy Technology Perspectives 2008: Scenarios and Strategies to 2050. OECD Publishing, Paris, 2008, 648 p. URL: https://doi.org/10.1787/9789264041431-en.

[21] Defay R., Prigogine I. Tension superficielle et adsorption. Editions Desoer, Liege, 1951, 295 p.

[22] Kovalenko A.N., Tugova E.A. Thermodynamics and kinetics of non-autonomous phases formation in nanostructured materials with variable functional properties. Nanosystems: Phys. Chem. Math., 2018, 9 (5), P. 641-662.

[23] Krasnenko T.I., Rotermel M.V., Samigullina R.F. Stabilizing the associated non-autonomous phase upon thermal expansion of $\mathrm{Zn}_{2} \mathrm{~V}_{2} \mathrm{O}_{7}$. Russ. J. Inorg. Chem., 2017, 62 (4), P. 413-417.

[24] Samarsky A.A., Galaktionov V.A., Kurdyumov S.P., Mikhailov A.P. Modes with exacerbation in problems for quasilinear parabolic equations. Nauka, Moscow, 1987, 480 p. (in Russian).

[25] Akhromeeva T.S., Kurdyumov S.P., Malinetskiy G.G., Samarsky A.A. Unsteady structures and diffusion chaos. Nauka, Moscow, 1992 , 544 p (in Russian).

[26] Grinchenko V.T., Matsypura V.T., Snarsky A.A. Introduction to nonlinear dynamics. Chaos and Fractals. LCI, 2007,264 p. (in Russian).

[27] Kurdyumov S.P. New in synergetics: A look into the third millennium. Informatics: unlimited possibilities and possible limitations. Nauka, Moscow, 2002, 480 p. (in Russian).

[28] Snyder W.S., Cook M. J., et al. Report of the task group on reference man. ICRP Publication 23. Pergamon Press, Oxford. 1975, 500 p.

[29] Fokin V.F., Ponomareva N.V. Neuronergetics and brain physiology. Antidor, Moscow, 2003, 288 p. (in Russian).

[30] Shaikh F.K., Zeadally S. Energy harvesting in wireless sensor networks: A comprehensive review. Renewable and Sustainable Energy Reviews, 2016, 55, P. 1041-1054

[31] Yildiz F. Potential ambient energy harvesting sources and techniques. Journal of Technology Studies, 2009, 35 (1), P. 40-48.

[32] Jaffe P., McSpadden J. Energy conversion and transmission modules for space solar power. Proceedings of the IEEE, 2013, 101 (6), P. 14241437.

[33] Siddique A.R., Rabari R., Mahmud Sh. et al. Thermal energy harvesting from the human body using flexible thermoelectric generator (FTEG) fabricated by a dispenser printing technique. Energy, 2016, 115 (1), P. 1081-1091.

[34] Leonov V. Thermoelectric energy harvesting of human body heat for wearable sensors. IEEE Sensors Journal, 2013,13 (6), P. $2284-2291$.

[35] Turkmen A.C., Celik C. Energy harvesting with the piezoelectric material integrated shoe. Energy, 2018 , 150, P. 556-564.

[36] Kapitsa P.L. Energy and Physics. Bulletin of the USSR Academy of Sciences, 1976, 46 (1), P. $34-43$ (in Russian).

[37] Bekzhanova N.V., Sereda S.B., Sidorenko N.A. Nobel lectures in Russian translations, 1901-1902: Biobibliographic index. Academy of Sciences Library, Saint-Petersburg, 2003, 166 p. (in Russian)

[38] Ugarov G.G., Soshinov A.G., Vdovina O.V. Energy converters. Volgograd state technical university, Volgograd, 2010,95 p. (in Russian)

[39] Alekseev G.N. Forecasting the development of power plants energy conversion. Nauka, Moscow, 1966, 190 p. (in Russian)

[40] Almyasheva O.V., Gusarov V.V., et al. A new type of super-energy storage based on non-carbon nanomaterials. Proceedings of the Research Center for Photonics and Optoinformatics, 2010, 1 (2), P. 187-204. (in Russian)

[41] Rychagov A.Y., Vol'fkovich Y.M., et al. Perspective electrode materials for supercapacitors. Electrochemical Energetics, 2012, 11 (4), P. 167-180.

[42] Medvedeva A.E., Pechen L.S., et al. Synthesis and electrochemical properties of lithium-ion battery cathode materials based on LiFePO $4-$ $\mathrm{LiMn}_{2} \mathrm{O}_{4}$ and $\mathrm{LiFePO}_{4}-\mathrm{LiNi}_{0.82} \mathrm{Co}_{0.18} \mathrm{O}_{2}$ composites. Russ. J. Inorg. Chem., 2019, 64 (7), P. 829-840.

[43] Basistaya A.O., Karushev M.P., et al. A new conducting polymer for lithium-ion batteries. Tech. Phys. Lett., 2020,46 (1), P. $77-79$.

[44] Polozhentseva Y.A., Karushev M.P., et al. A lithium-ion supercapacitor with a positive electrode based on a carbon material modified by polymeric complexes of nickel with Schiff bases. Tech. Phys. Lett., 2020, 46 (2), P. 196-199.

[45] Frackowiak E. Carbon materials for supercapacitor application. Phys. Chem. Chem. Phys., 2007, 9, P. $1774-1785$.

[46] Inagaki M., Konno H., Tanaike O. Carbon materials for electrochemical capacitors. J. Power Sources, 2010, 195, P. $7880-7903$.

[47] Emerson C. 100 Deadly Skills: The seal operative's guide to eluding pursuers, evading capture, and surviving any dangerous situation. Atria Books, New York, 2020, 272 p.

[48] Fokin B.S. Optimum values of energy converter efficiency. J. Eng. Phys. Thermophy, 2009, 82 (3), P. 598 -603.

[49] Tribus M. Thermostatics and thermodynamics: An introduction to energy, information and states of matter, with engineering applications. D. Van Nostrand Company Inc., 1961, 649 p.

[50] Glansdorff P., Prigogine I. Thermodynamic theory of structure, stability and fluctuation. Wiley-Interscience, New York, 1971,305 p.

[51] Nicolis G., Prigogine I. Exploring complexity, an introduction. W.H. Freedman and Co., New York, 1989,328 p.

[52] Khvesyuk V.I., Ostanko D.A., et al. Maximum efficiency of thermoelectric heat conversion in high-temperature power devices. Nauka $i$ Obrazovanie, 2016, 3, P. 81-105.

[53] Kovalenko A.N. Study of the characteristics of powerful power plants based on the methods of nonequilibrium thermodynamics. Proceedings of magnetovitational transport systems and technologies. Saint-Petersburg, October 29-31, Publishing House PGUPS, 2013, P. 38-42 (In Russian).

[54] Caplan S.R., Essig A. Bioenergetics and linear nonequilibrium thermodynamics. Harvard University Press, Cambridge, 1983,435 p. 
[55] Zotin A.I. The thermodynamic basis of body reactions to external and internal factors. Nauka, Moscow, 1988,272 p. (in Russian).

[56] Danilevich Ya.B., Kovalenko A.N., Nosyrev S.P. Irregularity of entropy processes in the body as an indicator of its functional stability. Doklady Biological Science, 2009, 429 (1), P. 490-493.

[57] Slovokhotov Y.L. Phase transitions associated with economy and demography. Computer Research and Modeling, 2010, 2 (2), P. $209-218$.

[58] Delogu F. Thermodynamics on the nanoscale. J. Phys. Chem. B, 2005, 109, P. 21938-21941.

[59] Hill T.L. Thermodynamics of small systems. Dover Publication, New-York, 2013, 416 p.

[60] Hill T.L. A Different approach to nanothermodynamics. Nano Letters, 2001, 1 (5), P. $273-275$.

[61] Babuk V.A., Zelikov A.D., Salimullin R.M. Nanothermodynamics as a tool to describe small objects of nature. Tech. Phys., 2013, 58, P. 151-157.

[62] Aranson I.S., Gaponov-Grekhov A.V., et al. Lattice models in the nonlinear dynamics of nonequilibrium media. Preprint No. 163. IAP Academy of Sciences of the USSR, Gorky, 1987, 24 p. (In Russian).

[63] Rekhviashvili S.Sh., Kishtikova E.V., Rozenberg B.A. Model of a nanoparticle in the theory of inhomogeneous medium. Technical physics, 2009, 79 (12), P. 1731-1735.

[64] Rusanov A. Nanothermodynamics. Russian Journal of Physical Chemistry, 2003, 77 (10), P. 1558-1563.

[65] Rusanov A.I. Nanothermodynamics: chemical approach. Russian Chemical Journal, 2006, 50 (2), P. 145-151. (In Russian)

[66] Rusanov A.I. Surface thermodynamics revisited. Surface Science Reports, 2005, 37 (25), P. 111-239.

[67] Rowlinson J.S. Statistical thermodynamics of small systems and interfaces. Pure and Applied Chemistry, 1987, 59 (1), P. 15-24.

[68] Shcherbakov L.M. On the statistical assessment of the excess energy of small objects in the thermodynamics of microheterogeneous systems. Reports of the USSR Academy of Sciences, 1966, 168 (2), P. 388-391. (In Russian)

[69] Tsallis C. Possible generalization of Boltzmann-Gibbs statistics. Journal of Statistical Physics, 1988, 52(1-2), P. 479-487.

[70] Sevick E.M., Prabhakar R., Williams S.R., Searles D.J. Fluctuation Theorems. Review of Physical Chemistry, 2008,59, P. 603-633.

[71] Rubi J.M. The non-equilibrium thermodynamics approach to the dynamics of mesoscopic systems. Journal of Non-Equilibrium Thermodynamics, 2004, 29, P. 315-325.

[72] Gemmer J., Michel M., Mahler G. Quantum thermodynamics. Emergence of thermodynamic behavior within composite quantum systems. Springer-Verlag Berlin Heidelberg, Berlin, 2009, 346 p.

[73] Jaycock M.J., Parfitt G.D. Chemistry of Interfaces. Ellis Horwood Limited, 1981, 279 p.

[74] Gyarmati I. Non-equilibrium Thermodynamics. Field Theory and Variational Principles. Springer-Verlag Berlin Heidelberg, Berlin, 1970, $184 \mathrm{p}$.

[75] Kondepudi D., Prigogine I. Modern Thermodynamics. From heat engines to dissipative structures. Wiley, UK, 1998,506 p.

[76] Onsager L., Hemmer P.C., Holden H. Kjelstrap S. The collected works of Lars Onsager: with commentary. World scientific, Singapore, 1996, $1086 \mathrm{p}$.

[77] Haase R. Thermodynamics of irreversible processes. New-York: Dover, 1990, 513 p.

[78] Petrov N., Brankov I. Modern problems of thermodynamics. Translation from the Bulgarians. Mir, Moscow, 1989, 385 p. (in Russian)

[79] Etkin V.A. On the origin of Onsager reciprocity relations. Proceedings of the Siberian Branch of the Academy of Sciences of the USSR, Engineering Sciences, 1989, 4, P. 52-57. (In Russian)

[80] Kovalenko A.N. Regulation and thermodynamic stability of non-equilibrium processes of energy conversion of speed. Trudy CKTI, JSC, 1996, 281 (2). (In Russian)

[81] Kovalenko A. Inner nonstationarness of energy conversion in non-equilibrium thermodynamic system. Proceedings of the fifth Baltic Heat Transfer Conference, Saint-Petersburg, 21-23 September, SPbGPU, 2009, 1, P. 446-453.

[82] Paradisi P., Cesari R., Mainardi F., Tampieri F. The fractional Fick's law for non-local transport processes. Physica A: Statistical Mechanics and its Applications, 2001, 293 (1), P. 130-142.

[83] Nigmatullin R.R. Fractional integral and its physical interpretation. Theor. Math. Phys., 1992, 90, P. $242-251$.

[84] Marcel O.V. Fractional diffusion equation on fractals: Self-similar stationary solutions in a force field derived from a logarithmic potential. Chaos, Solutions and Fractals, 1994, 4 (2), P. 191-199.

[85] Meilanov R.P., Shabanova M.R. The heat equation for media with a fractal structure. Modern high technology, 2007, 8, P. 74-75. (In Russian)

[86] Samko S.G., Kilbas A.A., Marichev O.I. Fractional integrals and derivatives. Theory and Applications. Gordon and Breach Science Publishers, 1993, $976 \mathrm{p}$.

[87] Feder J. Fractals. Physics of Solids and Liquids. Plenum Press, New York, 1988, 305 p.

[88] Haitun S.D. From the ergodic hypothesis to the fractal picture of the world. Moscow URSS, 2007, 251 p. (In Russian).

[89] Rényi A. On a new axiomatic theory of probability. Acta Mathematica Academiae Scientiarum Hungaricae, 1955 , 6, P. $285-335$.

[90] Klimontovich Yu.L. Entropy and information of open systems. Progress of physical sciences, 1999, 169 (4), P. 443-452. (in Russian)

[91] Kovalenko A.N. Fractal characterization of nanostructured materials. Nanosystems: Phys., Chem., Math., 2019,10 (1), P. $42-49$.

[92] Dozhdikova O.L., Zarichnyak Yu.P., et al. Anomalies in the concentration relationship of thermal conductivity of sintered composities with an ultradispersed component in the TiN-AlN system. Soviet Powder Metallurgy and Metal Ceramics, 1992, 31 (5), P. 429-433.

[93] Alekseev G.N. General heat engineering. Vysshaya shkola, Moscow, 1980, 552 p. (In Russian)

[94] Lee J.-K., Yang M. Progress in light harvesting and charge injection of dye-sensitized solar cells. Materials Science and Engineering B, 2011, 176, P. 1142-1160.

[95] Bonch-Bruevich V.L., Kalashnikov S.G. Semiconductor Physics. Nauka, Moscow, 1977, 674 p.

[96] Afanasyev V.P., Terukov E.I., Sherchenkov A.A. Thin film solar cells based on silicon, 2nd ed. SPbGETU "LETI", Saint-Petersburg, 2011, $168 \mathrm{p}$.

[97] Andreev V.M., Griliches V.A., Rumyantsev V.D. Photoelectric conversion of concentrated solar radiation. Nauka, Leningrad, 1989,310 p.

[98] Alferov Zh.I., Andreev V.M., Rumyantsev V.D. High-Efficient low-cost photovoltaics. Springer-Verlag, Berlin, Heidelberg, 2009,227 p.

[99] Sorokin S.V., Avdienko P.S., et al. Molecular beam epitaxy of layered group III metal chalcogenides on GaAs (001) substrates. Materials, 2020, 13 (16), 3447.

[100] Kalinovskii V.S., Kontrosh E.V., et al. Development and study of the p-i-n GaAs/AlGaAs tunnel diodes for multijunction converters of high-power laser radiation. Semiconductors, 2020, 54, P. 355-361. 
[101] Ivanov S.V., Chernov M.Y., et al. Metamorphic InAs(Sb)/InGaAs/InAlAs nanoheterostructures grown on GaAs for efficient mid-IR emitters. Prog. Cryst. Growth Charact. Mater, 2019, 65 (1), P. 20-35.

[102] Podoskin A.A., Golovin V.S., et al. Properties of external-cavity high-power semiconductor lasers based on a single InGaAs quantum well at high pulsed current pump. J. Opt. Soc. Am. B-Opt. Phys., 2020, 37 (3), P. 784-788.

[103] Andreev V.M., Malevskiy D.A., et al. On the main photoelectric characteristics of three-junction InGaP/InGaAs/Ge solar cells in a broad temperature range $\left(-197^{\circ} \mathrm{C} \leq T \leq+85^{\circ} \mathrm{C}\right)$. Semiconductors, 2016, 50, P. 1356-1361.

[104] Alferov Z.I., Andreev V.M. Rumyantsev V.D. Solar photovoltaics: Trends and prospects. Semiconductors, 2004, 38, P. 899-908.

[105] Antonyshyn I., Wagner F.R., et al. Micro-scale device - an alternative route for studying the intrinsic properties of solid-state materials: The case of semiconducting TaGeI. Angew.Chem. Int. Ed., 2020, 59 (1), P. 1136-11141.

[106] Shpeizman V.V., Nikolaev V.I., et al. The effect of texturing of silicon wafer surfaces for solar photoelectric transducers on their strength properties. Tech. Phys., 2020, 65 (7), P. 1123-1129.

[107] Cahen D. Where are we today in research in photovoltaics? 2007, URL: https: / / www. scribd. com/document/108703482/123.

[108] Komissarova T.A., Semenov A.N., et al. Peculiarities of the electrophysical properties of InSb/AlInSb/AlSb heterostructures with a high electron concentration in the two-dimensional channel. Semiconductors, 2014, 48 (3), P. 338-343.

[109] Joannopoulos J.D., Lucovsky G. The physics of hydrogenated amorphous silicon I: Structure, Preparation, and Devices. Springer Berlin Heidelberg, 1984, 290 p.

[110] Joannopoulos J.D., Lucovsky G. The physics of hydrogenated amorphous silicon II: Electronic and Vibrational Properties. Springer Berlin Heidelberg 1984. 373 p.

[111] Ken O.S., Andronikov D.A,, et al. Spectral features of the photoresponse of structures with silicon nanoparticles. Semiconductors, 2014, 48 (11), P. 1518-1524.

[112] Ayvazov A.A., Budagyan B.G., Vikhrov S.P., Popov A.I. Disordered semiconductors. MEI Publishing House, Moscow, 1995 , 352 p. (in Russian)

[113] Chopra K.L., Das S.R. Thin Film Solar Cells. Springer US, 1983, 607 p.

[114] Spear W.E., LeComber P.G. Investigation of the localised state distribution in amorphous Si films. J. Non-Cryst. Solids, 1972, 8-10, P. 727738 .

[115] Madan A., LeComber P.G., Spear W.E. Investigation of the density of localized states in a-Si using the field effect technique. J. Non-Cryst. Solids, 1976, 20. P. 239-257.

[116] Parashchuk D.Y., Kokorin A.I. Modern photoelectric and photochemical methods of solar power conversion. Russ. J. Gen. Chem., 2009, 79 (11), P. 2543-2555.

[117] Semenov K.N., Charykov N.A., et al. Phase equilibria in fullerene-containing systems as a basis for development of manufacture and application processes for nanocarbon materials. Russian Chem. Reviews, 2016, 85 (1), P. 38-59.

[118] Gracheva I.E., Moshnikov V.A., et al. Nanostructured materials obtained under conditions of hierarchical self-assembly and modified by derivative forms of fullerenes. J. Non-Cryst. Solids, 2012, 358, P. 433-439.

[119] Vasiliev R.B., Rumyantseva M.N., et al. Crystallite size effect on the conductivity of the ultradisperse ceramics of $\mathrm{SnO}_{2}$ and $\mathrm{In}_{2} \mathrm{O}_{3}$. Mendeleev Communication, 2004, 14 (4), P. 167-169.

[120] O'Regan B., Grätzel M. A Low-cost, high-efficiency solar cell based on dye-sensitized colloidal TiO2 films. Nature, 1991, 353, P. 737-740.

[121] Zvereva I.A., Kalinkina L.M., et al. Production of nanocrystalline titanium dioxide photoactive coatings for decomposition of organic water pollutants in a flow reactor. Glass Physics and Chemistry, 2012, 38 (6), P. 504-510.

[122] Kozyukhin S.A., Grinberg V.A., et al. Photoelectrochemical cells based on nanocrystalline TiO2 synthesized by high temperature hydrolysis of ammonium dihydroxodilactatotitanate (IV). Russian Journal of Electrochemistry, 2013, 49 (5), P. $423-427$.

[123] Kovalev I.A., Petrov A.A., et al. New hierarchical titania-based structures for photocatalysis. Mendeleev Communications, 2018, 28, P. 541542 .

[124] Bai Y., Cao Y., et al. High-performance dye-sensitized solar cells based on solvent-free electrolytes produced from eutectic melts. Nature Materials, 2008, 7 (8), P. 626-630.

[125] Vildanova M.F., Nikolskaia A.B., et al. Nanostructured ZrO2-Y2O3-based system for perovskite solar cells. Doklady Physical Chemistry, 2019, 484 (2), P. 36-38.

[126] Larina L.L., Alexeeva O.V., et al. Very wide-bandgap nanostructured metal oxide materials for perovskite solar cells. Nanosystems: Phys., Chem., Math., 2019, 10 (1), P. 70-75.

[127] Shevaleevskiy O. The future of solar photovoltics: from physics to chemistry. Pure Appl. Chem., 2008, 80, P. $2079-2089$.

[128] Vildanova M.F., Nikolskaia A.B., et al. Potassium doping effect on the photovoltaic performance of perovskite solar cells. Tech. Phys. Lett., 2020, 46, P. 231-234

[129] Alexeeva O.V., Kozlov S.S., Larina L.L., Shevaleevskiy O.I. Pt nanoparticle-functionalized RGO counter electrode for efficient dye-sensitized solar cells. Nanosystems: Phys., Chem., Math., 2019, 10 (6), P. 637-641.

[130] Belich N., Udalova N., et al. Perovskite puzzle for revolutionary functional materials. Front. Chem., $2020,8,550625$.

[131] Kulova T.L., Semenenko D.A., et al. Cathode materials based on vanadium pentoxide for rechargeable batteries. Electrochemical Energetics, 2008, 8 (4), P. 197-201.

[132] Medved'ko A.V., et al. The design and synthesis of thiophene-based ruthenium(II) complexes as promising sensitizers for dye-sensitized solar cells. Dyes and Pigments, 2017, 140, P. 169-178.

[133] Levshanov A.A., Grishina E.P., et al. Ni self-organized balls as a promising energy storage material. Material J. Phys. Chem. C, 2016, 120 (30), P. 16453-16458.

[134] Irgashev R.A., Karmatsky A.A., et al. A facile and convenient synthesis and photovoltaic characterization of novel thieno[2,3-b]indole dyes for dye-sensitized solar cells. Synthetic Metals, 2015, 199, P. 152-158.

[135] Zamaraev K.I. Photocatalytic conversion of solar energy. Vol. 1, 2. Nauka, Novosibirsk, 1985, 442 p. (in Russian)

[136] Pelizzetti E., Schiavello M. Photochemical conversion and storage of solar energy. Kluwer Academic Publishers, Dordrecht, 1991,660 p.

[137] Zamaraev K.I., Parmon V.N. Photocatalytic conversion of solar energy. Heterogeneous, homogeneous and molecular structurally organized systems: Collection of scientific papers, Nauka, Novosibirsk, 1991, 358 p.

[138] Fujishima A., Hashimoto K., Watanabe T. TiO 2 Photocatalysis. Fundamentals and Applications. BKC, Tokyo, 1999,176 p. 
[139] Rempel A.A., Kuznetsova Y.V., et al. High photocatalytic activity under visible light of sandwich structures based on anodic TiO ${ }_{2} / \mathrm{CdS}$ nanoparticles/sol-gel $\mathrm{TiO}_{2}$. Top Catal., 2020, 63, P. 130-138.

[140] Brdlik P.M. Testing and calculation of solar desalination plants in collected articles: Using solar energy, Publishing house Acad. Sciences of the USSR, Moscow, 1957, 248 p.

[141] Gel'dyyev A. Modern methods of water desalination. Ilim, Ashgabat, 1967, 181 p.

[142] Ioffe A.F. Semiconductor thermoelements and thermoelectric cooling. London, Infosearch, 1957, $254 \mathrm{p}$

[143] Ordin S.V. Achieving the problem of thermoelectricity, 2015, URL: http://www. nanonewsnet.ru/articles/2015/dostizheniya-problemy (in Russian)

[144] Rempel A.A. Nanotechnologies. Properties and applications of nanostructured materials. Russ. Chem. Rev., 2007,76 (5), P. $435-461$.

[145] Glass fabric, URL: https://novate.ru/blogs/201014/28210/.

[146] Daniel-Beck V., Voronin A., Roginskaya N. Thermoelectric generator TGK-3. Radio Journal, 1954, 2, P. 24-25. (in Russian)

[147] Shostakovsky P. Modern solutions of thermoelectric cooling for radio electronic, medical, industrial and household appliances. Components and technologies, 2009, 12 (1), P. 40-46. (in Russian)

[148] Postnikov V.S. Solid state physics and chemistry. Metallurgiya, 1978, 544 p. (in Russian)

[149] Anatychuk L.I., Bulat L.P. Semiconductors under extreme temperature conditions. Nauka, Saint-Petersburg, 2001, 197 p. (in Russian)

[150] Di Cicco A., Filipponi A. Semiconductors under extreme conditions. In: Schnohr C., Ridgway M. (eds) X-Ray Absorption Spectroscopy of Semiconductors. Springer Series in Optical Sciences, 2015, 190, Springer, Berlin, Heidelberg.

[151] Reay D., Macmichael D. Heat pumps: Design and application. Pergamon Press, Oxford, 1979, 224 p.

[152] Pinuela M., Mitcheson P.D., Lucyszyn S. Ambient RF energy harvesting in urban and semi-urban environments. IEEE transactions on microwave theory and techniques, 2013, 61 (7), P. 2715-2726.

[153] Cansiz M., Altinel D., Kurt G.K. Efficiency in RF energy harvesting systems: A comprehensive review. Energy, 2019, 174, P. $292-309$.

[154] Potapov A.A. Fractals, scaling and fractional operators in modern radio engineering and electronics: the current state and development. J. of Radio Electronics, 2010, 1, P. 1-100.

[155] Krasnok A.E., Maksymov I.S., et al. Optical nanoantennas. Phys. Usp., 2013, 56 (6), P. 539-564.

[156] Bharadwaj P., Deutsch B., Novotny L. Optical Antennas. Advances in Optics and Photonics, 2009,1 (3), P. $438-483$.

[157] Novotny L., van Hulst N. Antennas for light. Nature Photonics, 2011, 5, P. 83-90.

[158] Giannini V., Fernandes-Dominguez I.A., Heck C.H., Maier S.A. Plasmonic Nanoantennas: Fundamentals and Their Use in Controlling the Radiative Properties of Nanoemitters. Chem. Rev., 2011, 111 (6), P. 3888-3912.

[159] Maksymov I.S., Davoyan A.R., Kivshar Yu.S. Enhanced emission and light control with tapered plasmonic nanoantennas. Appl. Phys. Lett., 2011, 99, 083304.

[160] Acar H., Coenen T., Polman A., Kuipers L.K. Dispersive ground plane core-shell type optical monopole antennas fabricated with electron beam induced deposition. ACS Nano, 2012, 6 (9) P. 8226-8232.

[161] Suh J.Y., Huntigton M.D., et al. Extraordinary nonlinear absorption in 3D bowtie nanoantennas. Nano Letters, 2012 , 12 (1), P. $269-274$.

[162] Rosa L., Sun K., Juodkazis S. Sierpin 'ski fractal plasmonic nanoantennas. Phys. Status Solidi RRL, 2011, 5 (5-6), P. 175-177.

[163] Trompoukis C., Daif O.E., et al. Photonic assisted light trapping integrated in ultrathin crystalline silicon solar cells by nanoimprint lithography. Appl. Phys. Lett., 2012, 101, 103901.

[164] Jeong S., Garnett E.C., et al. Hybrid silicon nanocone-polymer solar cells. Nano Lett., 2012, 12 (6), P. $2971-2976$.

[165] Xu Z., Sadler B.M. Ultraviolet communications: potential and state-of-the-art. IEEE Communications Magazine, 2008,46 (5), P. 67-73.

[166] Elshimy M.A., Hranilovic S. Non-line-of-sight single-scatter propagation model for noncoplanar geometries. J. Opt. Soc. Am. A, 2011, 28, P. 420-428.

[167] Shaw G.A., Nischan M.L., et al. NLOS UV communication for distributed sensor systems. Proc. SPIE, 2000, 4126, P. 83-96.

[168] Wang L., Li Y., Xu Z., Sadler B.M. Wireless ultraviolet network models and performance in noncoplanar geometry. Proceeding of "2010 IEEE Globecom Workshops", Miami, FL, USA, 6-10 December, 2010, 1037.

[169] Wang L., Xu Z., Sadler B.M. Non-line-of-sight ultraviolet link loss in noncoplanar geometry. Opt. Lett., 2010,35 (8), P. $1263-1265$.

[170] Wang L., Xu Z., Sadler B.M. An approximate closed-form link loss model for non-line-of-sight ultraviolet communication in noncoplanar geometry. Opt. Lett., 2011, 36 (7), P. 1224-1226.

[171] Wang H., Li J., Qiu K. Ultraviolet communication system in free atmosphere, Patent. CN101986578A China: IPC G02 B 17/06; H04 B 10/07; H04 B 10/11.

[172] Wang H., Li J., Qiu K. Day blind ultraviolet laser communication system in free space, Patent. CN101986579A China: IPC G02 B 27/09; H04 B 10/07; H04 B 10/11.

[173] Zhen H., Binru L., Qiang L., Zhiqin L. Delay transmission system and method for ultraviolet light communications signals, Patent. CN106656338A China: IPC H04 B 10/11; H04 B 10/29; H04 B 10/297; H04 W 84/12.

[174] Bing S. Single-channel ultraviolet (uv) light communication system, Patent CN202918295U China: IPC H04 B 10/11.

[175] Xiaoyi L., Juan Y., Fang Z. Method for optimizing blind ultraviolet non line-of-sight Ad-hoc communication network shared channel, Patent CN103647603B China: IPC G06 N 3/12; H04 B 10/11; H04 L 29/06.

[176] Wang H., Zhao M., Deng Z. Ultraviolet light communication method and transmitter, Patent CN102638309A China: IPC H04 B 10/114; H04 B 10/50.

[177] Pozhidaev V.N. Feasibility of ultraviolet communication links based on the effect of molecular and aerosol scattering in the atmosphere. Radio Engineering and Electronic Physics, 1977, 22 (10), P. 2190-2192. (in Russian)

[178] Pozhidaev V.N. Estimation of attenuation and backscattering of millimeter radio waves in meteorological formations. Journal of Communications Technology and Electronics, 2010-2011, 55 (11), P. 1223-1230.

[179] Shaw G.A., Siegel A.M., Nischan M.L. Demonstration system and applications for compact wireless ultraviolet communications. Proc. SPIE, 2003, 5071, P. 241-252.

[180] Shaw G.A., Siegel A.M., Model J. Extending the range and performance of non-line-of-sight ultraviolet communication links. Proc. SPIE, 2006, 6231, 62310C.

[181] Xu Zh., Chen G., Abou-Galala, F., Leonardi M. Experimental performance evaluation of non-line-of-sight ultraviolet communication systems. Proc. SPIE, 2007, 6709, 67090Y. 
[182] Zhang H., Yin H., et al. Study of effects of obstacle on non-line-of-sight ultraviolet communication links. Opt. Express, 2011 , 19 (22), P. 21216-21226.

[183] Britvin A.V. The pulse charachteristic estimation of optical atmospheric UV-channel with scattering. Bulletin of the Novosibirsk state university. Series Physics, 2010, 5 (2), P. 5-7. (in Russian)

[184] Konstantinov I.S., Vasilyev G.S., et al. Numerical and analytical modeling of wireless UV communication channels for the organization of wireless ad- hoc network. IJCSNS International Journal of Computer Science and Network Security, 2018, 18 (8), P. $98-104$.

[185] Konstantinov I.S., Vasilyev G.S, et al. Modeling and Analysis of the Characteristics of Ultraviolet Channels under Different Conditions of Radiation Propagation for the Organization of Wireless AD-HOC Network. J. of Adv. Research in Dynamical and Control Systems, 2018, 10 (2), P. 1853-1859.

[186] Belov V.V., Abramochkin V.N., et al. Bistatic optoelectronic communication systems: Field experiments in artificial and natural water reservoirs. Atmos Ocean Opt, 2017, 30 (2), P. 366-371.

[187] Aouini A. System for converting wind energy, Patent. US20130181458A1 USA: IPC F03 D 9/00.

[188] Vorotnikov G.V. The modeling of the thermoacoustic electric generator by quadrupole approximation approach. Vestnik of Samara University. Aerospace and Mechanical Engineering, 2012, 3 (34), P. 191-199.

[189] Almjasheva O.V., Gusarov V.V. Prenucleation formations in control over synthesis of $\mathrm{CoFe}_{2} \mathrm{O}_{4}$ nanocrystalline powders. Russian Journal of Applied Chemistry, 2016, 89 (6), P. 851-856.

[190] Lomanova N.A., Tomkovich M.V., Sokolov V.V., Gusarov V.V. Special features of formation of nanocrystalline BiFeO3 via the glycinenitrate combustion method. Russian Journal of General Chemistry, 2016, 86 (10), P. 2256-2262.

[191] Kovalenko A.N. High-temperature superconductivity: From macro- to nanoscale structures, Nanosystems: Phys., Chem., Math., 2016, 7 (6), P. 941-970.

[192] Fedorov P.P. Nanotechnology and material science. Nanosystems: Phys., Chem., Math., 2020, 11 (3), P. $314-315$.

[193] Almjasheva O.V., Garabadzhiu A.V., et al. Biological effect of zirconium dioxide-based nanoparticles. Nanosystems: Phys., Chem., Math., 2017, 8 (3), P. 391-396.

[194] Tugova E., Yastrebov S., Karpov O., Smith R. NdFeO 3 nanocrystals under glycine nitrate combustion formation. J. Crystal Growth, 2017, 467, P. 88-92.

[195] Proskurina O.V., Tomkovich M.V., et al. Formation of Nanocrystalline BiFeO3 under hydrothermal conditions. Russian Journal of General Chemistry, 2017, 87 (11), P. 2507-2515.

[196] Krasilin A.A., Gusarov V.V. Redistribution of Mg and Ni cations in crystal lattice of conical nanotube with chrysotile structure. Nanosystems: Phys., Chem., Math., 2017, 8 (5), P. 620-627.

[197] Lomanova N.A., Tomkovich M.V., Osipov A.V., Ugolkov V.L. Synthesis of nanocrystalline materials based on the $\mathrm{Bi}_{2} \mathrm{O}_{3}-\mathrm{TiO}_{2}$ system. Russian Journal of General Chemistry, 2019, 89 (10), P. 2075-2081.

[198] Zlobin V.V., Krasilin A.A., Almjasheva O.V. Effect of heterogeneous inclusions on the formation of TiO 2 nanocrystals in hydrothermal conditions. Nanosystems: Phys., Chem., Math., 2019, 10 (6), P. 733-739.

[199] Lomanova N.A., Panchuk V.V., et al. Bismuth orthoferrite nanocrystals: magnetic characteristics and size effects. Ferroelectrics, 2020, 569, P. 240-250.

[200] Krasilin A.A., Khrapova E.K., Maslennikova T.P. Cation doping approach for nanotubular hydrosilicates curvature control and related applications. Crystals, 2020, 10, 654 .

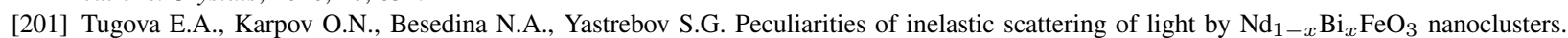
Nano Express, 2020, 1 (1), P. 010064-010072.

[202] Shchelokova A., Ivanov V., et al. Ceramic resonators for targeted clinical magnetic resonance imaging of the breast. Nat Commun., 2020, 11, P. 3840-3846.

[203] Egorysheva A.V., Skorikov V.M. Efficient nonlinear optical material BiB ${ }_{3} \mathrm{O}_{6}$ (BIBO). Inorg Mater., 2009,45 (13), P. 1461-1476.

[204] Sleight Arthur W. Oxide superconductors. Thermochimica Acta, 1991, 174, P. 1-7.

[205] Miyazaki C.M., Riul A. Low-Dimensional Systems: Nanoparticles. Nanostructures, 2017, 5, P. $125-146$.

[206] Vance M.E., Kuiken T., et al. Nanotechnology in the real world: Redeveloping the nanomaterial consumer products inventory. J. Nanotechnol., 2015, 6 (1), P. 1769-1780.

[207] Chislova, I.V., Matveeva A.A., Volkova A.V., Zvereva I.A. Sol-gel synthesis of nanostructured perovskite-like gadolinium ferrites. Glass Phys. Chem., 2011, 37 (6), P. 653-660.

[208] Mukasyan A.S., Rogachev A.S. Combustion synthesis: mechanically induced nanostructured materials. J. Mater. Sci., 2017, 52, P. 1182611833.

[209] Andrievski R.A. Review of thermal stability of nanomaterials. J. Mater. Sci., 2014, 49 (4), P. 1449-1460.

[210] Tretyakov Yu.D. Self-organisation processes in the chemistry of materials. Russ. Chem. Rev., 2003 , 72 (8), P. 651-679.

[211] Kazin P.E., Tretyakov Yu.D. Microcomposites based on superconducting cuprates. Russ. Chem. Rev., 2003 , 72 (10), P. 849-865.

[212] Defay R., Prigogine I., Sanfeld A. Surface thermodynamics. J. Colloid Interface Sci., 1977, 58 (3), P. $498-510$.

[213] Van-der-Vaal's I.D., Konstamm F. Kurs termostatiki (Course of Thermostatics). Moscow, ONTI, 1936, 452 p. (in Russian)

[214] Rusanov A.I. Phase equilibria and surface phenomena. Khimiya, Leningrad, 1967, 388 p.

[215] Adamson A.W., Gast A.P. Physical chemistry of surfaces (six edition). John Wiley and Sons, New-York, 1997,804 p.

[216] Gusarov V.V., Suvorov S.A. Transformations of nonautonomous phases and densification of polycrystalline systems. Journal of Applied Chemistry of the USSR, 1992, 65 (7), P. 1227-1235.

[217] Gusarov V.V. Kinetic features of heat effect of melting in polycrystalline systems. Russ. J. Appl. Chemistry, 1994,67 (3), P. $364-366$.

[218] Gusarov V.V., Suvorov S.A. Rapid thermal packing of materials. Russ. J. Appl. Chem., 1993, 66 (3), P. $431-437$.

[219] Gusarov V.V., Suvorov S.A. Thickness of 2-dimentional nonautonomous phases in local equilibrium polycrystalline systems based on a single bulk phase. Russ. J. Appl. Chem., 1993, 66 (7), P. 1212-1216.

[220] Gusarov V.V., Suvorov S.A. Melting points of locally equilibrium surface phases in polycrystalline systems based on a single volume phase. J. Appl. Chem. of the USSR, 1990, 63 (8), P. 1560-1565.

[221] Gusarov V.V., Malkov A.A., Malygin A.A., Suvorov S.A. Thermally activated transformations of 2D nonautonomous phases and contradiction of polycrystalline oxide materials. Inorganic Materials, 1995, 31 (3), P. 320-323. 
[222] Babaev A.A., Zobov M.E., Terukov E.I., Tkachev A.G. A technology for producing polymeric composites based on carbon nanofibers. Prot. Met. Phys. Chem. Surf., 2020, 56 (4), P. 734-739.

[223] Bespalova Zh.I., Khramenkova A.V. The use of transient electrolysis in the technology of oxide composite nanostructured materials: review. Nanosystems: Phys., Chem., Math., 2016, 7 (3), P. 433-450.

[224] Khaliullin S.M., Bamburov V.G., et al. $\mathrm{CaZrO}_{3}$ synthesis in combustion reactions with glycine. Doklady Chemistry, 2015, 461 (2), P. 93-95.

[225] Aruna S.T., Mukasyan A.S. Combustion synthesis and nanomaterials. Curr. Opin. Solid State Mater. Sci., 2008, 12 (3-4), P. 44-50.

[226] Byrappa K., Adschiri T. Hydrothermal technology for nanotechnology. Progress in Crystal Growth and Characterization of Materials, 2007, 53, P. 117-166.

[227] Lee J., Mahendra S., Alvarez P.J.J. Nanomaterials in the construction industry: A Review of their applications and environmental health and safety considerations. ACS Nano, 2010, 4 (7), P. 3580-3590.

[228] Vasilevskay A.K., Almjasheva O.V., Gusarov V.V. Peculiarities of structural transformations in zirconia nanocrystals. J. Nanopart. Res., 2016, 18 (7), P. 188-198.

[229] Van Tac D., Mittova V.O., Almjasheva O.V.,Mittova I.Ya. Synthesis and magnetic properties of nanocrystalline $\mathrm{Y}_{1-x} \mathrm{Cd}_{x} \mathrm{FeO}_{3-\delta}(0 \leq x \leq$ 0.2). Inorg Mater., 2011, 47 (10),P. 1141-1146.

[230] Uvarov N.F., Vanek P. Stabilization of new phases in ion-conducting nanocomposites. Journal of Materials Synthesis and Processing, 2000, $8(5 / 6)$, P. $319-326$.

[231] Nguyen A.T., Nguyen V.Y., et al. Synthesis and magnetic properties of PrFeO3 nanopowders by the co-precipitation method using ethanol. Nanosystems: Phys., Chem., Math., 2020, 11 (4), P. 468-473.

[232] Ostroushko A.A., Russkikh O.V. Oxide material synthesis by combustion of organic-inorganic compositions. Nanosystems: Phys. Chem. Math., 2017, 8 (4), P. 476-502.

[233] Zhukov V.P., Kostenko M.G., Rempel A.A., Shein I.R. Influence of carbon or nitrogen dopants on the electronic structure, optical properties and photocatalytic activity of partially reduced titanium dioxide. Nanosystems: Phys. Chem. Math., 2019,10 (3), P. $374-382$.

[234] Khaliullin Sh.M., Zhuravlev V.D., Bamburov V.G. Solution-combustion synthesis of $\mathrm{MZrO}_{3}$ zirconates $(\mathrm{M}=\mathrm{Ca}$, Sr, Ba) in open reactor: thermodynamic analysis and experiment. International Journal of Self-Propagating High-Temperature Synthesis, 2017,26 (2), P. $93-101$.

[235] Abryutin V., Nesterov S., Romanko V., Kholopkin A. Application of nanotechnology to create highly efficient thermoelectric materials. Nanoindustry, 2010, 1, P. 24-26.

[236] Ordin S.V., Wang W.N. Thermoelectric effects on micro and nano level. J. Advances in Energy Research, 2011, 9, P. 311-342.

[237] Matsukevich, I.V., Klyndyuk, A.I., et al. Thermoelectric properties of $\mathrm{Ca}_{3-x} \mathrm{Bi}_{x} \mathrm{Co}_{4} \mathrm{O}_{9+\delta}(0.0 \leq x \leq 1.5)$ ceramics. Inorg Mater., 2016, 52 (6), P. 593-599.

[238] Pikalova E.Y., Kolchugin A.A., Bamburov V.G. Ceria-based materials for high-temperature electrochemistry applications. International Journal of Energy Production and Management, 2016, 1 (3), P. 272-283.

[239] Almyasheva O.V., Gusarov V.V., et al. Nanocrystals of $\mathrm{ZrO}_{2}$ as sorption heat accumulators. Glass Physics and Chemistry, 2007, 33 (6), P. 587-589.

[240] Chupakhina T.I., Melnikova N.V., et al. Synthesis, structure and dielectric properties of new ceramics with $\mathrm{K}_{2} \mathrm{NiF}_{4}$-type structure. J. Eur. Ceram. Soc., 2019, 39 (13), P. 3722-3729.

[241] Galakhov V.R., Turkin D.I., et al. Effect of transition metal oxidations state on crystal structure and magnetic ordering in frustrated $A B a M 4 O 7$ systems $(A=\mathrm{Y}, \mathrm{Ca} ; M=\mathrm{Co}, \mathrm{Fe})$ : X-ray diffraction, soft X-ray absorption, and magnetization studies. Current Applied Physics, 2018, 18, P. 155-162.

[242] Talanov M.V., Bokov A.A., Marakhovsky M.A. Effects of crystal chemistry and local random fields on relaxor and piezoelectric behavior of lead-oxide perovskites. Acta Materialia, 2020, 193, P. 40-50.

[243] Pikalova E.Y., Bamburov V.G., et al. The development of electrolytes for intermediate temperature solid oxide fuel cells. WIT Transactions on Ecology and the Environment, 2014, 190 (1) P. 261-272.

[244] Lim H-D., Lee B., et al. Rational design of redox mediators for advanced Li-O 2 batteries. Nature Energy, 2016,1 (6), 16066.

[245] Zhuk A.Z., Kleymenov B.V., et al. Aluminum-hydrogen energy. JIHT RAS, Moscow, 2007, 278 p. (in Russian)

[246] Brusnetsov V.P. Solid oxide fuel cells: collection of articles. scientific and technical articles. RFNC-VNIITF Publishing House, Snezhinsk, 2003, 376 p. (in Russian)

[247] Predtechensky M.R., Smal A.N., Nakoryakov V.E., Bobrenok O.F. Fuel cells based on carbonate melts based on electrodes of a new design. Proceedings of the Institute for Advanced Study, 2003, 1, P. 2-13. (in Russian)

[248] Merkulov O.V., Markov A.A., et al. Structural features and high-temperature transport in $\mathrm{SrFe}_{0.7} \mathrm{Mo}_{0.3} \mathrm{O}_{3-\delta}$. J. Solid State Chem., 2018, 258, P. 447-452.

[249] Lukashin A.V., Eliseev A.A. Physical methods for the synthesis of nanomaterials. MSU, Moscow, 2007, 32 p. (in Russian)

[250] Kovalenko A.N., Kalinin N.V. Thermodynamic instability of compound and formation of nanosized particles nearby the critical point of phase generating media. Nanosystems: Phys., Chem., Math., 2014, 5 (2), P. 258-293.

[251] Feynman R.P. There's plenty of room at the bottom. An invitation to enter a new field of physics. Engineering and Science magazine, 1960, 23 (5), P. 22-36.

[252] Kolesnik I.V., Eliseev A.A. Chemical methods for the synthesis of nanomaterials. Ed. Tretyakov Yu.D. MSU, Moscow, 2011, 41 p. (in Russian)

[253] Rowe D.M. (ed.). Handbook of Thermoelectrics. CRC Press, Boca Raton, FL, 1995, 701 p.

[254] Yepremyan A.O., Aroutiounian V.M., Vahanyan A.I. Figure of merit of modern semiconducting thermoelectric materials. Int. Sci. J. for Alternative Energy and Ecology, 2005, 5 (25), P. 7-18.

[255] Gridnev S.A., Kalinin Yu.E., Makagonov V.A., Shuvaev A.S. Promising thermoelectric materials. Int. Sci. J. for Alternative Energy and Ecology, 2013, 1-2 (118), P. 117-125 (in Russian).

[256] Sherchenkov A.A., Shtern Yu.I., et al. Current state of thermoelectric material science and the search for new effective materials. Nanotechnologies in Russia, 2015, 10(11-12), P. 827-840.

[257] Shevelkov A.V. Chemical aspects of the design of thermoelectric materials. Russ. Chem. Rev., 2008,77 (1), P. 1-19.

[258] Goldsmid H.J. Bismuth telluride and its alloys as materials for thermoelectric generation. Materials, 2014 , 7, P. $2577-2592$. 
[259] Sootsman J.R., Chung D.Y., Kanatzidis M.G. New and old concept in thermoelectric materials. Angew. Chem. Int. Ed., 2009, 48, P. 86168639.

[260] Populoh S., Aguirre M.H., et al. High figure of merit in (Ti, Zr, Hf) NiSn half-Heusler alloys. Scripta Materialia, 2012, 66, P. $1073-1076$.

[261] Minnich A.J., Dresselhaus M.S., Ren Z.F., Chen G. Bulk nanostructured thermoelectric materials: current research and future prospects. Energy Environ. Sci., 2009, 2, P. 468-479.

[262] Tugova E.A., Klyndyuk A.I., Gusarov V.V. Synthesis of solid solutions of double layered Ruddlesden-Popper phases in the Gd ${ }_{2} \mathrm{O}_{3}-\mathrm{SrO}_{-}$ $\mathrm{Fe}_{2} \mathrm{O}_{3}-\mathrm{Al}_{2} \mathrm{O}_{3}$ system. Russian Journal of Inorganic Chemistry, 2013, 58 (7), P. 848-854.

[263] Tugova E.A. P/RS intergrowth type phases in the $\mathrm{Ln}_{2} \mathrm{O}_{3}-\mathrm{MO}-\mathrm{Al}_{2} \mathrm{O}_{3}$ systems. Russian Journal of General Chemistry, 2016 , 86 (11), P. 2410-2417.

[264] Zvereva I.A., Tugova E.A., et al. The impact of $\mathrm{Nd}^{3+} / \mathrm{La}^{3+}$ substitution on the cation distribution and phase diagram in the $\mathrm{La}_{2} \mathrm{SrAl}_{2} \mathrm{O}_{7}-$ $\mathrm{Nd}_{2} \mathrm{SrAl}_{2} \mathrm{O}_{7}$ system. Chimica Techno Acta, 2018, 5 (1), P. 80-85.

[265] Carvillo P., Chen Y., et al. Thermoelectric performance enhancement of calcium cobaltite through barium grain boundary segregation. Inorg. Chem., 2015, 54, P. 9027-9032.

[266] Matsukevich I.V., Klyndyuk A.I., et al. Synthesis and properties of materials based on layered calcium and bismuth cobaltites. Russ. J. Appl. Chem., 2015, 88 (8), P. 1241-1247.

[267] Jankowski O., Huber S., et al. Towards highly efficient thermoelectric: $\mathrm{Ca}_{3} \mathrm{Co}_{4} \mathrm{O}_{9+\delta} \cdot n$ CaZrO ${ }_{3}$ composite. Ceramics - Silikaty, 2014, 58 (2), P. 106-110.

[268] Gupta R.K., Sharma R., Mahapatro A.K., Tandon R.P. The effect of $\mathrm{ZrO}_{2}$ dispersion on the thermoelectric power factor of Ca ${ }_{3} \mathrm{Co}_{4} \mathrm{O}_{9}$. Physica B, 2016, 483, P. 48-53.

[269] Krasutskaya N.S., Klyndyuk A.I., et al. Thermoelectric properties of the ceramics based on the layered calcium cobaltite doped by bismuth oxide. Refractories and Technical Ceramics, 2016, 10, P. 25-29.

[270] Kozhevnikov V.L., Leonidov I.A., et al. High-temperature thermopower and conductivity of $\mathrm{La}_{1-x} \mathrm{Ba}_{x} \mathrm{MnO}_{3}(0.02 \leq x \leq 0.35)$. J. Solid State Chem., 2003, 172 (1), P. 1-5.

[271] Estemirova, S.K., Yankin A.M., et al. Phase composition and structure of $\mathrm{La}_{1-x} \mathrm{Ca}_{x} \mathrm{MnO}_{3+\delta}(0 \leq x \leq 0.2)$ solid solutions. Inorg Mater., 2008. 44, P. 1251-1256.

[272] Xu J., Wei C., Jia K. Properties and device of $\mathrm{Ca}_{2.7} \mathrm{Sr}_{0.3} \mathrm{Co}_{4 O 9}$ and $\mathrm{Ca}_{0.95} \mathrm{Sm}_{0.05} \mathrm{MnO}_{3}$ thermoelectric materials. J. Chin. Ceram. Soc., 2010, 38 (6), P. 1136-1139.

[273] Han L., Jiang Y., et al. High temperature thermoelectric properties and energy transfer devices of $\mathrm{Ca}_{3} \mathrm{Co}_{4-x} \mathrm{Ag}_{x} \mathrm{O}_{9} \operatorname{and~Ca}_{1-y} \mathrm{Sm}_{y} \mathrm{MnO}_{3}$. J. Alloys Compd., 2011, 509, P. 8970-8977.

[274] Lim C.-H., Choi S.-M., Seo W.-S., Park H.-H. A power-generation test for oxide-based thermoelectric modules using p-type Ca $3 \mathrm{Co}_{4} \mathrm{O}_{9}$ and n-type $\mathrm{Ca}_{0.9} \mathrm{Nd}_{0.1} \mathrm{MnO}_{3}$ legs. J. Electron. Mater., 2012, 41 (6), P. 1247-1255.

[275] Zhu Y., Wang C., et al. Influence of Dy/Bi dual doping on thermoelectric performance of CaMnO 3 ceramics. Mat. Chem. Phys., 2014, 144, P. 385-389.

[276] Thiel P., Populoh S., Yoon S., Weidenkaff A. Enhancement of redox- and phase-stability of thermoelectric CaMnO $3-\delta$ by substitution. $J$. Solid State Chem., 2015, 229, P. 62-67.

[277] Yasukawa M., Murayama N. High-temperature thermoelectric properties of the oxide material: $\mathrm{Ba}_{1-x} \mathrm{Sr}_{x} \mathrm{PbO}_{3}(x=0-0.6) . J$. Mat. Sci. Lett., 1997, 16 (21), P. 1731-1735.

[278] Yasukawa M., Murayama N. A promising oxide material for high-temperature thermoelectric energy conversion: Ba1-xSrxPbO3 solid solution system. Mat. Sci. and Eng. B, 1998, 54, P. 64-69.

[279] Yasukawa M., Kono T. Preparation of dense $\mathrm{BaPbO}_{3}$-based ceramics by a coprecipitation and their thermoelectric properties. J. Alloys and Comp., 2006, 426, P. 420-425.

[280] Chizhova E.A., Klyndyuk A.I. Synthesis and thermoelectric properties of ceramics based on barium-strontium metaplumbates. Glass Physics and Chemistry, 2013. 39 (4), P. 453-457.

[281] Muta H., Kurosaki K., Yamanaka S. Thermoelectric properties of doped $\mathrm{BaTiO}_{3}-\mathrm{SrTiO}_{3}$ solid solution. J. of Alloys Compd., 2004, 368, P. 22-24.

[282] Ohta H. Thermoelectrics based on strontium titanate. Mater. Today, 2007, 10, P. 44-49.

[283] Ohta H., Sugiura K., Koumoto K. Recent progress in oxide thermoelectric materials: p-type $\mathrm{Ca}_{3} \mathrm{Co}_{4} \mathrm{O}_{9}$ and n-Type $\mathrm{SrTiO}_{3}$. Inorg. Chem., 2008, 47, P. 8429-8436.

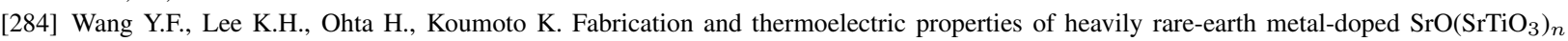
( $n=1,2)$ ceramics. Ceram. Int., 2008, 34, P. 849-852.

[285] Tang J., Wang W., Zhao G.-L., Li Q. Colossal positive Seebeck coefficient and low thermal conductivity in reduced TiO 2 . J. Phys.: Condens. Matter, 2009, 21, 205703.

[286] Liu J., Wang H.C., et al. Synthesis and thermoelectric properties of $\mathrm{Sr}_{0.95} \mathrm{La}_{0.05} \mathrm{TiO}_{3-\delta}-\mathrm{TiO}_{2}$ solid solutions. Solid State Sciences, 2010, 12, P. 134-137.

[287] Wang H.C., Wang C.L., et al. Enhancement of thermoelectric figure of merit by doping Dy in $\mathrm{La}_{0.1} \mathrm{Sr}_{0.9} \mathrm{TiO}_{3}$ ceramic. Mat. Res. Bull., 2010, 45, P. 809-812.

[288] Zhang Y., Feng B., et al. Thermoelectric phase diagram of the $\mathrm{SrTiO}_{3}-\mathrm{SrNbO}_{3}$ solid solution system. J. Appl. Phys. Lett., 2017 , 121, 185102.

[289] Boston R., Schmidt W.L., et al. Protocols for the fabrication, characterization, and optimization of n-type thermoelectric ceramic oxides. Chem. Mater, 2017, 29 (1), P. 265-280.

[290] Robert R., Bocher L., et al. Ni-doped cobaltates as potential materials for high temperature solar thermoelectric converters. Progr. Solid State Chem., 2007, 35, P. 447-455.

[291] Tomeš P., Trottmann M., et al. Thermoelectric Oxide Modulus (TOMs) for the Direct Conversion of Stimulated Solar Radiation into Electrical Energy. Materials, 2010, 3, P. 2801-2814

[292] Suter C., Tomeš P., Weidenkaff A., Steinfeld A. Heat transfer and geometrical analysis of thermoelectric converters driven by concentrated solar radiation. Materials, 2010, 3, P. 2735-2752.

[293] Tugova E.A. New DySrAlO 4 compound synthesis and formation process correlations for $\mathrm{LnSrAl}_{O} 4$ ( $\mathrm{Ln}=\mathrm{Nd}$, Gd, Dy) series. Acta Metallurgica Sinica (English Letters, 2016, 29 (5), P. 450-456. 
[294] Semenov N.N. Thermal theory of combustion and explosions. III Theory of normal flame propagation. Progress of Physical Science (USSR), 1940, 24 (4) 80 p.

[295] Tretyakov Yu.D., Lukashin A.V., Eliseev A.A. Synthesis of functional nanocomposites based on solid-phase nanoreactors. Russ. Chem. Rev., 2004, 73 (9), P. 899-923.

[296] Shaporev A.S., Zeng H., Ivanov V.K. Tret'yakov Yu.D. Mechanism of formation of finely dispersed zinc oxide in homogeneous hydrolysis of zinc nitrate in the presence of hexamethylenetetramine. Dokl. Chem., 2009, 426 (1), P. 101-104.

[297] Tugova E.A., Zvereva I.A. Formation mechanism of $\mathrm{GdFeO}_{3}$ nanoparticles under the hydrothermal conditions. Nanosystems: Phys., Chem., Math., 2013, 4 (6), P. 851-856.

[298] Al'myasheva, O.V., Korytkova, E.N., Maslov, A.V. Gusarov V.V. Preparation of nanocrystalline alumina under hydrothermal conditions. Inorg. Mater., 2005, 41 (5), P. 460-467.

[299] Klyndyuk A., Chizhova E., Matsukevich I., Tugova E. Thermoelectric properties of inhomogeneous ceramics based on the layered calcium cobaltate. Universal Journal of Materials Science, 2019. 7 (4), P. 43-53.

[300] Wu N.Y., Holgate T.C., et al. High temperature thermoelectric properties of $\mathrm{Ca}_{3} \mathrm{Co}_{4} \mathrm{O}_{9+\delta}$ by auto-combustion synthesis and spark plasma sintering. Journal of the European Ceramic Society, 2014, 34 (4), P. 925-931.

[301] Agilandeswari K., Ruban Kumar A. Synthesis, characterization, temperature dependent electrical and magnetic properties of $\mathrm{Ca}_{3} \mathrm{Co}_{4} \mathrm{O}_{9}$ by a starch assisted sol-gel combustion method. Journal of Magnetism and Magnetic Materials, 2014, 364, P. 117-124.

[302] Sotelo A., Rasekh Sh., et al. Effect of synthesis methods on the $\mathrm{Ca}_{3} \mathrm{Co}_{4} \mathrm{O}_{9}$ thermoelectric ceramic performances. Journal of Solid State Chemistry, 2015, 221, P. 247-254.

[303] Zaboeva E.A., Izotova S.G., Popkov V.I. Glycine-nitrate combustion synthesis of $\mathrm{CeFeO}_{3}$-based nanocrystalline powders. Russian J. of Appl. Chem., 2016, 89 (8), P. 1228-1236.

[304] Bachina A.K., Ivanov V.A., Popkov V.I. Peculiarities of $\mathrm{LaFeO}_{3}$ nanocrystals formation via glycine-nitrate combustion. Nanosystems: Phys., Chem., Math., 2017, 8 (5). P. 647-653.

[305] Martinson K.D., Kondrashkova I.S., Popkov V.I. Synthesis of EuFeO3 nanocrystals by glycine-nitrate combustion method. Russ. J. Appl. Chem., 2017.90 (8), P. 980-985.

[306] Kondrashkova I.S., Martinson K.D., Zakharova N.V., Popkov V.I. Synthesis of nanocrystalline $\mathrm{HoFeO}_{3}$ photocatalyst via heat treatment of products of glycine-nitrate combustion. Russ. J. Gen. Chem., 2018, 88 (12), P. 2465-2471.

[307] Martinson K.D., Ivanov V.A., et al. Facile combustion synthesis of $\mathrm{TbFeO}_{3}$ nanocrystals with hexagonal and orthorhombic structure. Nanosystems: Phys., Chem., Math., 2019, 10 (6), P. 694-700.

[308] Komova O.V., Simagina V.I., et al. A modified glycine-nitrate combustion method for one-step synthesis of LaFeO 3. Adv. Powder Technol., 2016, 27 (2), P. 496-503.

[309] HaoX., Zhang Y. Low temperature gel-combustion synthesis of porous nanostructure $\mathrm{LaFeO}_{3}$ with enhanced visible-light photocatalytic activity in reduction of $\mathrm{Cr}(\mathrm{VI})$. Mater. Lett., 2017, 197, P. 120-122.

[310] Salehabadi A., Salavati-Niasari M., Gholami T., Khoobi A. Dy ${ }_{3} \mathrm{Fe}_{5} \mathrm{O}_{12}$ and $\mathrm{DyFeO}_{3}$ nanostructures: Green and facial auto-combustion synthesis, characterization and comparative study on electrochemical hydrogen storage. Int. J. Hydrog. Energy, 2018, 43 (20), P. 9713-9721.

[311] Popkov V.I., Almjasheva O.V., Gusarov V.V. The investigation of the structure control possibility of nanocrystalline yttrium orthoferrite in its synthesis from amorphous powders. Russ. J. Appl. Chem., 2014, 87 (10), P. 1417-1421.

[312] Popkov V.I., Tugova E.A., Bachina A.K., Almjasheva O.V. The formation of nanocrystalline orthoferrites of rare-earth elements XFeO 3 (X = Y, La, Gd) via heat treatment of coprecipitated hydroxides. Russ. J. Gen. Chem., 2017, 87 (11), P. 1771-1780.

[313] Popkov V.I., Almjasheva O.V., et al. The role of pre-nucleus states in formation of nanocrystalline yttrium orthoferrite. Doklady Chem., 2016, 471 (4), P. 439-443.

[314] Popkov V.I., Almjasheva O.V., et al. Effect of spatial constraints on the phase evolution of $\mathrm{YFeO}_{3}$-based nanopowders under heat treatment of glycine-nitrate combustion products. Cer. Intern., 2018, 44 (17), P. 20906-20912.

[315] Almjasheva O.V., Lomanova N.A., et al. The minimum size of oxide nanocrystals - phenomenological thermodynamic vs crystal-chemical approaches. Nanosystems: Phys., Chem., Math., 2019, 10 (4), P. 428-437.

[316] Kopeychenko E.I., Mittova I.Ya., et al. Nanocrystalline heterogeneous multiferroics based on yttrium ferrite (core) with calcium zirconate (titanate) shell. Russ. J. Gen. Chem., 2020, 90, P. 1030-1035.

[317] Alekseeva O.A., Naberezhnov A.A., Stukova E.V., Popkov V.I. The effect of barium titanate admixture on the stability of potassium nitrate ferroelectric phase in $(1-x) \mathrm{KNO}_{3}+(x) \mathrm{BaTiO}_{3}$ composites. St. Petersburg Polytechnical University Journal: Physics and Mathematics, 2015, 1 (3), P. 229-234.

[318] Popkov V.I., Tolstoy V.P., Semenov V.G. Synthesis of phase-pure superparamagnetic nanoparticles of $\mathrm{ZnFe}_{2} \mathrm{O}_{4}$ via thermal decomposition of zinc-iron layered double hydroxysulphate. Journal of Alloys and Compounds, 2020, 813, 152179.

[319] Gusev A.I., Rempel A.A. Nanocrystalline Materials. Cambridge International Science Publishing, 2004,351 p.

[320] Martinson K.D., Sakhno D.D., et al. Synthesis of Ni0.4Zn0.6Fe2O4 spinel ferrite and microwave adsorption of related polymer composite. Nanosystems: Phys., Chem., Math., 2020, 11 (5), P. 595-600.

[321] Rempel A.A. Hybrid nanoparticles based on sulfides, oxides, and carbides. Russian Chemical Bulletin, 2013 , 62 (4), P. 857-868.

[322] Martinson K.D., Kozyritskaya S.S., Panteleev I.B., Popkov V.I. Low coercivity microwave ceramics based on LiZnMn ferrite synthesized via glycine-nitrate combustion. Nanosystems: Phys., Chem., Math., 2019, 10 (3), P. 313-317.

[323] Shevchenko E.V., Charnaya E.V., et al. Superconductivity in a Ga-Ag nanocomposite with dendritic morphology. Physica C, 2020, 574, 1353666.

[324] Albadi Y., Popkov V.I. Dual-modal contrast agent for magnetic resonance imaging based on gadolinium orthoferrite nanoparticles: synthesis, structure and application prospects. Medicine: theory and practice, 2019, 4, P. 35-36.

[325] Pinho S.L.C., Amaral J.S., et al. Synthesis and characterization of rare-earth orthoferrite $\mathrm{LnFeO}_{3}$. Nanoparticles for Bioimaging, 2018, 38, P. 3570-3578.

[326] Albadi Y., Martinson K.D., et al. Synthesis of $\mathrm{GdFeO}_{3}$ nanoparticles via low-temperature reverse co-precipitation: the effect of strong agglomeration on the magnetic behavior. Nanosystems: Phys., Chem., Math., 2020, 11 (2), P. $252-259$.

[327] Dmitriev D.S., Popkov V.I. Layer by layer synthesis of zinc-iron layered hydroxy sulfate for electrocatalytic hydrogen evolution from ethanol in alkali media. Nanosystems: Phys., Chem., Math., 2019, 10 (4), P. 480-487. 
[328] Chebanenko M.I., Lobinsky A.A., Nevedomskiy V.N., Popkov V.I. NiO-decorated graphitic carbon nitride toward electrocatalytic hydrogen production from ethanol. Dalton Trans., 2020, 49, P. 12088-12097.

[329] Kodintsev I.A., Martinson K.D., Lobinsky A.A., Popkov V.I. SILD synthesis of the efficient and stable electrocatalyst based on CoO-NiO solid solution toward hydrogen production. Nanosystems: Phys., Chem., Math., 2019, 10 (6), P. 681-685.

[330] Belmesov A.A., Baranov A.A., Levchenko A.V. Anodic Electrocatalysts for Fuel Cells Based on Pt/Ti ${ }_{1-x} \mathrm{Ru}_{x} \mathrm{O}_{2}$. Russ. J. Electrochem., 2018, 54, P. 493-499.

[331] Voloshin Y.Z., Buznik V.M., Dedov A.G. New types of the hybrid functional materials based on cage metal complexes for (electro) catalytic hydrogen production. Pure Appl. Chem. 2019, 92 (7), P. 1159-1174.

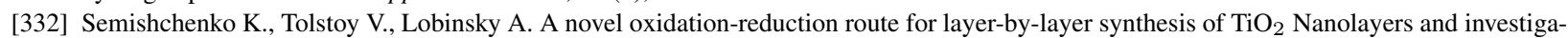
tion of its photocatalytical properties. J. Nanomater, 2014, 10, P. 1-7.

[333] Cam T.S., Vishnievskaia T.A., Popkov V.I. Catalytic oxidation of $\mathrm{CO}$ over $\mathrm{CuO} / \mathrm{CeO}_{2}$ nanocomposites synthesized via solution combustion method: effect of fuels. Reviews on Advanced Materials Science, 2020, 59, P. 1-13.

[334] Sheshko T.F., Sharaeva A.A., et al. Carbon oxide hydrogenation over $\mathrm{GdBO}_{3}$ (B = Fe, Mn, Co) complex oxides: Effect of carbon dioxide on product composition. Pet. Chem., 2020, 60, P. 571-576.

[335] Cam T.S., Vishnevskaya T.A., et al. Urea-nitrate combustion synthesis of $\mathrm{CuO} / \mathrm{CeO}_{2}$ nanocatalysts toward low-temperature oxidation of CO: the effect of Red/Ox ratio. J. Mater. Sci., 2020, 55, P. 11891-11906.

[336] Kryuchkova T.A., Kost V.V., et al. Effect of cobalt in $\mathrm{GdFeO}_{3}$ catalyst systems on their activity in the dry reforming of methane to synthesis gas. Petroleum Chemistry, 2020, 60 (5), P. 609-615.

[337] Cam T.S., Petrova A.E., et al. On the SCS approach to the $\mathrm{CeO}_{2} / \mathrm{CuO}$ nanocomposite: thermochemical aspects and catalytic activity in n-hexane conversion. Russ. J. Inorg. Chem., 2020, 65 (5), P. 725-732.

[338] Shamanaeva I.A., Yu Zh., et al. Role of texture and acidity of SAPO-34 in methanol to olefins conversion. Pet. Chem., 2020, 60, P. 471-478.

[339] Martinson K.D., Kondrashkova I.S., et al. Magnetically recoverable catalyst based on porous nanocrystalline $\mathrm{HoFeO}_{3}$ for processes of n-hexane conversion. Advanced Powder Technology, 2020, 31 (1), P. 402-408.

[340] Chebanenko M.I., Zakharova N.V., Popkov V.I. Synthesis and visible-light photocatalytic activity of graphite-like carbon nitride nanopowders. Russian Journal of Applied Chemistry, 2020, 94 (4), P. 490-497.

[341] Shcherban N.D., Mäki-Arvela P., et al. Melamine-derived graphitic carbon nitride as a new effective metal-free catalyst for Knoevenagel condensation of benzaldehyde with ethylcyanoacetate. Catal. Sci. Technol., 2018, 8, P. 2928-2937.

[342] Chebanenko M.I., Zakharova N.V., Lobinsky A.A., Popkov V.I. Ultrasonic-assisted exfoliation of graphitic carbon nitride and its electrocatalytic performance in process of ethanol reforming. Semiconductors, 2019, 53 (16), P. 28-33.

[343] Ivanov V.K., Baranchikov A.E., et al. Effect of hydrothermal and ultrasonic/hydrothermal treatment on the phase composition and micromorphology of yttrium hydroxocarbonate. Russ. J. Inorg. Chem., 2007, 52 (9), P. 1321-1327.

[344] Ivanov V.K., Kopitsa, G.P., et al. Mesostructure of hydrated hafnia xerogels. Dokl. Chem., 2009, 427 (1), P. 160-163.

[345] Rutberg F.G., Gusarov V.V., et al. Analysis of physicochemical properties of nanoparticles obtained by pulsed electric discharges in water. Tech. Phys., 2012, 57 (12), P. 1641-1645.

[346] Rutberg F.G., Kolikov V.A., et al. Phase composition and magnetic properties of iron oxide nanoparticles obtained by impulse electric discharge in water. High Temperature, 2016, 54 (2), P. 170-174.

[347] Wu J., Shen X., et al. Solvothermal synthesis and characterization of sandwich-like grafen/ZnO nanocomposite. Appl. Surface Sci., 2010, 256, P. 2826-2830.

[348] Andrievski R.A. Size-dependent effects in properties of nanostructured materials. Rev. Adv. Mater. Sci., 2009, 21, P. 107-133.

[349] Tananaev I.V., Fedorov V.B, Morokhov I.D., Malyukova L.V. Fundamentals of physical chemistry of substances in a metastable ultradispersed state and prospects for their use. Inorg. Mater., 1984, 20 (6), P. 1026-1033. (in Russian)

[350] Tananaev I.V., Fedorov V.B., et al. Characteristic peculiarities of ultrafine structures, Dokl. Akad. Nauk USSR, 1985,283 (6), P. $1364-1368$. (in Russian)

[351] Gleiter H. Nanostructured material: basic concepts and microstructure. Acta Mater, 2000, 48 (1), P. 1-29.

[352] Golovin Y.I. Nanoindentation and mechanical properties of materials at submicro- and nanoscale levels: recent results and achievements. Phys. Solid State, 2021, 63, P. 1-41

[353] Schoonman J. Nanostructured materials in solid state ionics. Solid State Ionics, 2000, 135, P. 5-19.

[354] Burtsev V.A., Kalinin N.V., Luchinsky A.V. Electrical explosion of conductors and its application in electrophysical installations. Energoatomizdat, Moscow, 1990, 288 p.

[355] Oreshkin V.V., Sedoi V.S., Chemezova L.I. Application of electrical explosion of wires to obtain nanoscale powders. Applied Physics, 2001, 3, P. 94-102. (in Russian)

[356] Kotov Yu.A., Ivanov V.V. Powder nanotechnology to create functional materials and devices for electrochemical energy. Herald of the RAS, 2008, 78 (9), P. 777-787. (in Russian)

[357] Bulgakov A.V., Bulgakova N.M., Burakov I.M. Synthesis of nanoscale materials under the influence of powerful energy flows on matter. IT SB RAS, Novosibirsk, 2009, 462 p. (in Russian)

[358] Ilyin A.P. Development of electroexplosive technology for producing nanopowders in the Research Institute of high voltage at the Tomsk Polytechnic University. Bulletin of the Tomsk Polytechnic University, 2003, 306 (1), P. 133-139.

[359] Gusarov V.V., Almjasheva O.V. The role or status of substances in the formation of structure and properties of materials. In: Nanomaterials: properties and applications. Scientific world, Moscow, 2014, 456 p. (in Russian)

[360] Aleskovskiy V.B. Chemistry and technology of solid substances. J. Appl. Chem. USSR, 1974, 47, P. 2145-2156. (in Russian)

[361] Aleskovskiy V.B. Chemical Assembly materials. Bulletin of the USSR Academy of Sciences, 1975, 45, P. 48-51. (in Russian)

[362] Malygin A.A. The molecular layering nanotechnology: basis and application J. Ind. Eng. Chem., 2006,12 (1), P. 1-11.

[363] Malygin A.A., Drozd V.E., Malkov A.A., Smirnov V.M. From V. B. Aleskovskii's "Framework" Hypothesis to the Method of Molecular Layering/Atomic Layer Deposition. Chem. Vap. Deposition, 2015, 21, P. 216-240.

[364] Malygin A.A., Malkov A.A., Sosnov E.A. Structural dimensional effects and their application in the 'core-nanoshell' systems synthesized by the molecular layering. Russian Chemical Bulletin, International Edition, 2017, 66 (11), P. 1939-1962. 